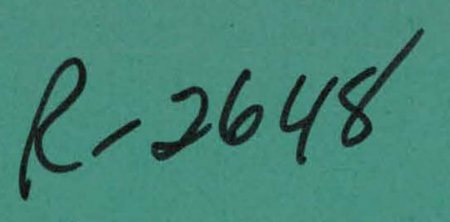

Satellite Power System Concept Development and Evaluation Program System Definition Technical Assessment Report

December 1980

Prepared for:

U.S. Department of Energy

Office of Energy Research

Solar Power Satellite Projects Division

Under Inter-Agency Agreement Al01-79ER10035

DOE/NASA

Satellite Power System

Concept Development

and

Evaluation Program 


\section{DISCLAIMER}

This report was prepared as an account of work sponsored by an agency of the United States Government. Neither the United States Government nor any agency Thereof, nor any of their employees, makes any warranty, express or implied, or assumes any legal liability or responsibility for the accuracy, completeness, or usefulness of any information, apparatus, product, or process disclosed, or represents that its use would not infringe privately owned rights. Reference herein to any specific commercial product, process, or service by trade name, trademark, manufacturer, or otherwise does not necessarily constitute or imply its endorsement, recommendation, or favoring by the United States Government or any agency thereof. The views and opinions of authors expressed herein do not necessarily state or reflect those of the United States Government or any agency thereof. 


\section{DISCLAIMER}

Portions of this document may be illegible in electronic image products. Images are produced from the best available original document. 
NOTICE

This report was prepared as an account of work sponsored by the United States Government. Neither the United States nor the United States Department of Energy, nor any of their employees, makes any warranty, express or implied, or assumes any legal liability or responsibility for the accuracy, completeness, or usefulness of any information, apparatus, product, or process disclosed, or represents that its use would not infringe privately owned rights. Reference herein to any specific commercial product, process, or service by trade name, mark, manufacturer, or otherwise, does not necessarily constitute or imply its endorsement, recommendation, or favoring by the United States Government or any agency thereof. The views and opinions of authors expressed herein do not necessarily state or reflect those of the United States Government or any agency thereof.

\footnotetext{
Avallable from:

Nat1onal Technical Information Service (NTIS)

U.S. Dedartment of Commerce

5285 Port Royal Road

Springfield, Virginía 2216$]$

Price: Printed Copy

Microfiche:

$\$ 11.00$
$\$ 4.00$
} 


\section{Satellite Power System Concept Development and'Evaluation Program System Definition Technical Assessment Report}

December 1980

Prepared for:

U.S. Department of Energy

Office of Energy Research

Solar Power Satellite Projects Division

Washington, D.C. 20585

Prepared by:

National Aeronautics and Space Administration

Washington, D.C. 20546

Under Inter-Agency Agreement AT01-79ER10035

DOE/NASA

Satellite Power System

Concept Development

and

Evaluation Program

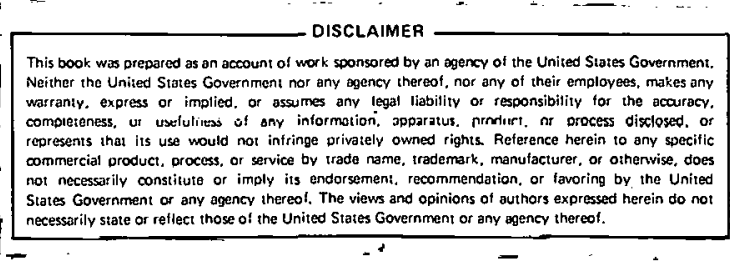


CONTENTS

Section Page

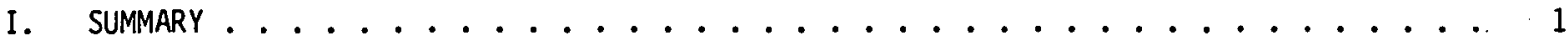

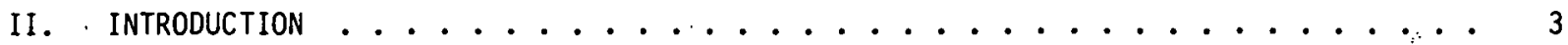

III. SYSTEM STUDIES ......................... 7

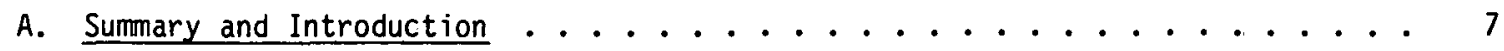

B. Reference System Description .................. . . 7

1. Reference System quidelines ................. 7

2. Reference System description ................. 8

3. Reference System development, acquisition, and maintenance costs .... 9

C. Alternate Concepts ........................ 10

1. Power level and transmission frequency ............. 10

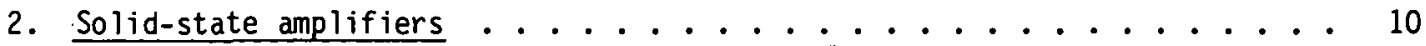

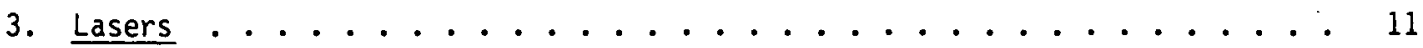

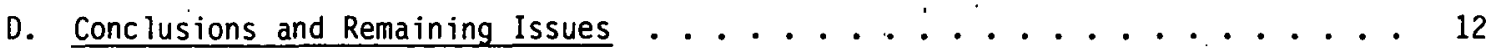

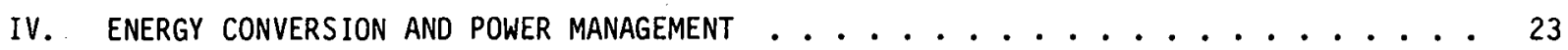

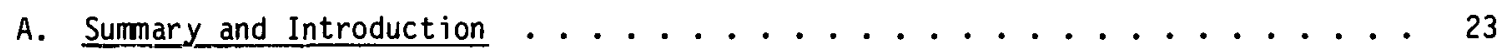

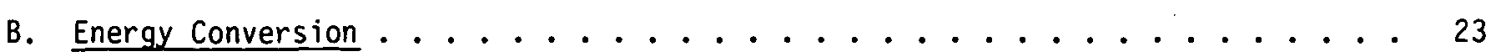

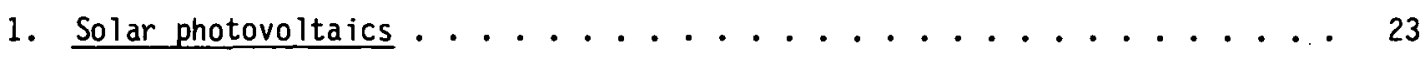

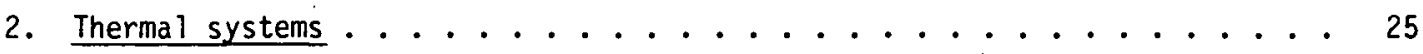

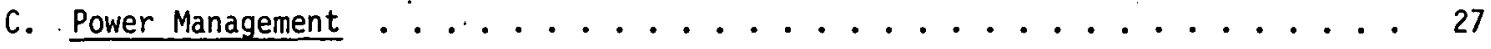

D. Workshop Summary ...................... 27

1. Photovoltaics ........................ 27

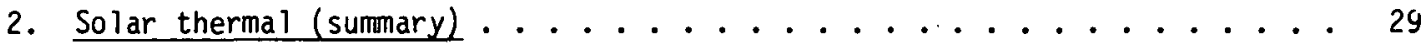

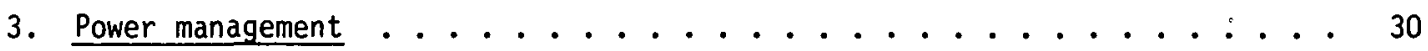

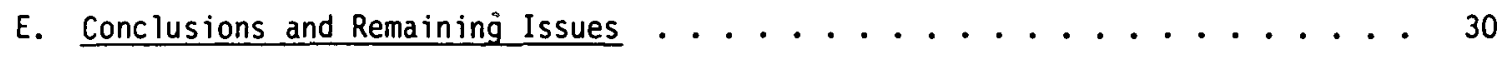

1. Energy conversion ...................... 30

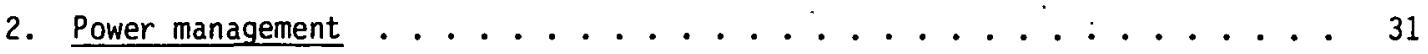

v. POWER TRANSMISSION AND RECEPTION .............................. 45

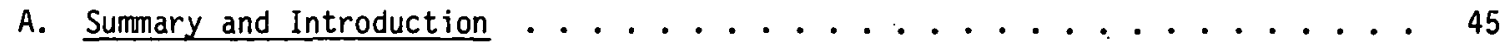


B. System Assessment Activities ................... . . 45

1. SPS contracted efforts .................... 45

2. NASA-sponsored efforts ........................ 46

3. System workshop. . . . . . . . . . . . . . . 46

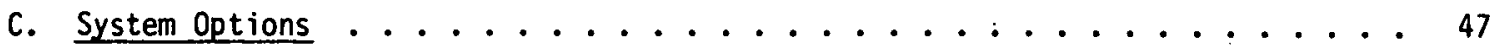

D. System Definition Drivers ................... 47

E. Reference System Updates and Studies .................. . . 48

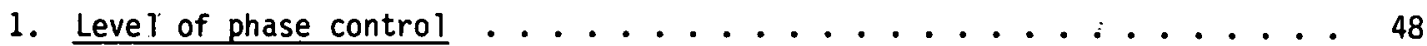

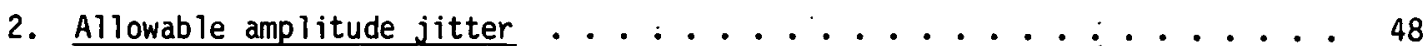

3. Startup/shutdown procedure .................. 48

4. Additional studies ......................... 49

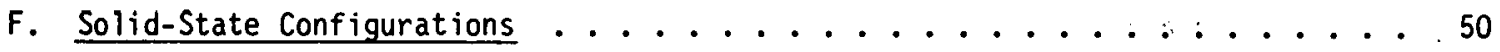

G. Critical Supporting Investigations ................ 50

1. Design and breadboard evaluation of the SPS reference phase control

2. SPS fiber optics link assessment ............... 50

3. Six-element S-band active retrodirective array phase error evaluation . . 51

4. SPS antenna element evaluations ................. 51

5. SPS solid-state antenna power combiner evaluation ......... 51

6. SPS solid-state amplifier development ............. 51

7. SPS magnetron tube assessment ................ 51

8. Microwave ionospheric interaction experiment .......... 51

9. Solid-state-sandwich concept design considerations and issues . . . . . 52

H. System Conclusions and Remaining Issues . . . . . . . . . . 52

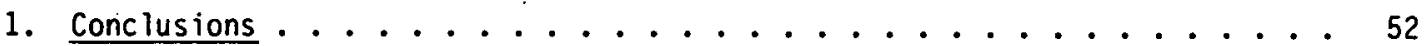

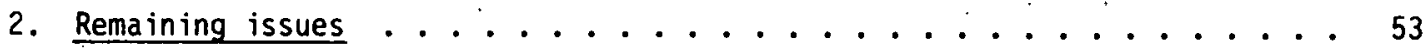

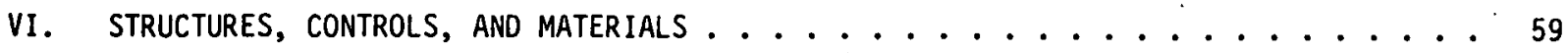

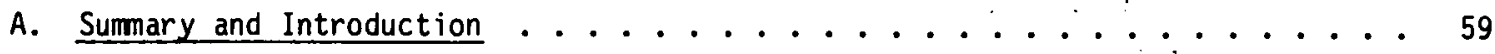




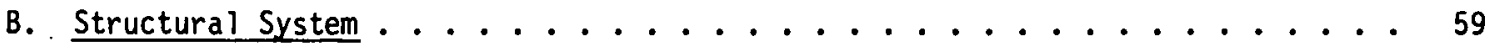

1. Loads ............................ 59

2. Environment .......................... 60

3. Structural design .................... 61

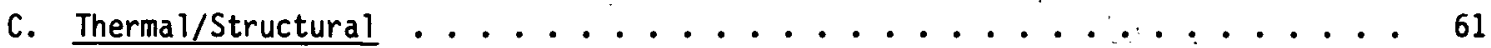

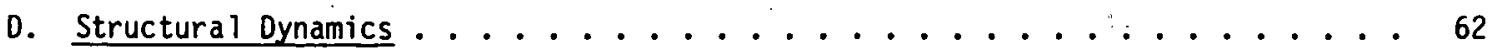

E. Control (Rigid Body) .......................... 62

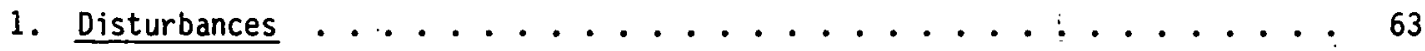

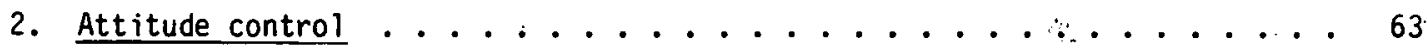

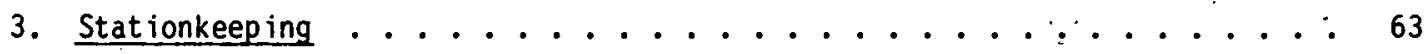

4. Control system...................... 64

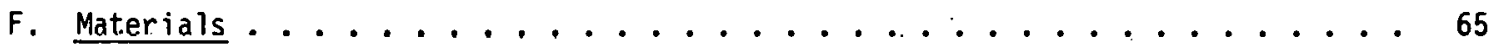

G. Workshop Summary ...................... 65

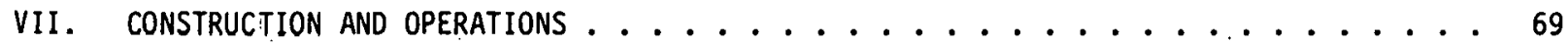

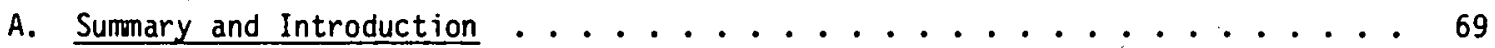

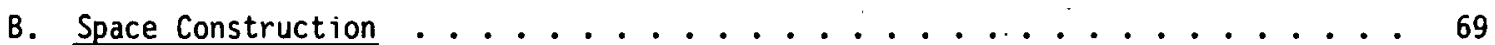

1. Guidelines ..................... 69

2. SPS construction location ...................... 69

3. Tasks, equipment, and facilities ...................... 70

C. Rectenna Construction ..................... 70

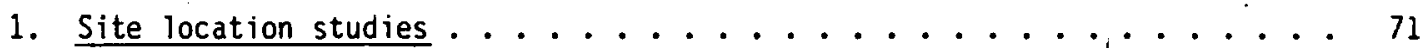

2. Construction concepts ....................... 71

D. Operations and Maintenance .................. . 71

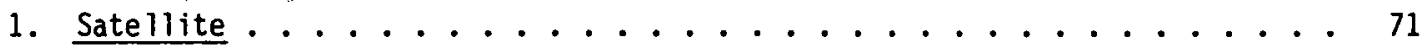

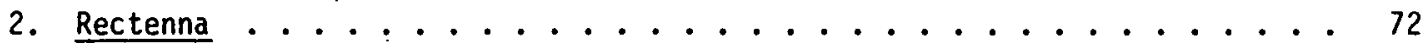

E. Workshop Summary ..................... 72

F. Conclusions and Remaining Issues ................ 73

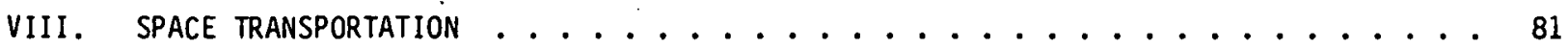

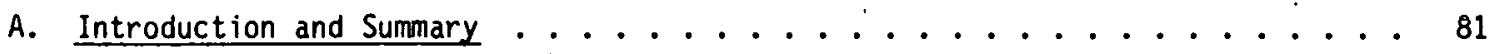

B. Heavy Lift Launch Vehicle ................... 81 
C. Orbital Transfer Vehicle Concepts ................. 82

D. Personnel Launch Vehicle .................... 83

E. Personnel Orbit Transfer Vehicle ................. 84

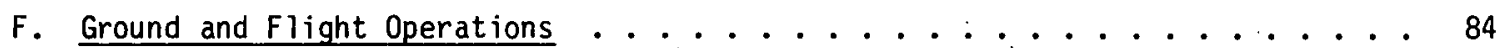

G. Technology Summary ........................ 84

H. Workshop Summary . . . . . . . . . . . . . 85

I. Conclusions and Remaining Issues ................ 86

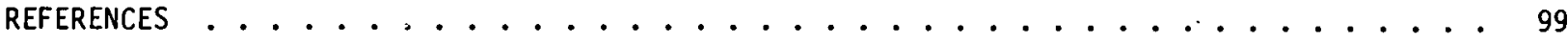


II-1 SATELLITE POWER SYSTEM CONCEPT DEVELOPMENT AND EVALUATION PROGRAM SYSTEMS

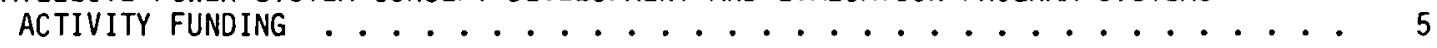

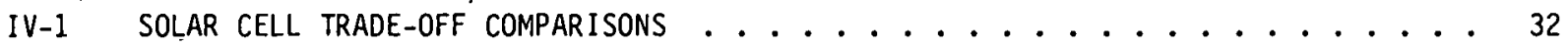

$V-1 \quad$ MICROWAVE PTAR INDEPENDENT SUBSYSTEM STUDIES . . . . . . . . . . . . 54

V-2 MICROWAVE PTAR EXPERIMENTAL CRITICAL SUPPORTING INVESTIGATIONS $\ldots \ldots$

VIII-1 PARAMETER COMPARISON FOR PRINCIPAL LEO/GEO TRANSPORT SYSTEMS $\ldots \ldots$

\section{FIGURES}

Figure Page

III-1 Reference configurations ....................... 13

III-2 Reference efficiency chain .................. 14

III-3 Space transportation and construction .............. 15

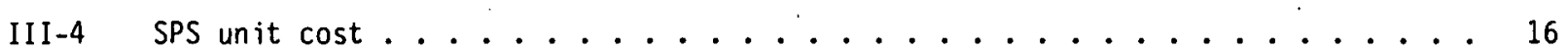

III-5 SPS nonrecurring costs ...................... 17

III-6 SPS total program costs by year ................. 18

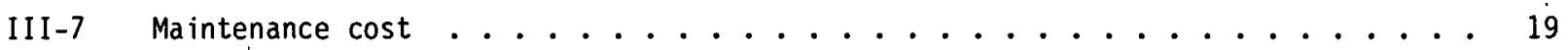

III-8 Solid-state "sandwich" concept ...................... 20

III-9 Laser SPS mass comparison . . . . . . . . . . . . . . . 21

IV-1 SPS reference system - silicon cell ............... 33

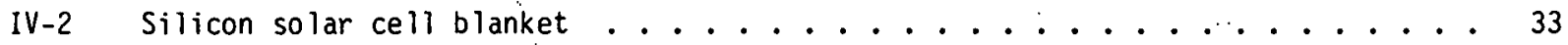

IV-3 SPS reference system - gallium arsenide cell .................. 34

IV-4 Gallium arsenide solar cell blanket ............... 34

IV-5 Cost-reduction projections based on industry experience (ref. 27) . . . . 35

IV-6 Silicon and gallium arsenide solar cell technology issues . . . . . . 36

IV-7 Thermal conversion studies . . . . . . . . . . . . . 37

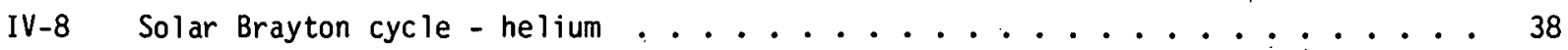

IV-9 Rankine cycle schematic - potassium . . . . . . . . . . . . . 39

IV-10 Potassium Rankine cycle design fealures, 10 -GW system . . . . . . . . 10 
IV-11 Cesium/steam Rankine cycle, $5 \mathrm{GW} \ldots \ldots \ldots \ldots$

IV-12 Energy conversion comparison, SPS mass ................. 42

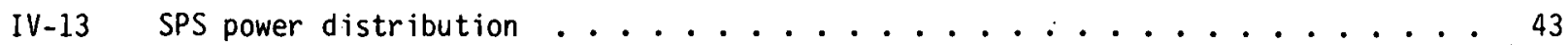

IV-14 Power distribution system block diagram ................... 44

v-1 Microwave system options .................... 56

V-2 Microwave power transmission design concept .............. 57

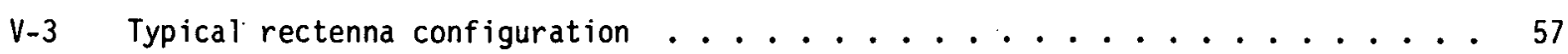

V-4 Reference SPS microwave system ................. 58

VI-1 Environmental disturbances during GEO construction ............ 67

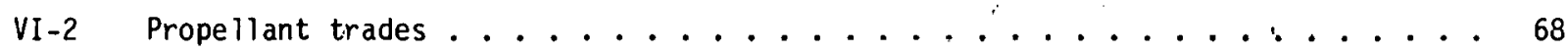

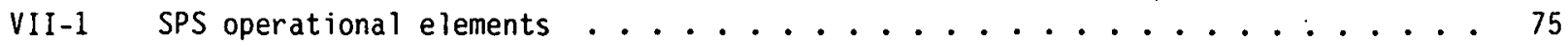

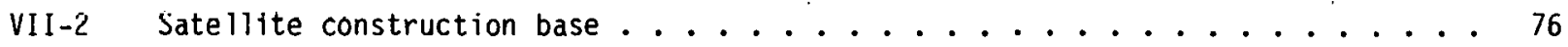

VII-3 SPS construction - four-bay endbuilder ............... 77

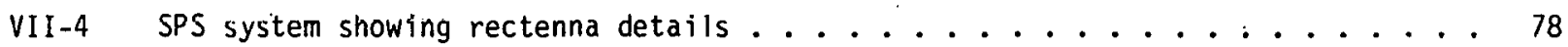

VII-5 Rectenna construction concept ................... 79

VII-6 Integrated maintenance mission concept $\ldots \ldots \ldots$

VIII-1 Two-stage ballistic series-burn HLLV ................990

VIII-2 Two-stage winged series-burn HLLV .................990

VIII-3 Small-HLLV comparison with other launch vehicles . . . . . . . . . 91

VIII-4 Two-stage winged parallel-burn HLLV ....................... 92

VIII-5 Single-stage winged horizontal-take-off HLLV . . . . . . . . . . 92

VIII-6 120-cm argon ion thruster characteristics . . . . . . . . . . 93

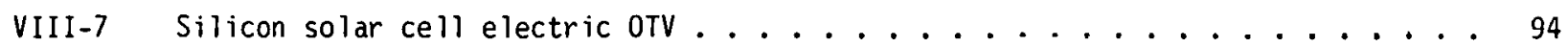

VIII-8 Galliun arsenide solar cell EOTV .................. 95

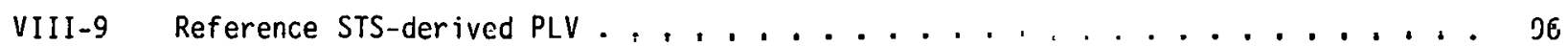

VIII-10 Alternative STS-derived PLV . . . . . . . ........ 96

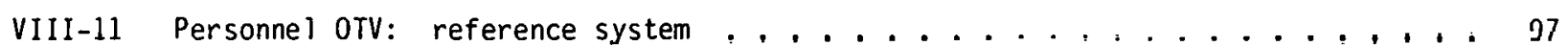

VIII-12 Personnel OTV: single-stage POTV concept . . . . . . . . . . . 97 


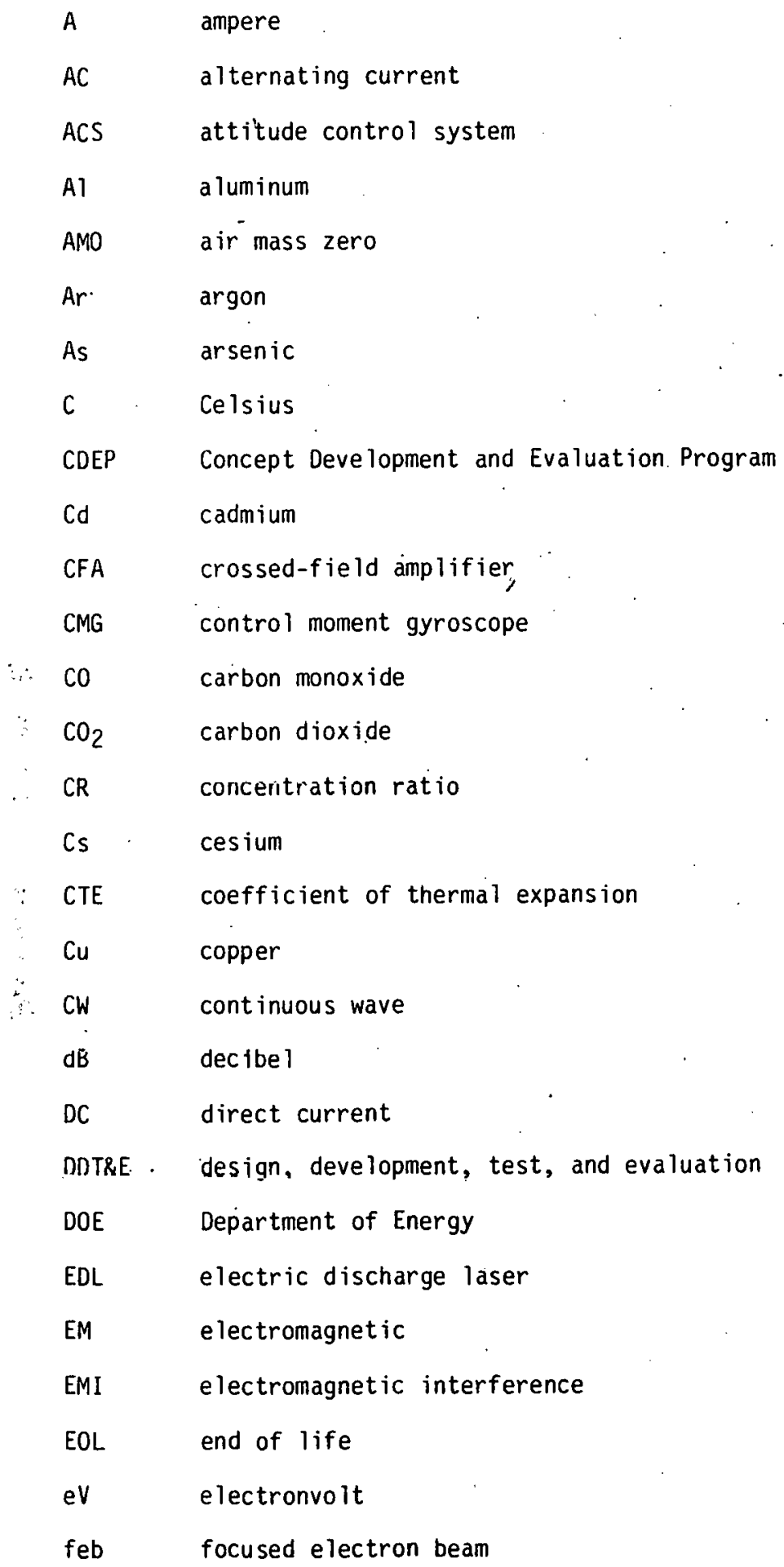




\begin{tabular}{|c|c|}
\hline FEL & free electron laser \\
\hline FET & field-effect transistor \\
\hline $\mathrm{Ga}$ & gallium \\
\hline GaAlAs & gallium aluminum arsenide \\
\hline GBED & Ground-Based Exploratory Deve lopment. (Program) \\
\hline GEO & geosynchronous Earth orbit \\
\hline $\mathrm{Gg}$ & gigagram ( $10^{9}$ grams) \\
\hline $\mathrm{GHz}$ & gigahertz ( $10^{9}$ cycles $\left./ \mathrm{sec}\right)$ \\
\hline GW & gigawatt $\left(10^{9}\right.$ watts $)$ \\
\hline H & momentum \\
\hline $\mathrm{H}_{2}$ & hydrogen \\
\hline $\mathrm{He}$ & helium \\
\hline$I_{s p}$ & specitic impulse \\
\hline In & indium \\
\hline IOPL & indirect solar-pumped laser \\
\hline ISM & industrial, scientific, and medical \\
\hline ITS & Institute of Telecommunication Sciences \\
\hline JPL & Jet Propulsion Laboratory \\
\hline JSC & Johnson Space Center \\
\hline K & Kelvin; potassium \\
\hline KSC & Kennedy Space Center \\
\hline kV & kilovolt \\
\hline $\mathrm{kW}$ & kilowatt \\
\hline lbf & pound force \\
\hline LEMSCO & Lockheed Engineering and Mạnagement Servịce Co. \\
\hline LEO & low Earth orbit \\
\hline LeRC & Lewis Research Center \\
\hline um & micrometer \\
\hline MPTS & microwave power transmission system \\
\hline
\end{tabular}




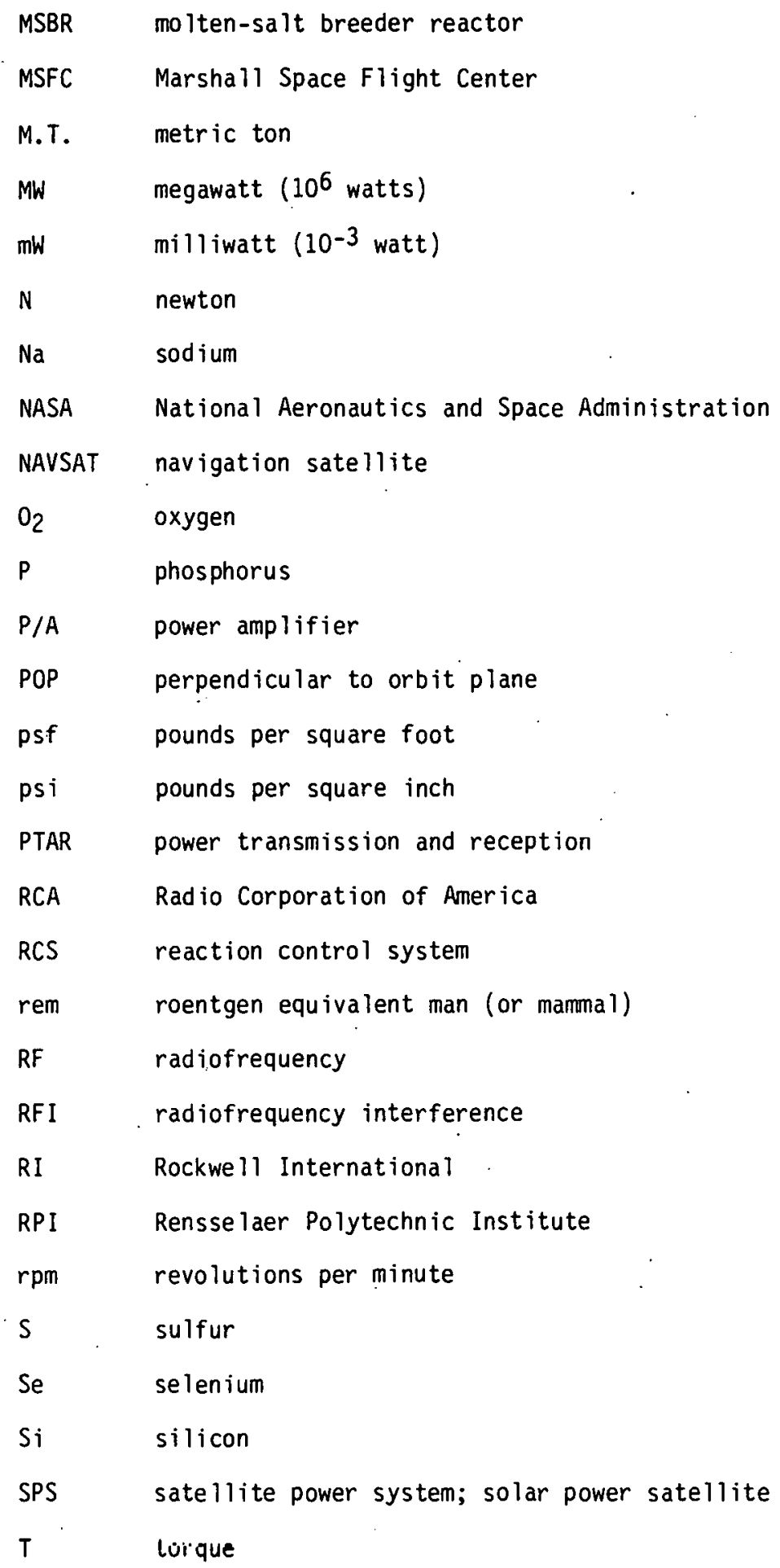




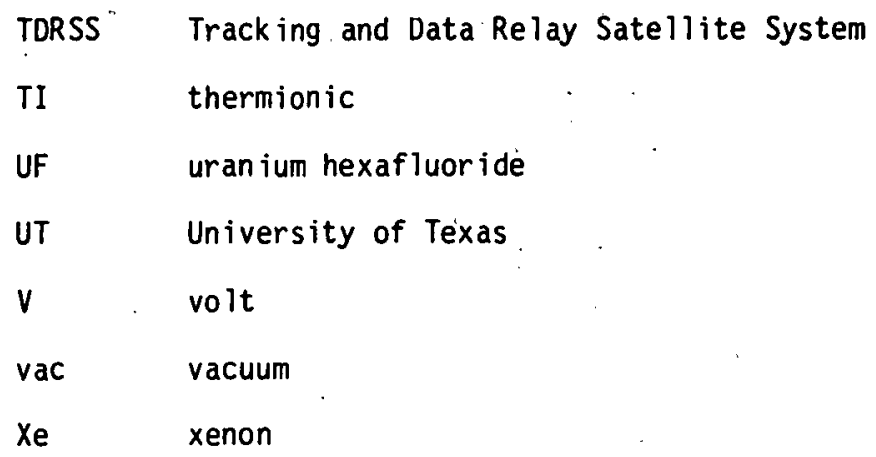




$\begin{array}{ll}\text { OTV } & \text { orbital transfer vehicle } \\ P_{C} & \text { chamber pressure } \\ \text { P/L } & \text { payload } \\ \text { PLV } & \text { personnel launch vehicle } \\ \text { PM } & \text { personnel module } \\ \text { POTV } & \text { personnel orbit transfer vehicle } \\ \text { RP } & \text { rocket propellant } \\ \text { SL } & \text { sea level } \\ \text { SRB } & \text { solid rocket booster } \\ \text { SSME } & \text { Space Shuttle main engine } \\ \text { SSTO } & \text { single stage to orbit } \\ \text { STS } & \text { space transportation system } \\ \text { WP } & \text { propellant weight }\end{array}$


Blank

xii 


\section{SUMMARY}

This report summarizes the results of the system deiinition studies conducted by NASA as a part of the Department of Energy/National Aeronautics and Space Administration SPS Concept Development and Evaluation Program. The purpose of the system definition efforts was to identify and define candidate SPS concepts and to evaluate the concepts in terms of technical and cost factors. Although the system definition efforts consisted primarily of evaluation and assessment of alternative technical approaches, a reference system was also defined to facilitate economic, environmental, and societal assessments by the Department of Energy. This reference system was designed to deliver 5 GW of electrical power to the utility grid. Topics covered in this report include system definition; energy conversion and power management; power transmission and reception; structures, controls, and materials; construction and operations; and space transportation.

Several energy conversion options were considered during initial studies. These options included single-crystal silicon, gallium arsenide (single and multiple junction), and amorphous silicon thinfilm photovoltaics; solar/Brayton and solar/Rankine cycle thermal engines; solar/thermionic; and nuclear/Brayton. Of these, the last two have significantly larger masses relative to the other systems. The Brayton and Rankine systems are nearly competitive in mass and cost with the photovoltaic options. Thin-film amorphous silicon systems may be competitive if radiation resistance and sufficiently high efficiencies can be achieved. The reference system considered both optional singlecrystal silicon or gallium arsenide solar cells. A geometric sunlight concentration ratio (CR) of 2 was used with a gallium arsenide system, and no concentration $(C R=1)$ was used for the silicon system.

Power transmission by microwave (RF) radiation was emphasized in the studies; however, laser transmission was also investigated. For RF generation, the klystron, the amplitron, and the magnetron were studied. Also, solid-state RF generator concepts were defined. The reference system used microwave power transmission. The klystron tube was used for DC-RF conversion because of high gain, projected high efficiency, low noise, and high output per tube.

The reference system ground rectifying antenna (rectenna) consisted of dipole receiving elements and Schottky barrier diodes on a ground plane which was on panels normal to the microwave beam, with power distribution and conditioning equipment for the required interfaces with the power grid. 0ther concepts, such as waveguides or parabolic concentrators, were also investigated.

With the power conversion-transmjssion-reception efficiency chain defined for the reference system, a power density $1 \mathrm{imit}$ of $21 \mathrm{~kW} / \mathrm{m}^{2}$ at the transmitter together with a 1 imit of $23 \mathrm{~mW} / \mathrm{cm}^{2}$ at the ionosphere and a 10-dB antenna taper led to a maximum power of $5 \mathrm{GW}$ per microwave link delivered to the power grid. There is recent evidence (ref. 1) that the $23-\mathrm{mW} / \mathrm{cm}^{2}$ limit may be conservative; if so, the maximum power per link could be increased and/or the rectenna size could be reduced.

Preliminary studies of laser power transmission indicated technical feasibility; however, high satellite mass (more than twice the reference system) and atmospheric absorption were noted as major disadvantages relative to microwave systems. A breakthrough in laser technology would change this conclusion, however.

The geostationary Earth orbit (GE0), with zero eccentricity and inclination, is preferred on an overall basis, although slightly inclined geostationary orbits offer features of reduced mutual shadowing or increased use of urlil sjace.

Several different space construction concepts and operational approaches were investigated. The scale of the SPS mandates the highest possible degree of automation in the construction process; this in turn places a premium on highly regular configurations that can be constructed with a small number of frequently repeated operations. For the reference system, construction in synchronous orbit using material transported from low Earth orbit (LEO) by electric orbit transfer vehicles was defined. Construction in low orbit of sections of the satellite with subsequent self-powered transfer to synchronous orbit for assembly is an alternate approach.

The implementation of a commercial network of solar power satellites will require a space transportation system (STS) capable of placing large and massive payloads into geosynchronous orbit at low cost and with acceptable environmental impact. Payloads consist of cargo (satellite components, building materials, construction equipment, and expendable supplies) and construction personnel. The major elements of a technically feasible STS include cargo launch vehicle (Earth to LEO), cargo orbit transfer (LEO to GEO) vehicles, personnel launch vehicles, and personnel orbit transfer vehicles. Multiple reuse capability of each STS element is a key requirement based on cost considerations. 
The system definition studies provided insight into the technology advancement requirements of SPS. To become economically competitive, technology improvements are required in several areas. Solar energy collection and conversion technology (photovoltaic and thermal) should be advanced in terms of increased output per unit mass, long-life reliability, and reduced hardware production costs. Space transportation technology should be extended to provide fully reusable launch and orbit transfer vehicles with low operational costs. Space construction, a new technical discipline, should be developed in the principal areas of hardware fabrication in space (e.g., structural beams); materials and components handling and aligning equipment; and docking and berthing of large structures. Solar power satellite structures, controls, and materials should be developed and proven for long-life operation in the geosynchronous orbit environment. Integrated structure and control systems should be developed and analyzed for large, flexible structural systems. High strength-to-weight ratio materials such as graphite composites should be developed and tested for long-term stability to assure maintenance of strength and thermal characteristics. Space projects should be conducted to verify power transmission performance, to verify space construction techniques and equipment, and to evaluate high-voltage output devices in the space plasma environment.

Finally, projects should be defined to encompass the total requirements of a space technology program for the SPS. A key consideration in this area is the type and size of demonstration system that may be required to prove the technical feasibility of the concept. Several optional approaches to system demonstration have been proposed during the system definition studies; however, additional study is required to determine the sçope. emphasis, and timing of surh prnjerts. 


\title{
II. INTRODUCTION
}

In the summer of 1977, the Department of Energy (DOE) and the National Aeronautics and Space Administration (NASA) embarked on a joint assessment of the Satellite Power System (SPS) concept according to the SPS Concept Development and Evaluation Program (CDEP) Plan (ref. 2). Under this plan, DOE and NASA undertook evaluation of the SPS concept in four major areas: Systems Definition, Environmental, Societal, and Comparative Assessments. NASA's principal effort was in the Systems Definition area. This report is a summary of the results of NASA activities in systems definition. Detailed results are provided in Volumes II to VII as listed below.

\author{
Volume II - Systems Definition \\ Volume III - Power Transmission and Reception \\ Volume IV - Energy Conversion and Power Management \\ Volume V - Structures, Controls, and Materials \\ Volume VI - Construction and Operations \\ Volume VII - Space Transportation
}

The above-reports integrate the findings from earlier studies with those conducted as part of the joint DOE/NASA Concept Development and Evaluation Program.

The assessment of SPS by DOE and NASA was in response to mounting interest and controversy over the SPS concept for utilizing solar energy in a way that would overcome perceived problems of daily and weather-induced variations of sunlight received in Earth-based solar powerplants. The key to the SPS concept, as first reported in 1968 (ref. 3), is the placement of the soiar energy collector and converter into space where nearly continuous illumination is received, with transmission of energy to receiving stations on Earth by means of focused beams of electromagnetic waves.

Because of various economic and technical factors, which will be discussed later in this report, SPS designs are led toward high power levels which results in space systems that have unprecedented large sizes and masses and that require levels of activity in space operations well beyond the scope foreseen in current and future plans. Nevertheless, an examination of the SPS concept.by aerospace contractors, certain academic groups, and NASA led some people to the conclusion the idea had merit in that the required advances in technology could be accomplished and that the projected costs of developing and building these systems would result in delivery of baseload electrical energy in a competitive price range. Furthermore, the urgency of the energy crisis manifested in the events of 1973 and thereafter influenced studies of the SPS concept in the direction of systems and technologies which could be developed and brought to operational status as soon as possible.

NASA began its studies of SPS in 1972 which are reported in reference 4 . These early studies were. followed by investigations at the Jet Propulsion Laboratory, particularly in the area of power transmission via microwaves (ref. 5). Intensive studies of SPS were conducted during 1975-1976 (refs. 6 to 8 ) by several NASA groups.

During 1976, a task group was formed by the Energy Research and Development Administration (ERDA), now DOE, for the purpose of reviewing the NASA SPS concepts and recommending an appropriate ERDA policy position for addressing this concept within the broader goals of the national energy research, development, and demonstration effort. This task group (ref. 9) concluded that, "considering the tremendous electric generation needs that are projected for the post-2000 period and the inherent uncertainties in the commercialization of other advanced technologies..., it behooves ERDA, in cooperation with NASA, to pursue some studies of the SPS concept and its potential." The findings of the ERDA task group led to the formulation of plans and scope for the joint Concept Development and Evaluation Program for making assessments of SPS. 
The systems definition effort in the COEP had these primary objectives (as modified from the CDEP plan): to evaluate the technical feasibility of the SPS concept, to define and analyze alternative system design and operational approaches, and to provide the requisite technical information for environmental, societal, and comparative assessments conducted by the Department of Energy. Table II-1 lists the major systems definition areas and the approximate funding distribution for the CDEP period of performance. Included in these activities are studies and critical supporting investigations, some of which were experimental in nature, which were conducted to address key areas of SPS feasibility. Major emphas is was given to studies of systems and power transmission and reception which are the key, unique areas of concern in SPS.

To allow the CDEP to function in its assessment areas, it was necessary to define a version of SPS toward which all studies could be focused. This version of SPS became known as the "Reference System," and it provided, to varying levels of detail, a description of all aspects of SPS, the satellite and ail its subsystems, the orbital bases and equipment required to construct and maintain the satellite, all elements of a transportation system including launch sites, the ground receiving station, and the associated industrial facilities for manufacturing all required hardware (ref. 10).

The Reference System was amalgamated from the results of the system definition studies of SPS, and the design choices gave emphasis to those components and subsystems which would be ready for development by 1990 in anticipation of operation of the first. SPS by 2000 . This emphasis restricted the range of possible options for the Reference System and provided a technically plausible concept for use in the assessment. proness.

Because of its role in the assessment of SPS, the Reference System is described briefly in Section III. Much of the system definition effort during the CDEP was spent in evaluating and expanding on the data base of the Reference System, which also served as a basis for consideration of alternatives.

The cost of an energy system is, in the final analysis, the key to its acceptability. Inherent in the early studies by NASA and others were estimates of the costs of the energy delivered by SPS. Not only were these cost estimates useful in judging whether SPS could be viable, they also served in evaluating the importance and worth of various design options and operational concepts. A summary of cost estimates for a reference SPS concept has been reported (ref. 11); these are also briefly reviewed in Section III.

Sections IV through VIII contain summary discussions in the areas of energy conversion and power management; microwave power transmission and reception; structures, controls, and materials; construction and operations; and space transportation. The primary thrust of the discussion is to present study findings and unresolved issues and to describe how these factors affect the SPS concept. The basic information for the previously mentioned sections is drawn primarily from reports issued by Boeing Aerospace Company under contract to the NASA Johnson Space Center (refs. 12 to 17) and Rockwe 1 International under contract to Marshall Space Flight Center (refs. 18 to 21). Considerable benefit iñ the assessment process was also obtained through a series of technical workshops in which expert evaluation and advice on SPS was obtained. The findings of anch workshop are recorded in appruprlate sections of this report.

Throughout this report, there are references to a Ground-Based Exploratory Development (GBED) plan. A plan for future activities in SPS was a requirement of the CDEP, and the GBED, which will be published in the future, describes one approach or option for addressing critical technology issues in SPS as defined largely through an evaluation of the Reference System. The GBED plan is a program of some urgency having the goal of resolving major remaining technological questions in 5 or 6 years. At the present time, the GBED plan does not represent a oreferred nrngram notion for the futurc: 
TABLE II-1.- SATELLITE POWER SYSTEM CONCEPT DEVELOPMENT AND EVALUATION PROGRAM SYSTEMS ACTIVITY FUNDINGa

[Thousands of dollars]

\begin{tabular}{lrrrrr}
\hline \multicolumn{1}{c}{ Activity } & FY 77 & FY 78 & FY 79 & FY 80 & Total. \\
\hline Systems definition & 715 & 765 & 235 & b490 & 2,205 \\
Solar energy conversion & 85 & 60 & 100 & 50 & 295 \\
$\begin{array}{l}\text { Electrical power processing } \\
\text { and distribution }\end{array}$ & 150 & 50 & 100 & - & 300 \\
Power transmission and reception & 735 & 565 & \multicolumn{1}{c}{ c1,240 } & 260 & d 2,800 \\
Structures/controls and materials & 200 & 165 & 285 & 150 & 800 \\
Operations & 150 & .225 & 490 & 50 & 915 \\
Space transportation & 165 & 170 & 150 & 100 & 585 \\
$\quad$ Total & 2,200 & $\overline{2,000}$ & $\overline{2,600}$ & $\overline{1,100}$ & $\overline{7,900}$ \\
$\quad$ & & & &. &. \\
\hline
\end{tabular}

aSource: "Overview of Systems Definition Activities for Satellite Power Systems," F. Carl Schw'enk, NASA Headquarters, presented at the Satellite Power System (SPS) Program Review and Symposium, April 22-25, 1980.

b Includes $\$ 125,000$ for laser SPS.

CIncludes $\$ 400,000$ for solid-state SPS.

dincludes $\$ 700,000$ for MW (microwave) at JPL. 
Blank

6 
III. SYSTEM STUDIES

\section{A. Summary and Introduction}

The Satellite Power System requires the integration of many subsystems, components, and operations to provide the overall capability to deliver energy from space to Earth. This section reports on those aspects of the CDEP which generally involved studies of complete systems. It sumnarizes the reference system and describes the cost model and costs for development, acquisition, and operation of SPS based on the reference system.

Studies of systems design options are also covered in this section. Where possible, comparisons with the reference system are provided.

\section{B. Reference System Description}

A specific SPS concept was required to provide a traceable set of technical information on every aspect of SPS for use in the assessment activities of the CDEP. Accordingly, a Reference System, for SPS was defined and reported (ref. 10). The Reference System was derived from studies conducted by NASA (refs. 12 to 14, 18, and 19). It represents a compromise approach which may be far different from future versions of SPS. Nevertheless, the Reference System has served as a useful tool in the assessment process; but it is no more than this.

\section{Reference System guidelines:}

In establishing a Reference System, the major objective was the selection of a concept having the highest degree of certainty for development around the end of this century. This objective meant that, although substantial technological advances would undoubtedly be necessary, major breakthroughs should not be involved. Earlier work (e.g., ref. 6) had indicated that such an approach could yield a reasonably competitive system with recognized uncertainties. Any subsequent advances that were not contemplated in the reference system would, of course, only enhance the competitive position of the SPS concept.

Based on the preliminary studies of the SPS concept which identified constraints on system size (ref. 7), a set of specific guidelines was develnped for the reference system definition effort. These guidelines should not necessarily be taken as firm requirements for future studies; their criticality should be re-assessed by appropriate trade studies in the future.

The most significant of these guidelines are:

a. Baseload electric power generation with maximum available power generation capability

b. Energy source - solar

c. Initial operational date - 2000

d. Satellites shall be in geosynchronous orbit

e. Power transmission by microwave at $2.45 \mathrm{GHz}$

f. Maximum microwave power density in the ionosphere shall be $23 \mathrm{~mW} / \mathrm{cm}^{2}$

g. Each satellite system shall be capable of delivering $5 \mathrm{GW}$ to the power grid

h. Nominal lifetime of the satellites and ground stations shall be 30 years

i. Construction rate shall be 10 GW per year for 30 years

j. Only terrestrial materials shall be used 


\section{Reference System description}

The reference SPS consists basically of a photovoltaic solar energy conversion system

about $54 \mathrm{~km}^{2}$ in area, a $1-\mathrm{km}$-diameter planar microwave transmitting antenna, and a ground receiving station about $10^{\prime}$ by $13 \mathrm{~km}$. Each system provides $5 \mathrm{GW}$ of electrical power to the utility grid. There are two versions of the solar energy conversion system: silicon cells without solar concentration (CR1) and gallium arsenide solar cells with a geometric concentration ratio of 2 (CR2).

A sunlight concentration ratio (CR) of 2 reduces the cost and weight of a gallium arsenide system but is not.effective for silicon (ref. 12b). The gallium arsenide system at CR2 is substantially lighter than the silicon system at CR1 but presents possible technology and cost problems. Pending resolution of these questions, both options were retained in the reference system.

A major consideration in selection of the reference configuration was ease of construction. The repeatability of the photovoltaic configurations gave them a constructibility advantage over the thermal systems, which require a relatively large number of different construction operations.

The two reference configurations are illustrated in figure III-1. The structure is fabricated in orbit of graphite-fiber-reinforced thermoplastic for minimum thermal cxpansion. [st iilialed mass of the energy conversion system including growth margin is $17,000 \mathrm{M}$. T. for gallium arsenide (CR2) and 34,000 M.T. for silicon (CR1).

The microwave power transmission system (MPTS) is the same for both configurations. The mass of the reference MPTS is 17,000 M.T., including margin.

For Kr generation, the klystron was selected over the amplitron because of higher gain, lower noise, and higher output per tube. The magnetron appears promising but had not been examined as thoroughly as the klystron and the amplitron when the reference system was defined. A slotted waveguide array is the preferred type of radiating element based on high efficiency and simplicity. The waveguides are assembled into $10-$ by $10-\mathrm{m}$ subarrays; th is size represented a compromise between the active mechanical alignment required for larger subarrays and the greater phase distribution complexity of small subarrays.

A wide variety of transmitter power density tapers has been studied (ref. 8). A 10-step, 10-dB Gaussian taper was selected for the reference system as a good compromise among peak power density, sidelobe levels, and mechanical complexity. The reference system employs a retrodirective phase control systerl.

The ground receiving station, or rectenna, is elliptical (except on the Equator). The active area is 10 by $13.2 \mathrm{~km}$ at $35^{\circ}$ latitude, plus a buffer zone to keep the microwave radiation exposure of the public below $0.1 \mathrm{~mW} / \mathrm{cm}^{2}$. The rectenna consists of dipole receiving elements and Schottky barrier diodes on a ground plane which is on panels normal to the microwave beam, with power distribution and conditioning equipment for the required interfaces with the power yrid.

A reference set of efficiencies has been defined (ref. 10) that represents reasonable goals for each step in the power conversion-transmission-reception chain. (See fig. III-2.) Because of thermal limitations on antenna materials, the projected antenna efficiencies permit a peak microwave power density of $22 \mathrm{~kW} / \mathrm{m}^{2}$ at the transmitter. This limit, together with a 1 imit of $23 \mathrm{~mW} / \mathrm{cm}^{2} \mathrm{at}$ the ionosphere and the reference antenna taper, leads to a maximum power of 5 GW per microwave link delivered to the power grid. (ref. 6). This is the value solacted for the reference systelll.

A geostationary orbit, with zero accentricity and inclination, was selected for the reference system because it provides continuous power transmission and permits uniform (unaccelerated) motion of the transmitting antenna. Geosynchronous orbits with small inclinations and/or eccentricities offer possibilities of reduced shadowing of one satellite by another and of several satellites sharing a single synchronous orbit slot. These possibilities have not becn cralunted in detail.

The satellite is oriented toward the Sun with the rotary joint axis always perpendicular to the orbit $p$ lane (POP). This attitude minimizes gravity-gradient torque but results in an average loss of $4 \%$ of the incident solar energy from solar declinalion variations during the year (ref. 6 ). 
Solar radiation pressure is the dominant orbit perturbing force, requiring on the order of 50 M.T. of propellant per year if eccentricity is to be held at zero. By differential thrusting, this orbitkeeping impulse can be applied to attitude control, which would otherwise require nearly as much propellant itself. It also appears possible to depart from the POP orientation by several degrees without additional propellant expenditure, thereby reducing solar energy losses (ref. 20b).

The reference system is constructed in geosynchronous orbit using material transported from low Earth orbit (fig. III-3). The construction base is permanently manned by a crew of about 400 for construction, plus several hundred for maintenance of operating satellites. The scale of the program mandates the highest possible degree of automation in the construction process (the alternative would be an on-orbit work force substantially greater than 400); this in turn places a premium on highly regular configurations that can be constructed with a small number of frequently repeated operations. Ease of construction was, for example, one consideration in the selection of an endmounted, rather than central, antenna for the reference system.

In the reference system, transportation of cargo to low orbit is assumed to be accomplished by a two-stage winged heavy lift launch vehicle (HLLV) with a payload of 420 M.T. Transportation of the crew (75 at a time) to low orbit would be accomplished with a personnel launch vehicle (PLV), derived from the current Shuttle. From the low-orbit staging base (fig. III-3), electric orbit transfer vehicles (EOTV's) transport 4000 M.T. of cargo per flight (one launch every 11 days) to synchronous orbit. Radiation damage to the EOTV solar cells during the long passage through the Earth's trapped radiation belts will be severe, but the EOTV offers a substantial cost saving relative to chemical propulsion. Personnel transfer would be by chemical rocket to minimize travel and radiation exposure times.

\section{Reference System development, acquisition, and ma intenance costs}

Because costs are the final determinant in the acceptance of an energy system, the systems definition effort has attempted to derive cost models and to estimate costs for the Reference System and has used the cost models to assess the value of alternative approaches and to provide guidance as to what are the important factors in a cost sense.

The estimates were based on the scenario defined in the reference system report (ref. 10) and the production rates associated with that scenario. Detailed cost data may be found in references 11, 16b, and 20c. Subsequent sections of this report will discuss cost estimates with in particular areas of technology.

The cost of a 5-GW silicon reference system satellite, based on the average unit cost of 60 satellites, was determined to be $\$ 5$ billion (1977 dollars). Space transportation, the cost of transporting the materials and personnel to construct a 5-GW satellite in geosynchronous orbit, was $\$ 2.8$ billion. The ground receiving station, including RF to DC conversion, power distribution and conditioning, grid interface, structure, and land acquisition, was $\$ 2.2$ bililion. Assembly and support during construction, based on crew salaries and resupply at LEO and GEO bases, was $\$ 840$ million. Program management and integration was estimated to be $\$ 430$ million. The sum of these costs is $\$ 11.3$ billion for each 5 -GW system, or $\$ 2260 / \mathrm{kW}$ (fig. III-4).

In addition to the cost of acquiring and building each power system, there are costs incurred in developing the industrial capability to produce hardware, the launch facilities, the fleets of vehicles for the transportation system, and the space bases at low Earth orbit and at geosynchronous Earth orbit. One estimate has been made for these nonrecurring costs under the assumption that an SPS program would bear the full burden and that there are no other activities which would serve to develop capabilities required in SPS. Although this assumption may not be realistic, the cost estimates thereby created give the max imum burden to SPS development.

The nonrecurring costs were assembled for several program phases: Research, Engineering, Demonstration, and Investment. The distribution of costs by phase could vary depending on the exact goals of each phase. This scenario is based on an evolutionary path leading to the construction of the first SPS. During the various phases, hardware capability and DDT\&E for SPS program parts are evolved such that the ability to construct an SPS in geosynchronous orbit would exist at the end of the Investment phase. Figure III-5 illustrates the distribution by phase of the total front-end cost of $\$ 102.4$ billion, which includes the cost of the first SPS. Figure III-6 shows the distribution of this cost over a 20-year period. It should be noted that the first two phases - Research and Engineering - are 
activities which most likely would have to be conducted with all funding supplied by government. This amount is approximately $\$ 25$ billion for the activities which should lead to a clear-cut determination of feasibility and economic viability. The subsequent phases - Demonstration and Implementation would be accomplished, therefore, all or in major part with private investments; otherwise, SPS would not be pursued.

Maintenance costs per satellite system are depicted in figure III-7. Transportation cost represents more than half of the total. More than $80 \%$ of the transportation cost is for personnel and their supplies, and about $20 \%$ is for transportation of replacement materials. The next largest item, $\$ 39 \mathrm{million} /$ year, is replacement parts for klystrons, DC-DC converters, and other satellite components.

All the costs given previously are for the silicon reference system. Costs for the gallium arsenide reference system are similar. Because of its lower mass, the GaAs system transportation cost is lower. The solar cell costs, however, are higher, and the total cost per system is estimated at $\$ 13.8$ billion (ref. 20c). Because of siight differences in cost estimating methods, this figure is not directly comparable to the $\$ 11.3$ billion given previously for the silicon system.

\section{Alternate Concepts}

\section{Power level and transmission frequency}

The large amount of power per microwave link and the large land area required by the rectenna are sometimes mentioned as disadvantages of the SPS reference systems. These parameters arose from natural constraints on the system (see previous discussion) and from a desire to minimize the cost of energy, which can be achieved by, among other things, economies of scale.

Sensitivity analyses (ref. 14, Appendix A) have shown that, although maximizing output per microwave link does in fact minimize energy cost, output per link can be reduced to about 2.5 to 3 GW without excessive increase in the cost per kilowatt-hour. Rectenna area for the small system is approximately half that of the reference system; rectenna siting is accordingly less constrained.

Rectenna size can also be reduced by use of a higher transmission frequency. An industrial band at $5.8 \mathrm{GHz}$ is potentially usable and has been investigated (ref. 22). Ionospheric heating is not a constraint, because of the frequency-dependent nature of the effect, but antenna heat rejection does limit the configuration. Transmission is satisfactory through dry atmosphere but degrades severely in rainy conditions; the impact of such degradation on the power grid is not known. A reasonable $5.8-\mathrm{GHz}$ system was derived that delivered $2.7 \mathrm{GW}$ to the grid with a $0.75-\mathrm{km}-\mathrm{di}$ ameter antenna and a 5.8 $\mathrm{km}$-diameter rectenna. Cost per kilowatt was estimated to be slightly more than the reference system.

\section{Solid-state amplifiers}

The klystron microwave generators in the reference system dominate the anticipated maintenance requirements of the SPS (ref. 15b): Since solid-state components typically have much higher mean times between failures than conventional electronic tubes, the ir use in the MPTS could greatly reduce maintenance time and personnel. They also offer the potential for mass production as part of an integrated circuit.

One approach is to replace the reference antenna with a solid-state version. Because solid-state devices require a lower operating temperature than the klystron, the optimum solid-state system has a larger transmitting antenna, a smaller rectenna, and lower total power output. For the reference taper and efficiency chain, typical values are $1.4 \mathrm{~km}, 7 \mathrm{~km}$, and $2.5 \mathrm{GW}$, respectively (ref. 15b). Because of the low voltages required by solid-state devices, the power distribution system must pay a substantial mass penalty (thousands of tons), either in conductors or in DC-DC conversion equipment.

The power distribution penalty can be which solar cells are mounted on one side of a substrate and the solid-state power amplifiers on the other, with direct electrical power connections between small groups of celis and amplifiers. To illuminate the solar array while the antenna points continuously at the ground, a system of reflectors is required. By using multiple reflecting paths, concentration can be achieved. Figure III-8 shows one proposed configuration which delivers $1.2 \mathrm{GW}$ to each of two rectenna sites $5 \mathrm{~km}$ in minor diameter. 
A major disadvantage of the sandwich concept is the difficulty in tapering the transmitter power density for sidelobe suppression without reintroducing power distribution penalties. Consequently, uniform illumjnation is used. A 10 - by $13-\mathrm{km}$ perimeter is necessary to contain illumination levels above $0.1 \mathrm{~mW} / \mathrm{cm}^{2}$ with the system in figure III-8.

\section{Lasers}

Lasers have been suggested as an alternative to microwaves for power transmission. Sev-. eral significant advantages and disadvantages of lasers have been identified (ref. 23). Some of the advantages over a microwave system are:

a. Much less land is required for receiving sites.

b. Radiation levels outside receiving site are negligible.

c. Sidelobes do not interfere with communications or other electromagnetic systems.

d. Power per receiver can be much lower.

e. Small-scale demonstration is feasible.

Some disadvantages are:

a. Attenuation by clouds appears to be a serious problem.

b. Thermal blooming may be a problem at very high intensities.

c. Clouds may be induced above the receiving station.

d. A laser SPS may be perceived as a potential weapon.

e. High-power laser technology is less developed than microwave technology. thorough evaluation.

Some of these disadvantages could rule -out the laser concept and, therefore, require

A laser SPS concept has been described in some detail (ref. 24), consisting of power satellites in Sun-synchronous orbits and relay satellites at GE0. Carbon dioxide electric discharge lasers (EDL's) are used for power transmission. Some questionable aspects of the concept are the assumed high efficiency of the energy conversion system, the reliability of the EDL, and the dependability of the energy exchanger.

Three types of laser that may be applicable to SPS have received primary emphasis in recent comparative studies (ref. 17). The EOL technology is well established, but solar energy must first be converted to electricity. An indirect solar-pumped laser can avoid the sunlight-toelectricity conversion, but feasibility has not been demonstrated. The free electron laser (FEL) is potentially efficient and does not require a lasant material; feasibility has not been established. other types that appeared noncompetitive in a preliminary screening include gas dynamic, chemical, and direct solar-pumped lasers. Figure III-9 shows the mass in orbit of the laser options studied. All are heavier per delivered kilowatt than the reference microwave system. The best (FEL) is within a factor of two in mass and cost per kilowatt. The FEL and the indirect solar-pumped laser (IOPL) offer the most promise for future research. 


\section{Conclusions and Remaining Issues}

This section is limited to system-level conclusions of the system definition effort. Those conclusions that deal. with a specific area, such as power conversion, are treated in that section. The principal overall conclusions are:

1. The reference SPS is a feasible baseload source of electrical power by virtue of nearly continuous illumination in GEO, minimal disturbance of the microwave beam by weather, and an absence of identified insurmountable obstacles.

2. Within the assumed guidelines, the maximum power delivered to the grid by each microwave link is. $5 \mathrm{GW}$. If solid-state amplifiers are used, the maximum is $2.5 \mathrm{GW}$.

3. Minimum cost per kilowatt is achieved at the maximum output of $5 \mathrm{GW}$. The cost penalty for lower output per system can be held to about $5 \%$ with a system optimized for an output as low as $3 \mathrm{GW}$. An optimum solid-state system is nearly as cost effective as the klystron reference system.

Major unresolved issues include the following:

1. Maximum allowable power density in the ionosphere must be defined. This limit determines the maximum power transmitted by each microwave link.

2. Laser power transmission appears to have substantial mass penalties relative to microwave systems, as we.ll as other disadvantages, but has not been defined in sufficient detail to warrant a final judgment. 


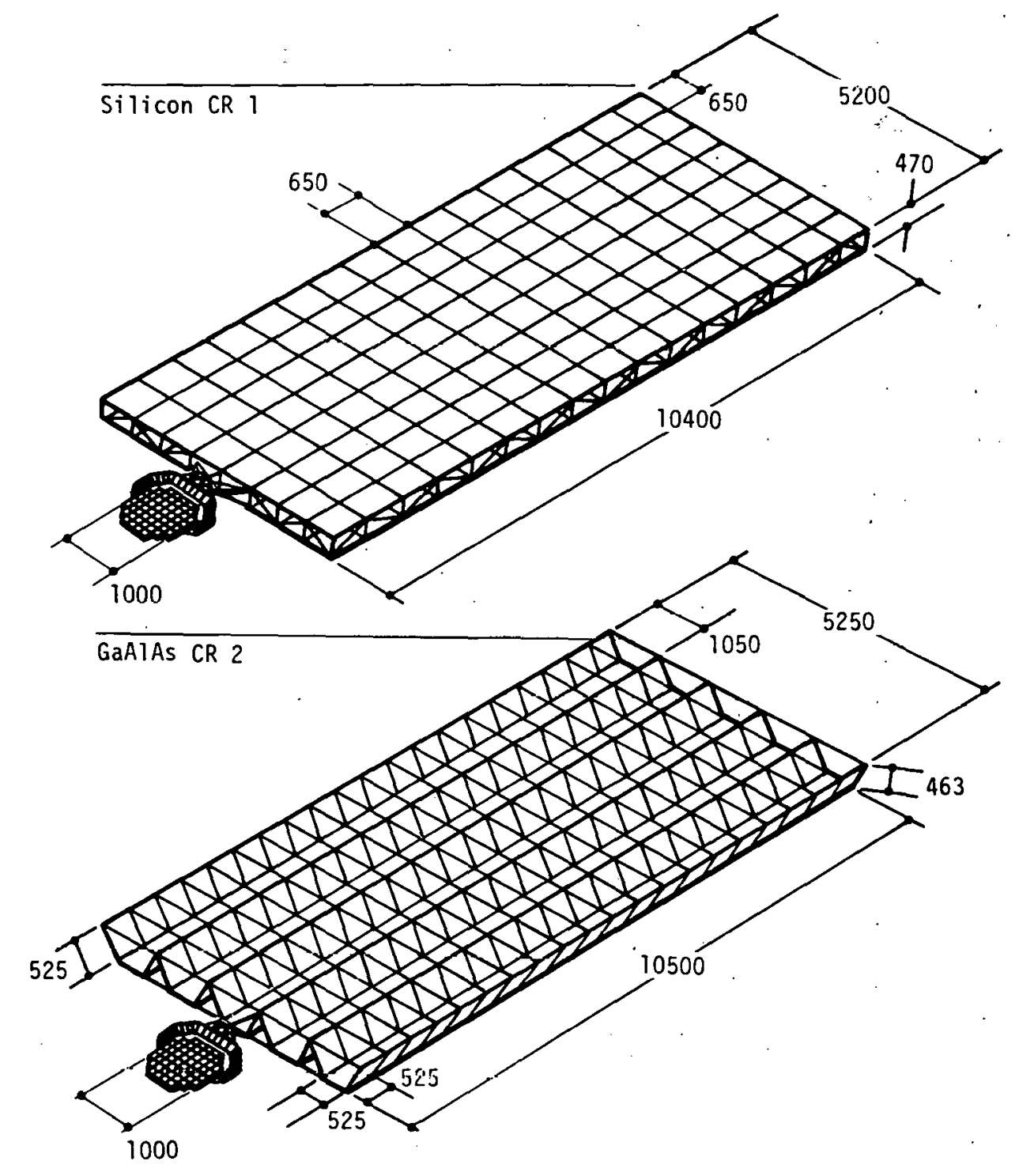

Dimensions in meters

Figure III-1.- Reference configurations. 


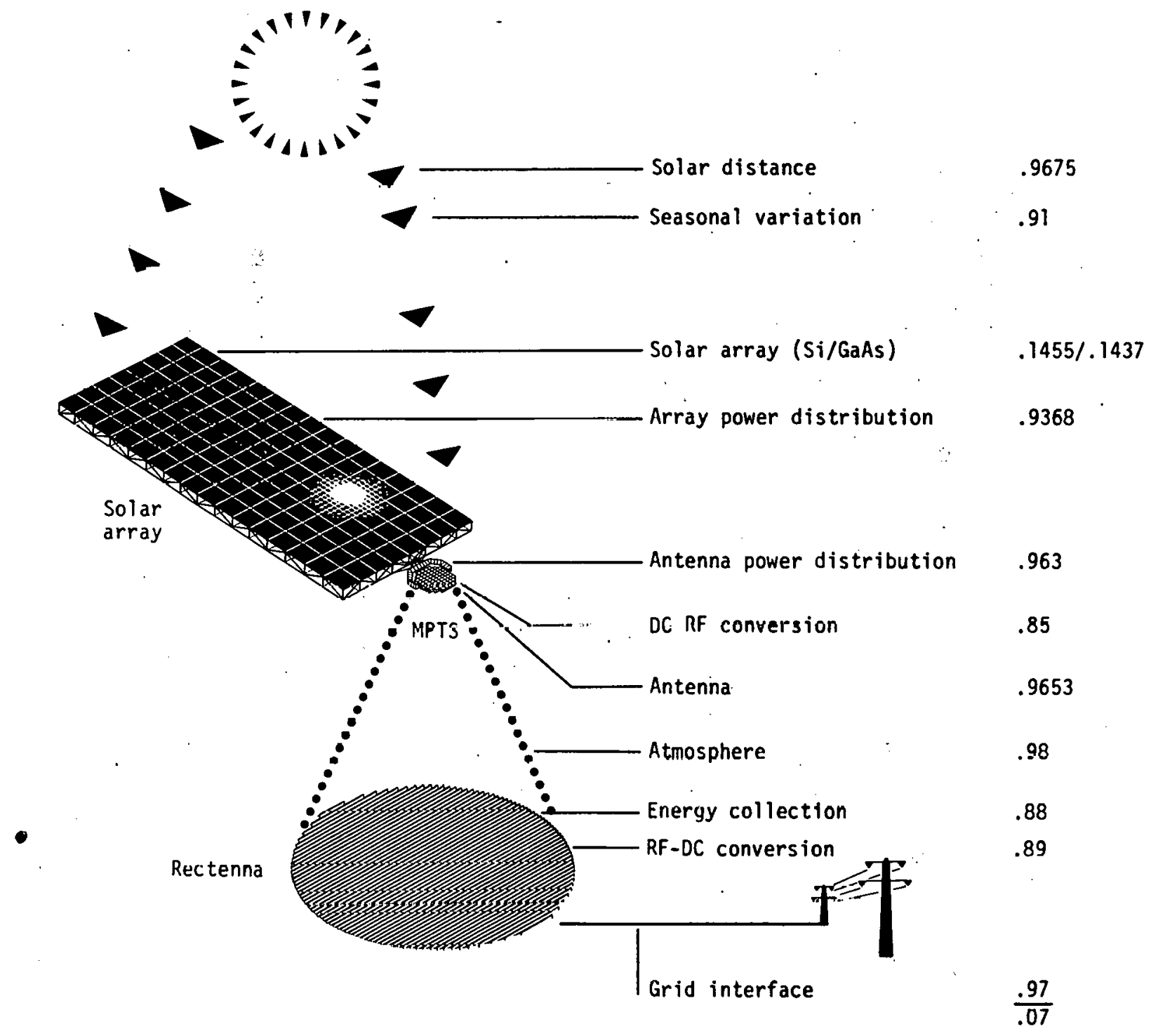

Figure III-2.- Reference efficiency chain. 


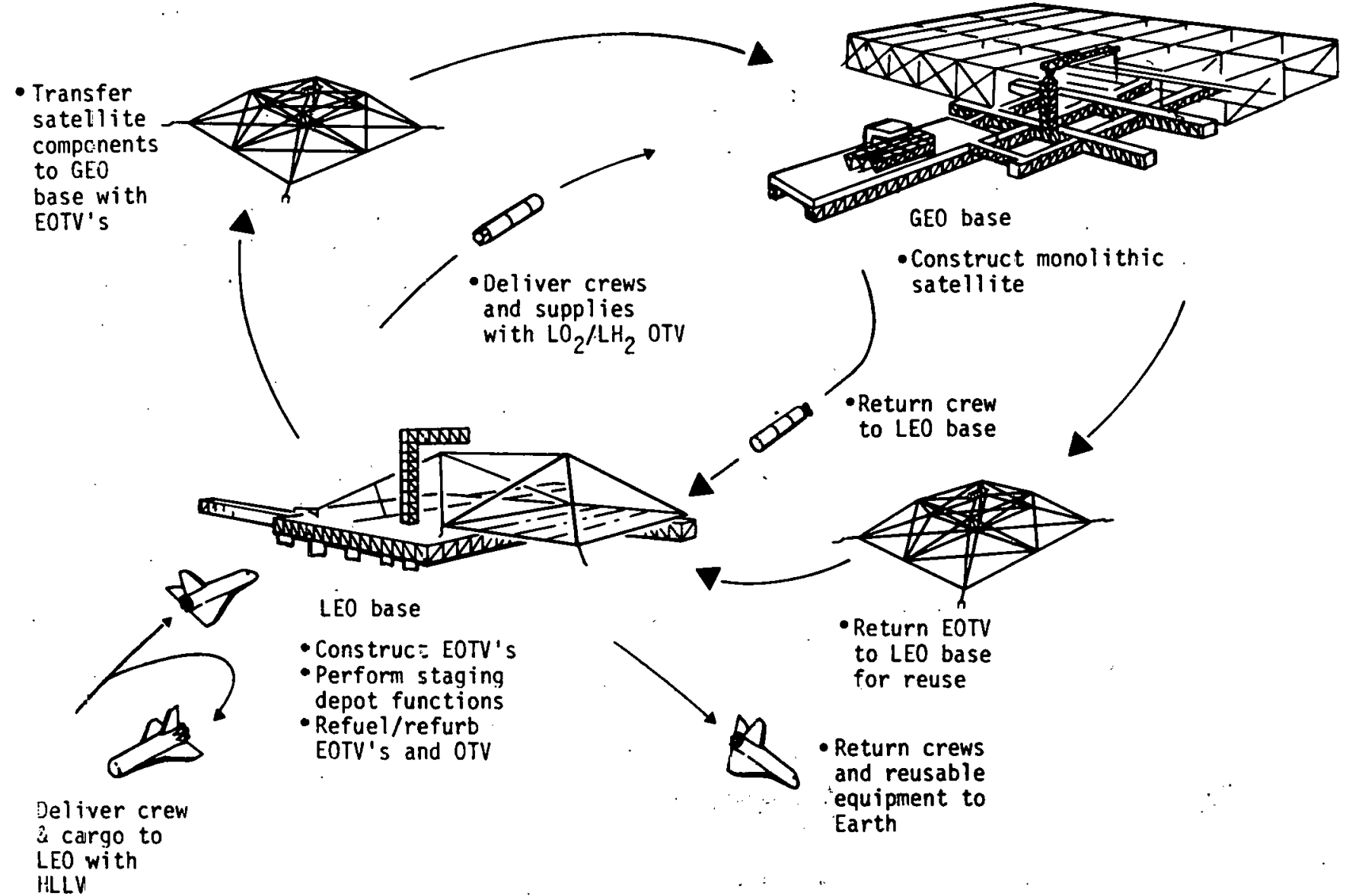

Figure III-3.- Space transportation and constrüction. 


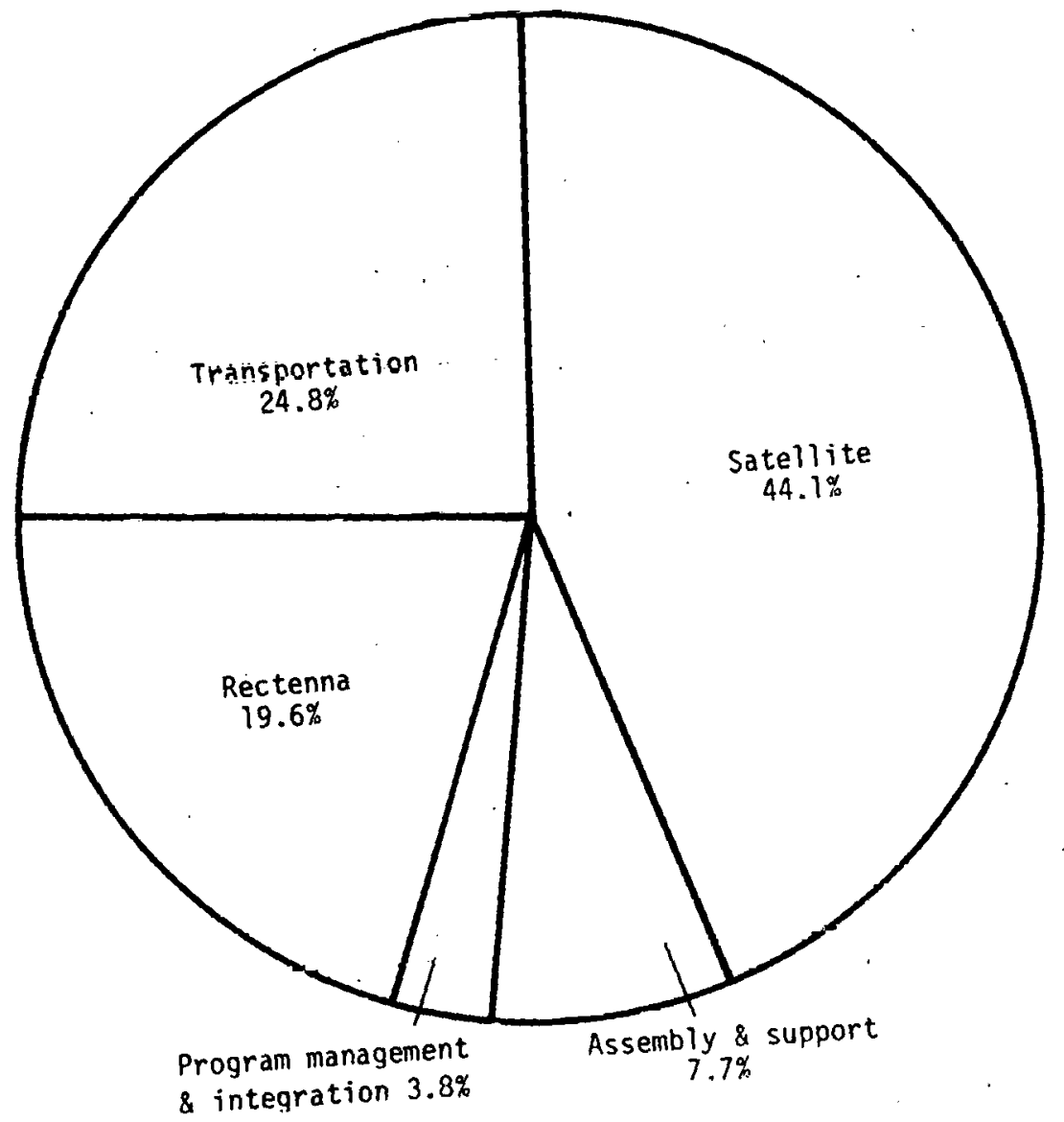

SPS recurring cost - $\$ 11.3 \mathrm{~B} / 5-\mathrm{GW}$ system

Figure III-4.- SPS unit cost. 


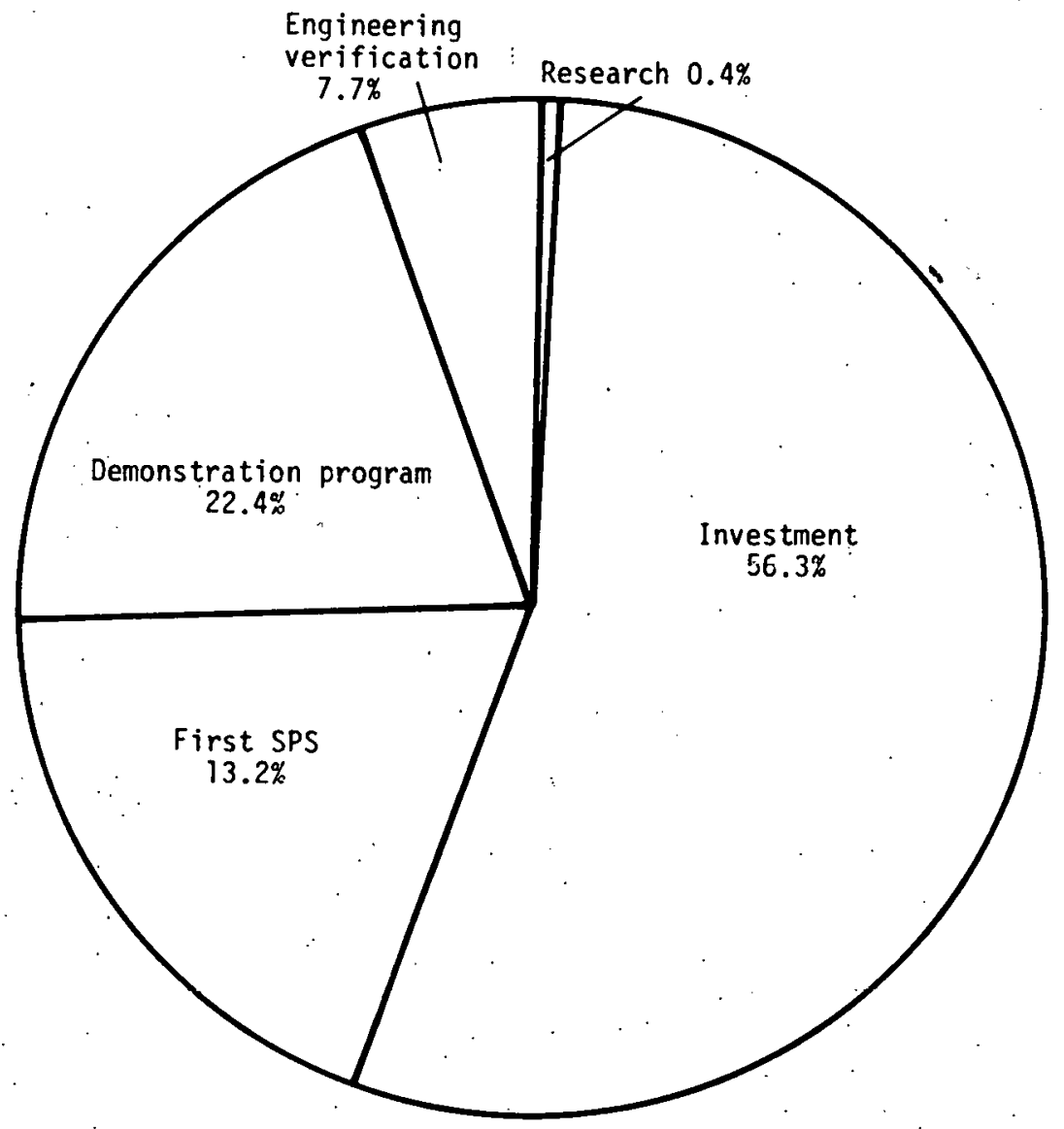

Total nonrecurring cost $-\$ 102 \mathrm{~B}$

Figure III-5.- SPS nonrecurring costs. 


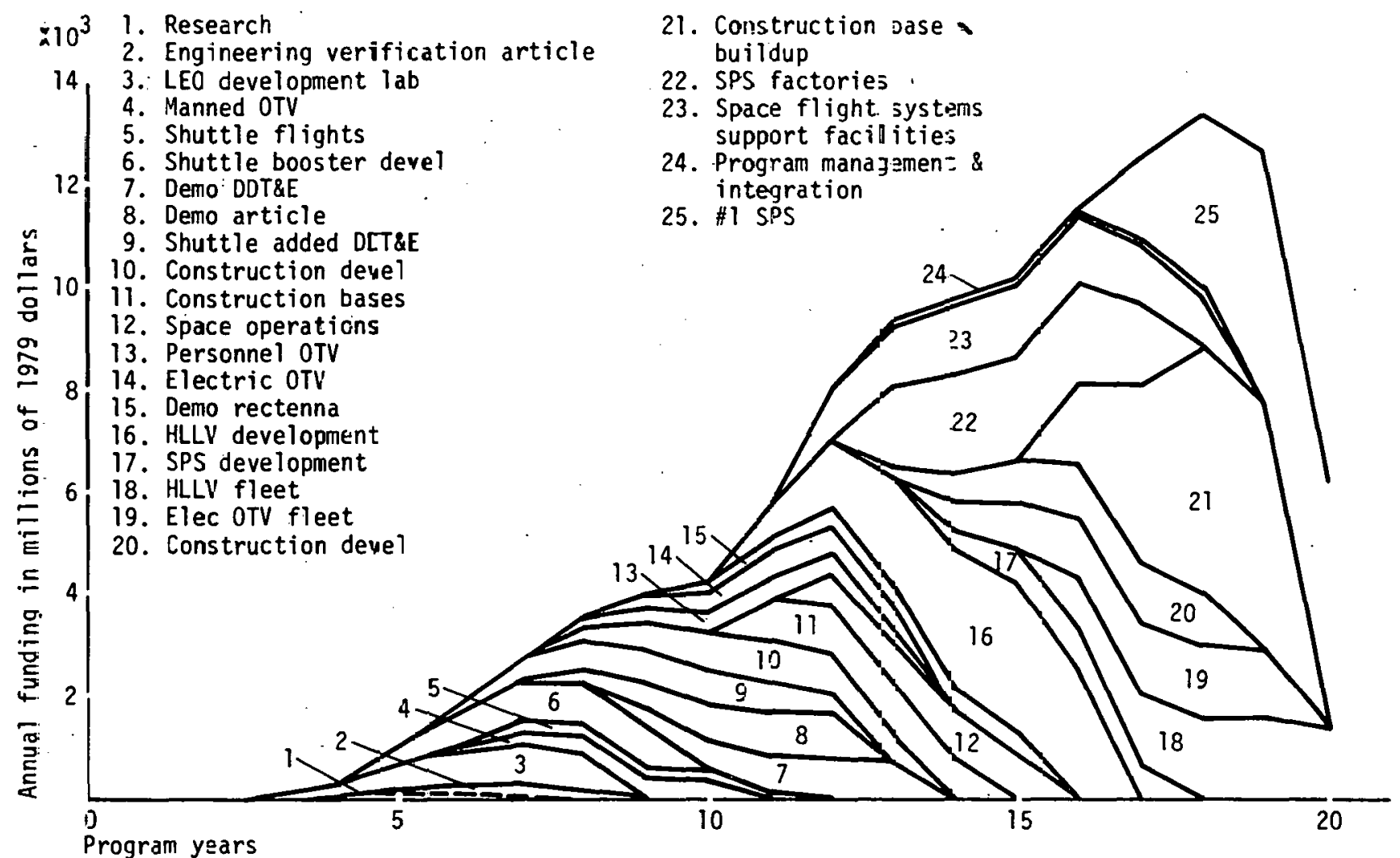

$=i$ cure III-6.- SPS total program costs by year. 


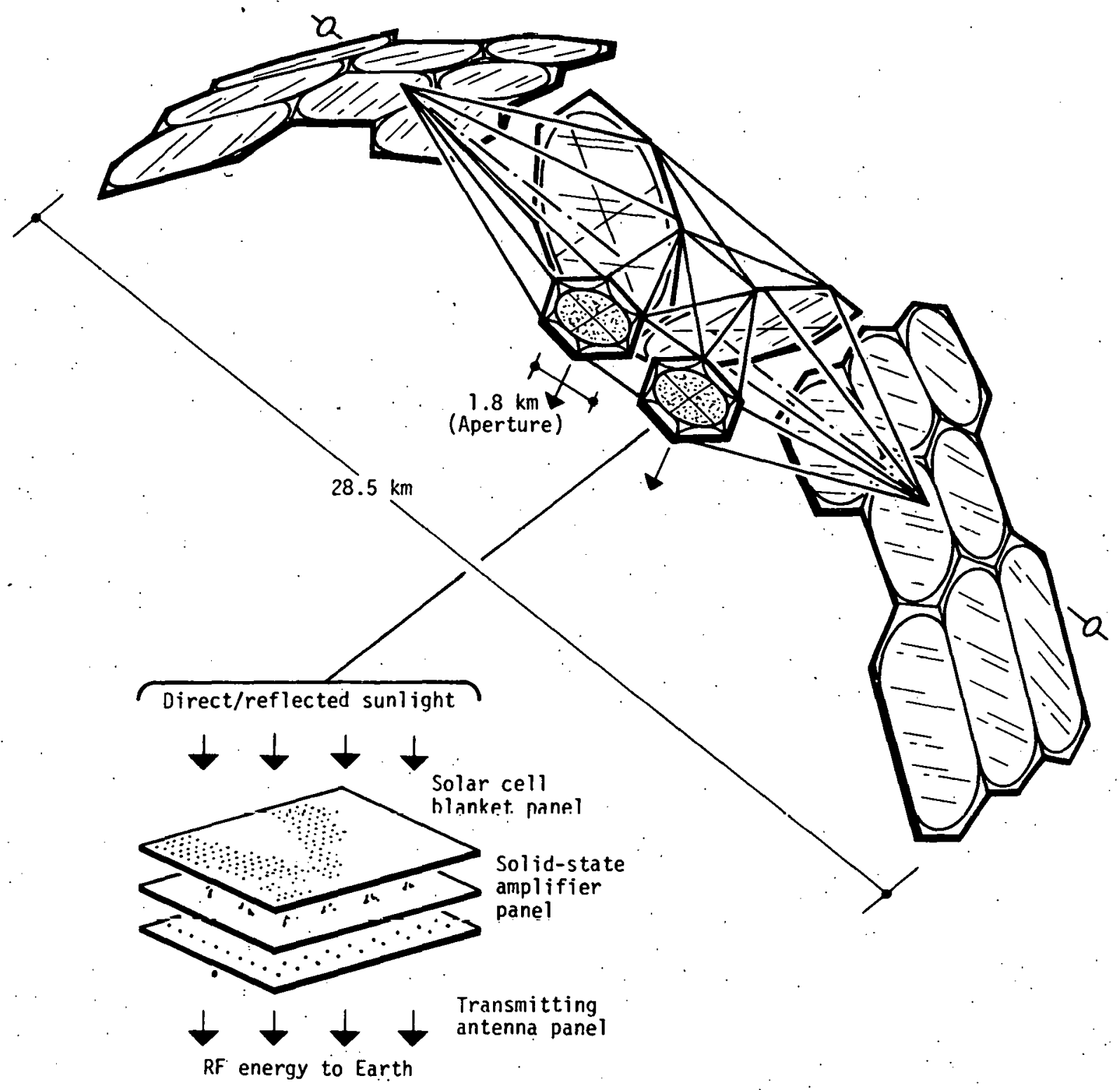

Figure III-8.- Solid-state "sandwich" concept. 


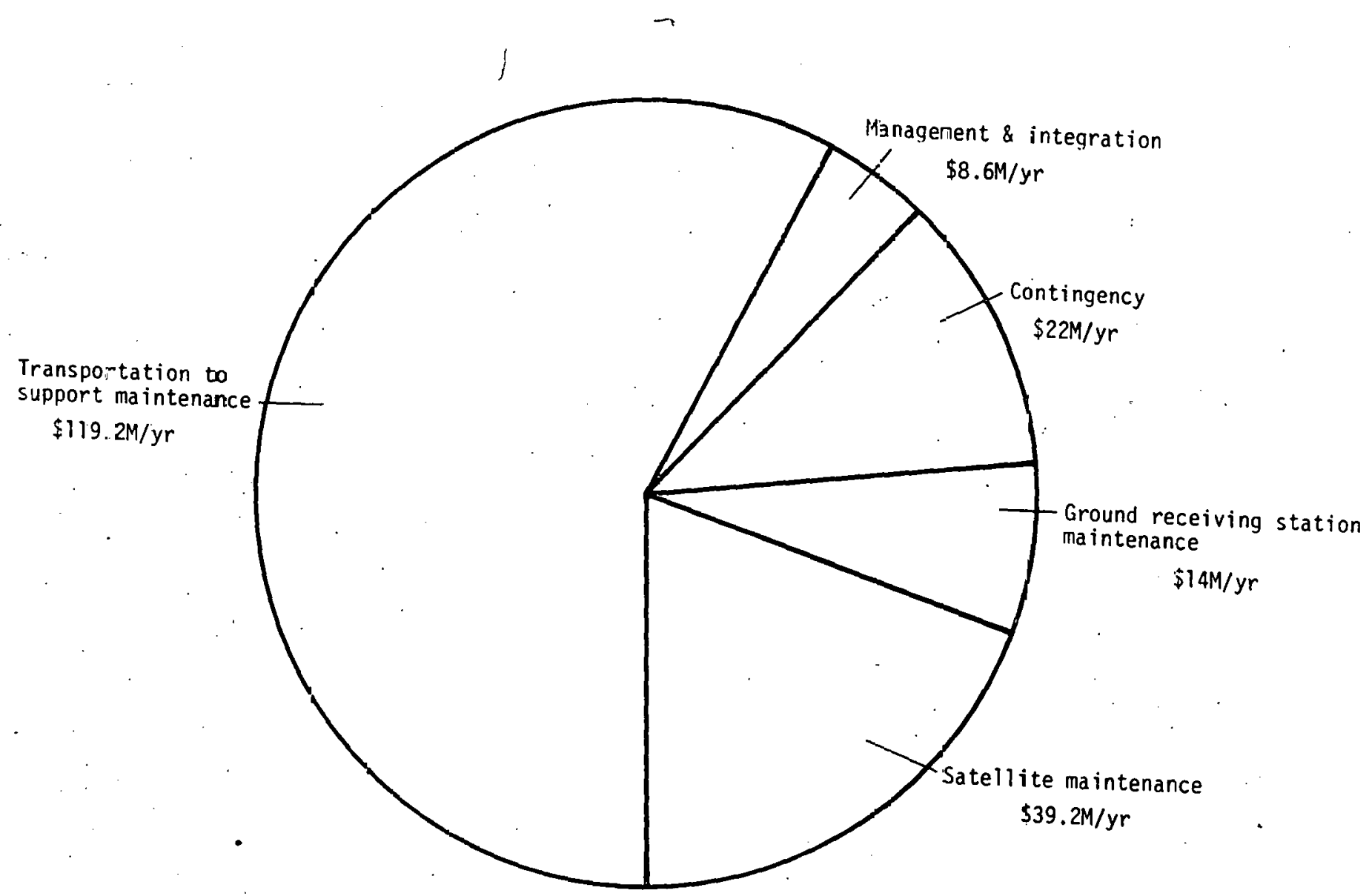

Anual meintenance expense - $\$ 203.4 M / 5-6 W$ system

Figure III-7.- Maintenance cost. 


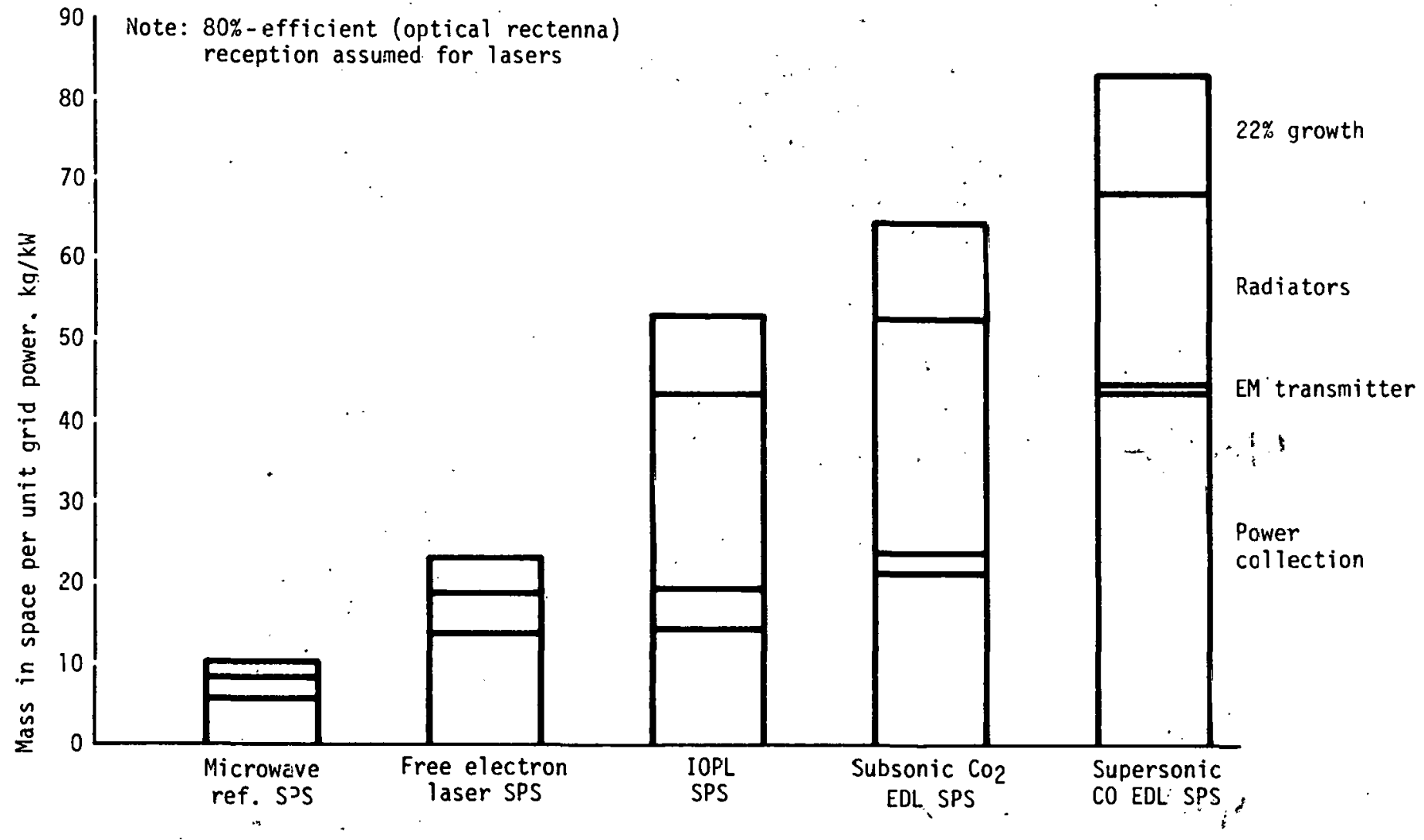

Figure III-9.- Laser SPS mass comparison. 
Blank 


\section{ENERGY CONVERSION AND POWER MANAGEMENT}

\section{A. Sumary and Introduction}

The function of the SPS energy conversion system is to collect solar energy and convert the solar energy to electrical power. The power management system collects, distributes, and controls the flow of electrical power on the satellite. Satellite power system definition studies have included consideration and analys is of all known potentially viable space energy conversion concepts. The emphasis has been on solar energy collection and conversion, although early studies (ref. 25) included definition and analysis of selected nuclear reactor systems. With respect to solar energy conversion systems, both photovoltaic and thermal energy conversion methods have been studied. Photovoltaic system studies involved consideration of a large number of solar cell types. In these studies, various levels of solar concentration were investigated (refs. 12 and 19).

Thermal systems studied included both static and dynamic conversion methods. The static system investigated was thermionic conversion, whereas the dynamic (rotating machinery) systems studied included Brayton cycle, Rankine cycle, and combined (cesium/steam) cycle concepts. Alternative working fluids, cycle temperatures, and associated performance/technology levels were analyzed and evaluated. A number of solar concentrator concepts (e.g., parabolic, faceted) with concentration ratios of 2000 and greater were investigated (refs. 12, 13, 19, and 20).

In the early nuclear reactor system studies (ref. 25), rotating particle bed, molten-salt breeder, and uranium hexafluoride reactor concepts in combination with Brayton, Rankine, and thermionic thermal energy conversion were investigated. The following sections contain summaries of the key results of the previously mentioned SPS energy conversion studies.

\section{B. Energy Conversion}

\section{Solar photovoltaics}

From the earliest SPS studies, solar photovoltaic technology has provided a standard of comparison for other solar collection/conversion systems. Initial NASA studies (refs. 6 and 7) emphasized the use of silicon solar cells; however, consideration was given to gallium arsenide and other, less developed solar cell types. Subsequent studies initiated during the CDEP (refs. 12 to 21 ) involved more in-depth evaluation of silicon and gallium arsenide and other cell types including amorphous silicon, cadmium sulfide, indium-cadmium-sulfide, copper-indium-selenide, multibandgap, and optically filtered concepts.

In evaluating the various photovoltaic options, a number of factors were considered including performance (efficiency), mass, materials availability, susceptibility to radiation damage (performance degradation), development status, and cost. The use of solar concentrators and their effects on system performance was also studied. In addition to the system definition efforts, surveys were made (ref. 26) to assess materials availability, manufacturing process requirements, and energy payback of several candidate solar cell designs. This work included an assessment of SPS solar cell requirements with respect to DOE's U.S. Photovoltaic Conversion Program.

In comparing the various photovoltaic options, the single-crystal silicon cell and the gallium-aluminum-disenide cells emerged as the most promising for SPS application. 0ther solar cell types, listed previously, generally have the potentiai advanlage of lower cost.s and/or lower mass per unit area; however, the performance (efficiency) currently is low and mass production methods have not been devised.

Single-crystal silicon solar cells are the only solar cell type that has been used for spacecraft solar power systems. Research and development has produced cont inuous improvements in unit mass, efficiency, and reliability; however, further improvements (in mass per unit area and production cost) are required for SPS application.

The SPS reference system incorporated silicon and gallium arsenide solar cells as optional energy conversion systems. Figure IV-1 is an overall conceptual drawing of the silicon cell concept. Figure IV-2 contains details of the silicon solar cell blanket construction used in the reference system. 
Gallium arsenide cells have been under investigation for a number of years, but significant improvements have been made since 1972. The development of the gallium-aluminum-arsenide "window," which is epitaxially grown on the basic gallium arsenide cell, has led to the improvement in cell efficiency. Since most solar radiation is absorbed within $1 \mu \mathrm{m}$ of the GaAs cell surface, it is possible to construct a very thin cell $(5 \mu \mathrm{m})$ with good efficiency. Consequently, the quantity of gallium needed to make the cells, is significantly reduced compared to the thickness of cells used today. The advantages of gallium arsenide cells are low mass, resistance to degradation by thermal and radiation effects, and relatively high efficiency. Use of solar concentration and the correspondingly higher temperatures may provide self-annealing of the cells. Disadvantages are relatively high cost and less developed technology base than silicon. Gallium availability is also a consideration; however, this does not appear to be a limiting factor for the year 2000.

Figure IV-3 is a conceptual drawing of the GaAs solar cell reference system. Figure IV-4 contains details of the GaAs solar blanket construction.

Table IV-I provides an example comparison of gallium arsenide and silicon cell options for a specific SPS configuration. The cost data shown in table IV-1 are presented for parametric comparison only and are, therefore, not directly comparable to the reference system cost.s given in Sectiun III. Note that with solar concentration $(C R=2)$, the gallium arsenide system and the silicon system are rnmpetitive in tenus of relative cost of hardware delivered to GEO. Because of this cluse competitinn, silicon and gallium arsenide are both viable candidates for SPS applicatiun.

The use of solar cells in SPS, whether silicon or gallium arsenide, is predicated on substantial reductions in the cost to produce multigigawatt quantities of cells. It is believed that such cost reduction will be forthcoming over the next 5 to 15 years as a result of the Department of Energy's photovoltaic conversion program. Projections of solar cell cost and associated production quantities are shown in figure IV-5. As indicated, the 1986 goal for terrestrial solar cells is $\$ 500$ per kilowatt in quantities of $500 \mathrm{MW}$. The SPS reference scenario would require 20,000 to 30,000 MW per year capacity in the 2000 time frame. The cost projection for the space-type cells in 2000 is $\$ 200 / \mathrm{kW}$ to $\$ 400 / \mathrm{kW}$. Although it is recognized that the weight and space radiation resistance requirements for space celis are different from those for terrestrial use, the $\$ 200$ to $\$ 400$ range appears reasonable for SPS. For comparison, present day space cells (silicon) cost $\$ 50,000 / \mathrm{kW}$ to $\$ 80,000 / \mathrm{kW}$ with annual production rates of only a few tens of kilowatts.

are as follows:

The significant findings resulting from the photovoltaic energy conversion studies

a. Solar cells - Among the solar cell types available for consideration, single-crystal silicon cells and gallium-aluminum-arsenide cells have the potential of lightweight components and lowcost production to meet SPS requirements. As a result, both Si and GaAlAs are considered viable options for SPS application. Key questions or unknowns to be resolved for each cell type are summarizcd in figure IV -6 .

b. Radiation performance degradation - Solar cell performance (efficiency) is degraded by exposure to space radiation in both silicon and gallium arsenide cells. Silicon solar cells may be used by initially oversizing the solar array, by adding solar arrays to maintain rated output, or by in situ annealing of the solar array through laser heating to recover performance loss. The in situ annealing approach appears to be the most cost-effective and appears to be technically feasible (refs. $15 b$ and 15d).

Based on preliminary test data (ref. 19), gallium arsenide solar cells operating at 398 $K(1250 \mathrm{C})$ (with $\mathrm{CR}=2.0)$ may have the capability of continuous annealing of radiation damage.

c. Solar concentrators - The use of solar concentrators with silicon solar cells is not warranted on the basis of cost and weight savings because of (1) increased coll operating teilperature, resulting in cell efficiency degradation; (2) lnw mijectcd cosl uf silicon solar array blankets; and (3) morc complex spacc conslruction of concentrator systems (refs. 12 and 13).

The use of solar concentrators with gallium arsenide solar cells is beneficial at a concentration ratio of 2 because (1) the sular cell area required is smaller and, therefore, system. cost is reduced and (2) higher cell operating temperature caused by increased solar heat input promules annealing of radiation-induced performance degradation on a cuntinuous basis (ref. 19). 


\section{Thermal systems}

Thermal energy conversion systems consist of means for collecting and concentrating solar energy and for the transfer of this thermal energy to a thermodynamic cycle or converter module, where work is accomplished to generate electrical power. The thermal system may be either a static converter such as thermionic and thermoelectric or a dynamic system (rotating machinery) such as Rankine and Brayton cycle. The dynamic systems use a working fluid for the transport of energy within the thermodynamic cycle. In all thermal cycle systems, residual or waste heat from the cycle must be rejected to space by a space radiator to sustain operation of the system with net power output.

Thermal cycle systems may use a nuclear reactor heat source in place of solar energy. Several nuclear reactor concepts have been investigated and are summarized herein.

The system definition studies have included consideration of a large number of thermal cycle systems and components. Figure IV-7 contains a list of the systems investigated with references in which detailed study rēsults are presented.

The following paragraphs consist of discussions and conclusions relative to the thermal cycle systems investigated.

a. Brayton cycle - A schematic diagram of a closed Brayton cycle system shown in figure IV-8 illustrates the fundamental elements of the Brayton cycle SPS. The solar concentrator reflects and focuses concentrated sunlight into the cavity absorber aperture. The cavity absorber is an insulated shell with heat exchanger tubing. Helium gas flowing through this tubing is heated to the turbine inlet temperature. The hot helium expands through the turbine, doing the work of turning the compressor and the electrical generator. Residual heat in the turbine exit gas is used to preheat compressor output gas before final heating in the cavity absorber. This heat transfer is accomplished in the recuperator, which is a gas-to-gas heat exchanger. The minimum gas temperature occurs at the exit of the cooler, which is a gas-to-liquid heat exchanger interfacing the helium loop to the radiator system. Waste heat. is rejected to space by a liquid-metal radiator system.

Conceptual designs of solar Brayton cycle systems were developed under NASA contract. One design was based on a 10-GW ground output with two microwave power transmitters. Turbine and materials technology levels to temperatures as high as $1610 \mathrm{~K}\left(2438^{\circ} \mathrm{F}\right)$ were investigated; however, the final design of this system used relatively conservative technology with a turbine inlet temperature of $1242 \mathrm{~K}(17760 \mathrm{~F})$, which is compatible with current superalloy materials capability for long-term operation. At this reduced temperature, the cycle efficiency was $21 \%$. The satellite system mass was 102 $\times 10^{6} \mathrm{~kg}$ for the $10-\mathrm{GW}$ system, or $10.2 \mathrm{~kg} / \mathrm{kW}$. Another Brayton cycle design used a $1652-\mathrm{K}(25140 \mathrm{~F})$ turbine inlet temperature with a cycle efficiency of $45 \%$. This elevated temperature requires the use of materials such as ceramic (e.g., silicon carbide) which are currently under development. The total mass of this Brayton cycle satellite system was about $43 \times 10^{6} \mathrm{~kg}$ for a 5 -GW system, or $8.6 \mathrm{~kg} / \mathrm{kW}$, an indication of the weight advantage provided by more advanced technology.

The general conclusions made from the Brayton cycle studies are as follows.

(1) Satellite system mass with solar Brayton cycle energy conversion is competitive with photovoltaic options.

(2) Areas of concern in Brayton systems are: (a) large, heavy radiator systems, including the requirement for leaktight fluid joints; (b) difficult requirements for efficiently constructing solar concentrators; and (c) low-packaging-density components (e.g., fluid ducts, radiator panels), which increase space transportation costs.

(3) In contrast to photovoltaics, hardware could be fabricated on an SPS scenario scale within current industrial capability.

b. Rankine cycle - The system definition studies produced conceptual designs of Rankine cycle systems using potassium, cesium, and a cesium/steam (dual cycle) working fluid. Figure IV-9 is a drawing of a potassium Rankine cycle satellite system (ref. 13b). Design features of this concept are shown in the figure. 
The satellite system mass, without growth allowance, was about $81 \times 10^{6} \mathrm{~kg}$ for 10 GW ground output. Figure IV-10 sumarizes the design features of the potassium Rankine cycle system.

The cesium/steam dual Rankine cycle concept is illustrated in figure IV-11. The satellite mass for this concept was about $33 \times 10^{6} \mathrm{~kg}$, without growth allowance, for 5 GW ground output.

Conclusions made regarding Rankine cycle systems are as follows.

(1) Like the Brayton cycle system, Rankine systems represent acceptable alternative approaches for SPS solar energy collection and conversion.

(2) The primary disadvantages of solar potassium Rankine cycle (relative to photovoltaics) are higher satellite mass and more difficult/complex space construction. Technology improvements that would make the potassium Rankine system more competitive are as follows.

(a) Development of easily constructed solar concentrators

(b) Development of high-temperature metal alloys with improved creep and creep rupture properties for thermal engine components - This improvement would yield higher system efficiency which, in turn, would reduce satellite mass and cost as well as provide longer life potential.

(c) Fluid systems development. such as lightweight radiators with leaktight juillte, linproved metcoroid protection lur filuld tubes, and heat pipe technology Novel radiator concepts such as dust and liquid drop radiators (ref. 28) may prove beneficial in this area.

The low projected mass of the cesium/stean Rankine dual-cycle satellite makes the concept competitive with the silicon and gallium arsenide photovoltaic options; however, satellite maintenance is a major concern for this system. The complexity associated with repair/replacement of a large number of massive components and potential problems of fluid system (leakage, cesium/steam interleaks) are major issues.

c. Thermionics - Thermionic energy conversion was studied early during the system definition activities. A comprehensive system study conducted before the CDEP effort (ref. 25) produced several different thermionic SPS system concepts. Both solar and nuclear energy source systems were defined and analyzed. The concepts studied were:

(1) Solar thermionic

(a) Direct radiation cooled

(b) Liquid-metal cooled

(c) Thermionic-Brayton cycle cascade, liquid-metal cooled

(2) Nuclear thermionic - Molten-salt breeder reactor

Study of the thermionic energy conversion for SPS application was discontinued early in the program because results of the previously mentioned study and subsequent system definition studies showed that satellite mass is $1-1 / 2$ to 2 times greater with thermionic conversion than with other thermal cycle systems and 2 to 5 times greater than with photovoltaic systems. (See fig. IV-12.) As a result, the thermionic system has a higher projected cost than other candidate systens because of high transportation costs. The major contributors to thermionic system mass are interelectrode busbar mass and radiator/pump systems for heat rejection (in liquid-cooled systems). The high electrode mass is a direct result of the low-voltage/high-current output characteristics of thermionic conversion. To make the thermionic system competitive, substantial improvements in electrode design and/or material would be required. The same is true for radiator/pump systems, which account for almost half of satellite mass in liquid-cooled thermionic designs. 


\section{Power Management}

The power management system collects, regulates, and controls power from the power generators (solar arrays or generators) and transmits this power by way of power busses through rotary joints with brushes and sliprings to the power transmission system. Limited energy storage is .provided during eclipse periods. The system also provides for monitoring faults and fault isolations.

Power levels in this system are several orders of magnitude larger than in any previous space system. Although the engineering of such a system appears to be a monumental task, insights gained from ground-based systems and component-by-component analysis of the requirements placed on the SPS system indicates technical feasibility. This feasibility is conditional on successful component development and system operation at very high voltage levels. Initial studies in this area (refs. 6, 7 , 12, 13,18 , and 19) investigated a number of trade-offs including DC versus AC power transmission on the satellite, alternative conductor materials, round versus flat conductors, transmission voltage/current effects, and power processing requirements. The significant conclusions of these studies are summarized in subsection E.2. Subsequent studies (refs. 14 to 17,20, and 21) emphasized definition and analysis of the reference system.

Figure IV-13 is a schematic diagram of a typical solar array power collection and distribution system. Solar array power sectors are switchable to provide main power bus isolation for servicing. High-voltage breakers near the busses provide power controls. Power transfer across the rotary joint is accomplished by a slipring/brush assembly. Mechanical drive is produced by a large turntable. The antenna is supported in the yoke by a soft joint to isolate the antenna from turntable vibrations. The microwave power transmitting antenna includes a power distribution system, which distributes $D C$ power from the sliprings to the DC to RF power amplifiers. Switchgear is provided for system protection and isolation for maintenance. The DC-DC converters are connected to voltage busses for power distribution to the power amplifiers. A typical power distribution system is shown in figure IV-14.

\section{Workshop Summary}

A workshop on SPS Energy Conversion and Power Management was held on February 5-7, 1980, at Huntsville, Alabama. The objectives of the workshop were to assess and critique the assumptions, methodologies, conclusions, identified critical issues, and planned follow-on work (Ground-Based Exploratory Development (GBEn) Plan) recommended in the areas of energy conversion and power management. The workshop was divided into three sessions as follows: Photovoltaics, Solar Thermal, and Power Management. The key findings of the workshop groups are as follows.

\section{Photovoltaics}

\section{a. Resource issues}

(1) GaAs alternative

(a) Gallium availability does not appear to be a limiting factor for the "year 2000" time period, based on studies done to date by Rockwell.

(b) Contact metallurgy must be changed to the use of nonnoble metals. Alternatives appear to exist in adequate supply.

(c) Sources of metal-organic starting materials are inadequate now, but should be available when needed. (This is a processing industry capacity problem.)

(2) Si alternative: Contact metallurgy of space power cells must be changed to the use of nonnoble metals, but work on this problem is already part of the terrestrial program.

(3) Summary: There are no resource critical issues needing solution or study in GBED. 
b. Performance demonstration issues

(1) GaAs alternative: Existence of a suitable film-type solar cell

(a) Supporting element

(b) $18 \%$ efficiency (AMO) in a cell $\leq 10 \mu \mathrm{m}$,thick and of $\geq 10 \mathrm{~cm}^{2}$ area, on a thin, large-area, potentially inexpensive substrate that is capable of meeting SPS weight and cost goals

(c) As a milestone to the preceding point, achievement of $16 \%$ efficiency in an adequately similar cell/substrate/cover structure within 2 years to permit starting of stability tests

(d) Cells with contacts that are "weldable" and use of nonnoble and nonmagnetic metals (trace use of noble metals acceptable)

(e) Achievability of $16.2 \%$ end-of-life efficiency after 30 years (radiation resistance or annealing)

(f) Preliminary manufacturability studies to show that the developed blanket structure is not incompatible with SPS cost goals

(2) Silicon aiternative: Advancement to meet SPS specifications

(a) $16 \%$ efficiency (AMO) in $50-\mu \mathrm{m}$-thick cells of $\geq 25 \mathrm{~cm}^{2}$ area capable of meel Iny the radiation resistance and/or annealing requirements for SPS within 3 years

(b) Contacts "weldable," nonnoble, nonmagnetic, capable of surviving arnealing temperatures

(c) Achievability of $14.4 \%$ end-of-life efficiency after 30 years (radiation resistance or annealing)

(3) Blanket: Demonstrate a "blanket" design that is capable of meeting the SPS design goals (power-to-mass ratio, temperature, compatible cost).

c. Performance stability issues

(1) Subject cells to a qualification test program with emphas is on a radiation damage and anneal program (including critical evaluation and assessment).

(2) Demonstrate annealing to $P_{E O L} / P_{O}>0.9$ ill GaAs and $S i$ as function of particle type, flux, temperature, concentration ratio, fabrication technique, $n / p$ or $p / n$ cell type.

(3) Develop and conduct an accelerated testing program to demonstrate 30-year life.

(4) Demonstrate that end-of-life blanket power densities of $300 \mathrm{~W} / \mathrm{m}^{2}$ in the GaAs alternative and $150 \mathrm{~W} / \mathrm{m}^{2}$ in the $\mathrm{Si}$ alternative are achievable (80\% SPS goal).

(5) Condust hasir research and solar cell development programs to understand and eliminate (or at least reduce) radiation damage in $\mathrm{Si}$ and $\mathrm{GaAs}$.

(6) Plan and conduct geosynchronous orbit flight tests (may be past 1986).

d. Issue: Alternatives through advanced concepts

(1) Demonstrate a 25\%-efficient AMO thin-film cascade solar cell and shuw a potential for $35 \%$ efficiency.

(2) Investigate alternative concepts leading to $50 \%$ conversion efficiency. 
e. Recommendations for the GBED phase

(1) The use of concentration ratio 1 with the silicon solar cells should be reevaluated in light of recent cell developments which resulted in considerably reduced absorptivity/emissivity ratios, thus permitting lower temperature operation.

(2) To permit evaluation of the impacts of potential changes in some of the cell or blanket goal parameters which may result from the GBED program, the systems analyses will need to be expanded during the GBED period to provide sensitivity data.

(3) As a minimum goal, regardless of other parts of this plan being performed or not, the GBED program should adequately address the critical need for a spaceworthy solar cell encapsulation/blanket-support system.

(4) The SPS system concept should be exposed to the technical community who will be charged with the responsibility of designing and fabricating this system. To accomplish this, there should be a continuing series of peer review workshops during the GBED phase of the SPS program, utilizing experts from the various detail technology areas of potential concern.

(5) Based on this very brief examination of the challenges presented by the SPS concept, it is felt that the proposed GBED plan is not sufficiently detailed to allow a meaningful assessment of the viability of the SPS concept to be made in 1986. A modified GBED photovoltaic conversion plan, reflecting the previously listed critical issues, is provided (ref. 28).

(6) The goals outlined here for the GBED phase are rather ambitious but necessary to permit assessment of SPS viability by 1986 . To accomplish what has been recommended, funding levels well in excess of those proposed for the present GBED program will be required. The time available did not permit preparation of any type of cost estimate. However, the consensus is that the needed funding might be a factor of three greater than planned in the best case and an order of magnitude greater in the worst case.

\section{Solar thermal (summary)}

a. All the concepts (photovoltaic as well as solar thermal) require substantial advances in technology to enable achievement of the goals set for SPS. Therefore, all the concepts competitive at this time must be supported until sufficient information is available to permit narrowing the choice.

b. The criticism of the reliability of dynamic power systems based on the low multiplicity of elements is overcome by the sheer scale of SPS, which would have on the order of 100 turbine-generator assemblies.

c. The solar-thermal power systems pose problems in mission execution that remain largely unresolved. These problems concern the packing density of components during launching and construction and mainlenance in space. An iterative design process should produce concepts for SPS significantly superior to existing concepts.

d. For solar receivers, the state of the art is still rather primitive at this stage, and considerable effort on design and experimental evaluation of concepts is required.

e. Existing technology on refractory metals (chiefly tantalum alloys) indicates that either Brayton or alkali-Rankine systems could be developed for peak cycle temperatures of $1500 \mathrm{~K} .(22500 \mathrm{~F})$.

f. Because radiators for both Brayton and Rankine systems are a substantial portion of total system mass and because the potential. for meteoroid penetration of their fluid passages tends to degrade system performance with operating time, substantial effort 
is required on the design of this critical component to enable achievement of low mass and high reliability. Advanced, novel concepts in radiator design are considered elsewhere in this report (ref. 28) as well as the technology for more conventional radiators that can be folded and packaged for launching and then erected or deployed in space. Exploitation of man in space for radiator assembly, erection, and maintenance has received only cursory attention.

g. A seldom recognized advantage of the dynamic power systems (whether Rankine or Brayton) is that they produce power in a highly usable form that greatiy simplifies the problems of power processing. Their output power is AC with a frequency of a kilohertz or two and a potential of a few kilovolts. This power would also be regulated as to frequency and voltage. The energy losses in and the heat rejection from the power processors are thereby reduced. The generators or motors can also handle significant amounts of reactive power, if desired.

\section{Power management}

a. The economic practicality of the SPS is greatly affected by operation at tens of thousands of kilovolts necessary to operate the power transmitters directiy from the soldr array or by way of power processors and also required to minimize the weight of the power conductors and ultimately the transportation cost.

b. The terhnical fcasibility or llue SPS wilt depend on the technology readiness of techniques, components, and equipment to reliably distribute, process, and interrupt hundreds of megawatts of power at tens of thousands of kilovolts. The combined requirements of dissipating concentrated heat and preventing breakdowns due to corona in the insulating.materials or arc-overs due to plasma discharges are much more severe in space - that is, in the absence of the insulating and the:mal transfer properties of air - than in similar high-power and high-voltage ground applications.

c. The technical feasibility of the proposed SPS power distribution and processing concepts hinges on the successful realization of high-power, high-voltage, and high-speed protection switches (one circuit breaker for each high voltage; 600,000 per SPS for the klystron concept) required to protect the transmitter tubes for the normally occurring tube arcs.

\section{E. Conclusions and Remaining Issues}

\section{Energy conversion}

Figure IV-12 shows a comparison of satellite mass for the various energy conversion concepts. Note that the masses shown are without growth allowance and are for a 5-GW ground output system. The overall conclusions made from the energy conversion studies are as follows.

a. Both photovoltaic (silicon or gallium arsenide) and thermal cycle. (Brayton or Rankine) are technically feasible solar energy conversion methods. Photovoltaic system masses are competitive with solar Brayton and Rankine cycle system concepts. The estimated cost of photovoltaic systems is less than that of thermal cycle systems. Photovoltaic systems have higher reliability potential than thermal cycle systems because of inherent redundancy features nf photovoltaic array desiyn, passive system characteristics, and no active cooling system required.

b. The space construction cost is judged to be higher for thermal engine systems than for photovoltaic systems because (1) a larger crew size and larger construction farility is requircd and ( 2 ) the packaging density of components is lower, resulting in increased space transportation rosts.

c. Maintenance considerations of the cesium/steam Rankine dual-cycle system pose diff $i-$ cuit problems such as repair/replacement of a large number of massive components and potential problems of fluid system (leakage, cesium/steam inter leaks). 
d. Thermionic conversion systems result in a satellite mass 1-1/2 to 2 times as great as with other thermal cycle systems and 2 to 5 times as great as with photovoltaic systems. As a result, the thermionic system has a higher projected cost than other candidate systems because of high transportation costs. The major contributors to thermionic system mass are interelectrode busbar mass and radiator/pump systems for heat rejection (in liquid-cooled systems). The high electrode mass is a direct result of the low-voltage/high-current output characteristics of thermionic conversion.

e. Space nuclear reactor systems using rotating particle bed, molten-salt, and uranium hexafluoride breeder reactor systems with thermal cycle (Brayton, Rankine, and thermionic) offer the advantage of compactness relative to solar powered systems; however, satellite mass, cost, and technical complexity are significantly greater (less attractive) than solar powered systems.

Technology issues for the photovoltaic and thermal systems have been previously reviewed.

\section{Power management}

a. High-voltage $D C$ for $k$ lystrons - Analys is has shown that high-voltage $D C$ distribution provides a minimum-weight system for a photovoltaic SPS. with a separate transmitting antenna. For a k lystron antenna system, a nominal 40- to 45-kV DC voltage level appears to be weight-optimum. The actual voltage will depend on the specific operating characteristics of the DC-RF power amplifiers, whereas the capability to employ these high-voltage levels is contingent on further analysis and test relative to any plasma interaction effects.

b. Low-voltage DC for solid state - Solid-state DC-RF amplifiers operate at low voltages $(25$ to $200 \mathrm{~V} \mathrm{DC})$. Use of such devices in a separate antenna causes a significant distribution and processing system weight increase because of the additional DC-DC conversion and low-voltage distribution requirements.

c. High-frequency power processors - Power processors must be operated at high frequencies (15 to $20 \mathrm{kHz}$ ) to achieve reasonable weight. Active cooling may be required to maintain the integrity of the dielectric materials so as to achieve acceptable reliability.

d. Conductor materials - Trade-offs in which electrical/thermal and mechanical performance, weight, cost, and availability were considered indicate that conductor-grade aluminum of $1 \mathrm{~mm}$ thickness is preferred for the array power busses. Similar trades indicated that solid, round aluminum busses are preferred for the antenna power distribution (ref. 7).

e. Technology advancement - The following areas require technology advancement.

(1) High-speed switchgear: To protect the klystrons from fault currents, switching speeds measured in microseconds are required of the switchgear. State-of-the-art speeds are measured in milliseconds. The discrepancy between requirements and performance is considered the most significant switchgear problem (ref.. 10 and ref. 2, Appendixes $B$ and $C$ ).

(2) Spacecraft charging and plasma: Plasma-sheet electrons may charge up the sate1lite to high voltages, which may cause arcing shock hazards and other associated problems. Quantitative estimates of these effects have been determined for the reference system (ref. 29). Unresolved questions include high-voltage operation, satellite-induced environment, and acceptability of insulating material. 
TABLE IV-1.- SOLAR CELL TRADE-OFF COMPARISONS

\begin{tabular}{|c|c|c|c|c|c|c|c|c|}
\hline \multicolumn{3}{|c|}{ Solar cell } & \multirow{2}{*}{$C R$} & \multirow{2}{*}{ Anneàling } & \multirow{2}{*}{ Cell area, } & \multirow{2}{*}{$\begin{array}{l}\text { Mass, a } \\
10^{6} \mathrm{~kg}\end{array}$} & \multirow{2}{*}{$\begin{array}{l}\text { Cell para- } \\
\text { metric cost, } \\
\$ / \mathrm{m}^{2}\end{array}$} & \multirow{2}{*}{$\begin{array}{l}\text { Relative } \\
\text { costb }\end{array}$} \\
\hline Type & $\begin{array}{l}\text { Efficiency, } \\
\text { percent }\end{array}$ & $\begin{array}{c}\text { Specific } \\
\text { mass, } \mathrm{kg} / \mathrm{m}^{2}\end{array}$ & & & & & & \\
\hline GaAlAs & $c_{20}$ & 0.252 & 1 & Yes & 44.31 & 15.81 & 71 & 1.26 \\
\hline GaAlAs & $\mathrm{c}_{20}$ & .252 & 2 & Yes & 26.52 & .13 .55 & 71 & .91 \\
\hline Silicon & $d_{17.3}$ & .421 & 1 & Yes & 52.33 & 27.06 & 35 & 1.0 \\
\hline
\end{tabular}

ancludes solar. cells, reflectors, primary and secondary structure, and power distribution only.

bIncludes energy conversion, power distr-bution, support structure; and transportation ( $\$ 40 / \mathrm{kg}$ to GEO). CAt $301 \mathrm{~K}\left(28^{\circ} \mathrm{C}\right)$ air mass zero (AMO).

dAt $298 \mathrm{~K}$ (25.0. C) AMO. 


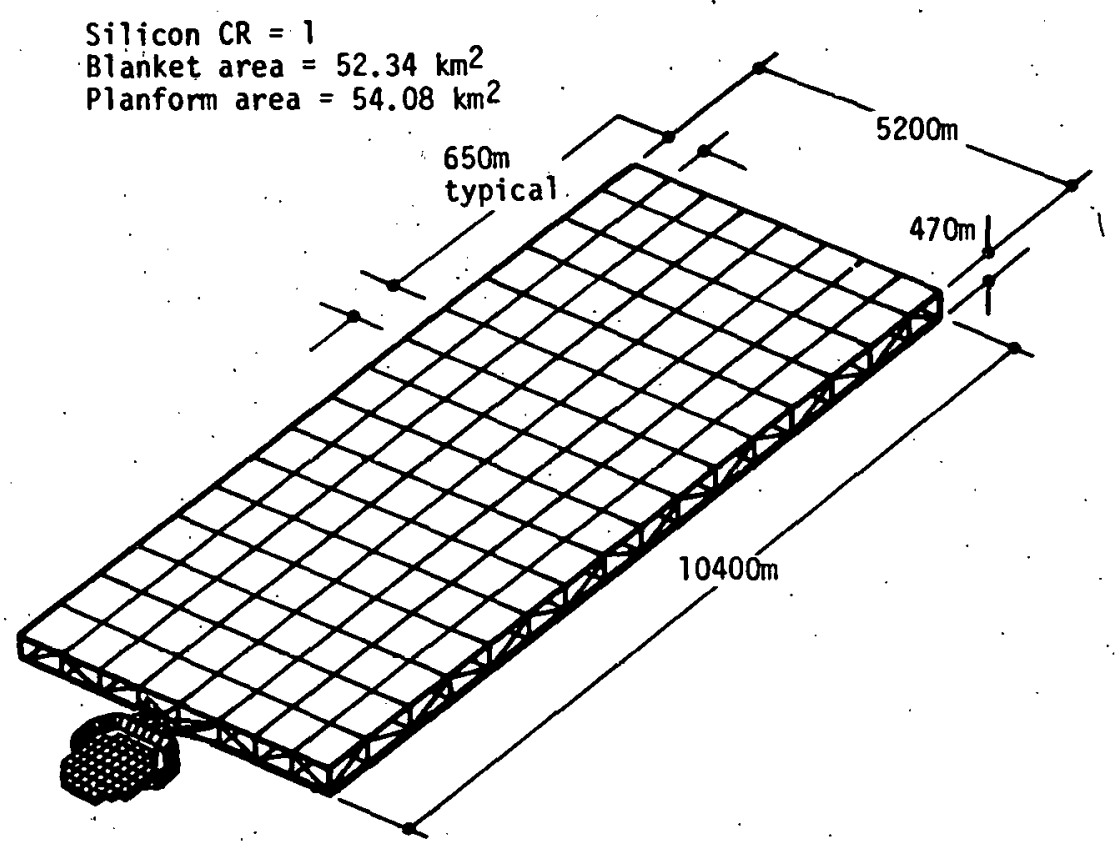

Figure IV-1.- SPS reference system - silicon cell.

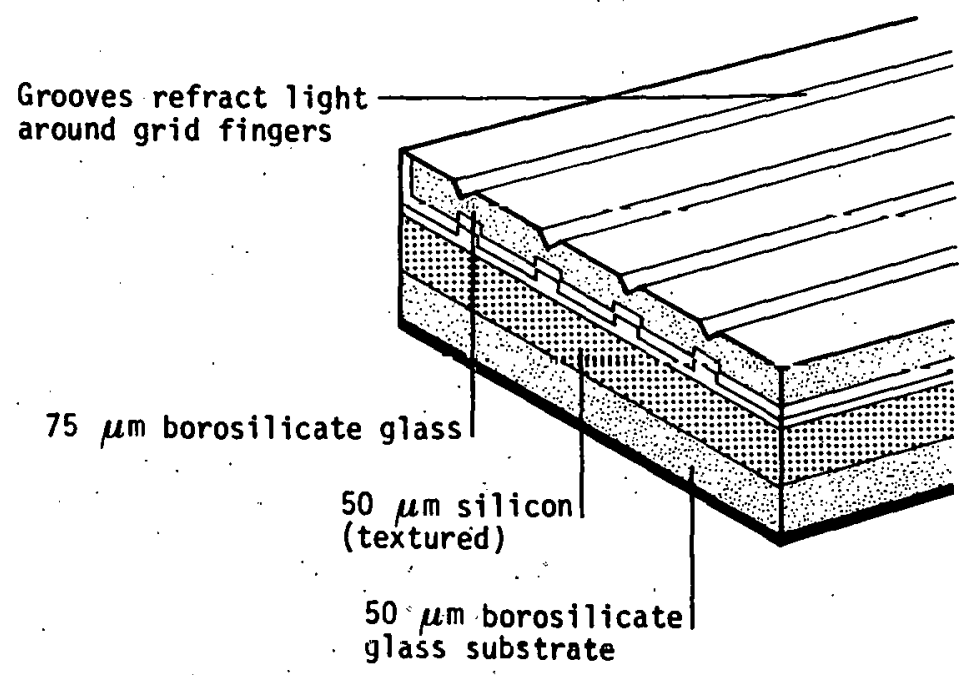

Figure IV-2:- silirnn solar cell blanket. 


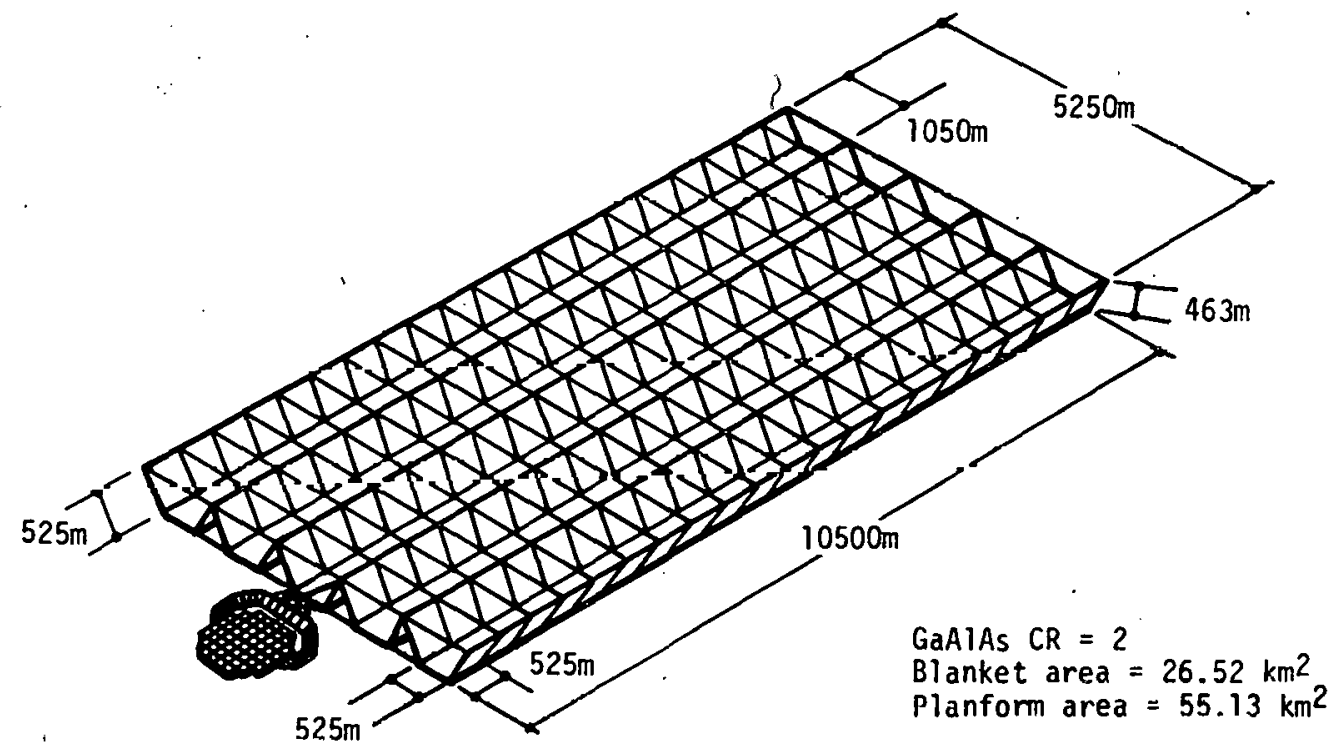

Figure IV-3.- SPS reference system - gallium arsenide cell.

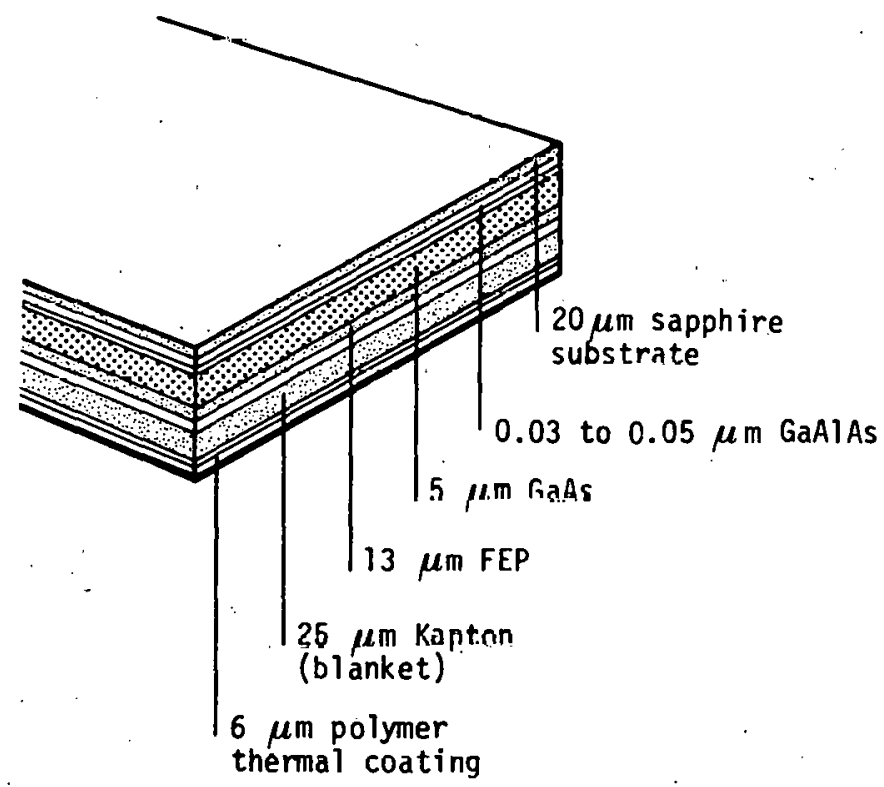

Figure IV-4.- Gallium arșenide solar cell blanket. 


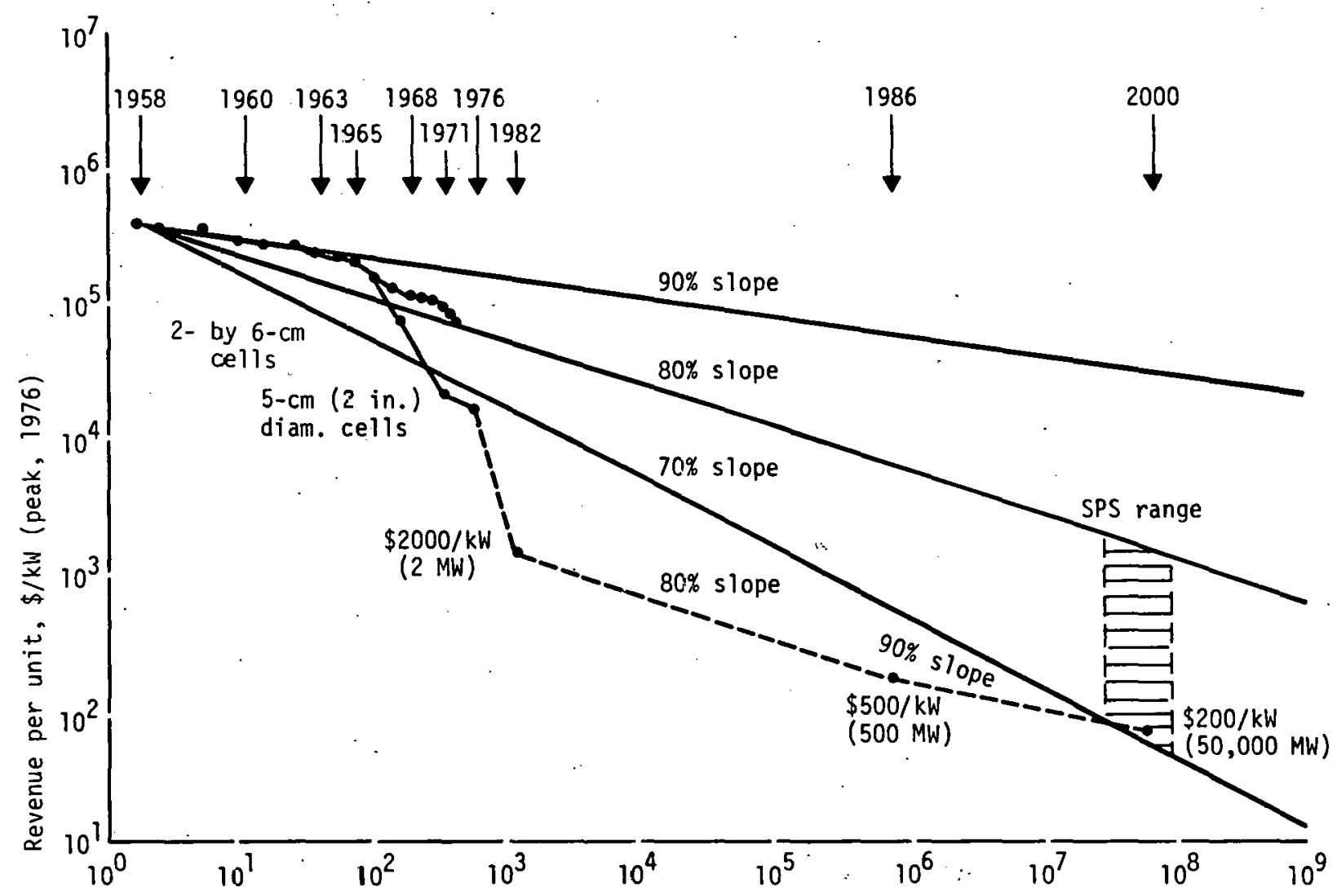

Industry accumulated volume, (kW)

Figure IV-5.- Cost-reduction projections based on industry experience (ref. 27). 
- Falrication and prccess develojnent of inin cells with an efficiency of $17 \%$.

- Improved sface radiation resistance to performance degradition.

- Detemine c.nnealing characteristics for annea:ing cuf radiation-induced performence degradation.

- Develop process for the fab-ication of lightueight solar cell blanzets that are compa:ible with annealing temperatures and long $l:$ fe.
- Development of thin-film gallium arsenide cell with an efficiency of $20 \%$.

- Radiation performan:e degradation characteristics and potential annealing recovery techniques.

- Verify recovery of jallium in sufficient quantities and at a cost compatible with SPS requirements.

- Process development for the fabrication of lightweight solar cell tilankets that are compatible with annealing techniques and long life.

Figure IV-6.- Silicon and gallium arsenide solar cell technclogy issues. 
SOLAR-THERMAL

\section{Brayton}

Potassium Rankine

Cesium/steam combined cycle (Rankine)

Organic Rankine

Thermionic (TI) (including TI/Brayton combined)

Thermoelectrics

SOLAR CONCENTRATORS

Parabolic (including compound parabolic conc.)

Faceted

Planar (CR $=2$ to 8$)$

Inflated

NUCLEAR-THERMAL REACTOR

Rotating particle bed reactor

Molten-salt breeder reactor (MSBR)

Uranium hexafluoride (UF)

Conversion cycles (Brayton, Rankine, Thermionic)

RADIATOR TYPES

Heat pipe

Fin-tube, liquid

Fin-tube, vapor/gas

Figure IV-7.- Thermal conversion studies.
$12 b, 13,19$

$13 b, 13 c, 19$

19,20

$13 \mathrm{~b}$

$12 b, 25$

$13 \mathrm{~b}$

$12 b, 13 b, .19,20$

$12 b, 13 b, 19,20$

$12 \mathrm{~b}, 13 \mathrm{~b}, 19,20$

19,20

25

25

25

25

$12 \mathrm{~b}, 13 \mathrm{~b}, 13 \mathrm{c}$

$12 b ; .13 b, \cdot 13 c$

12h, 13b, 13c 


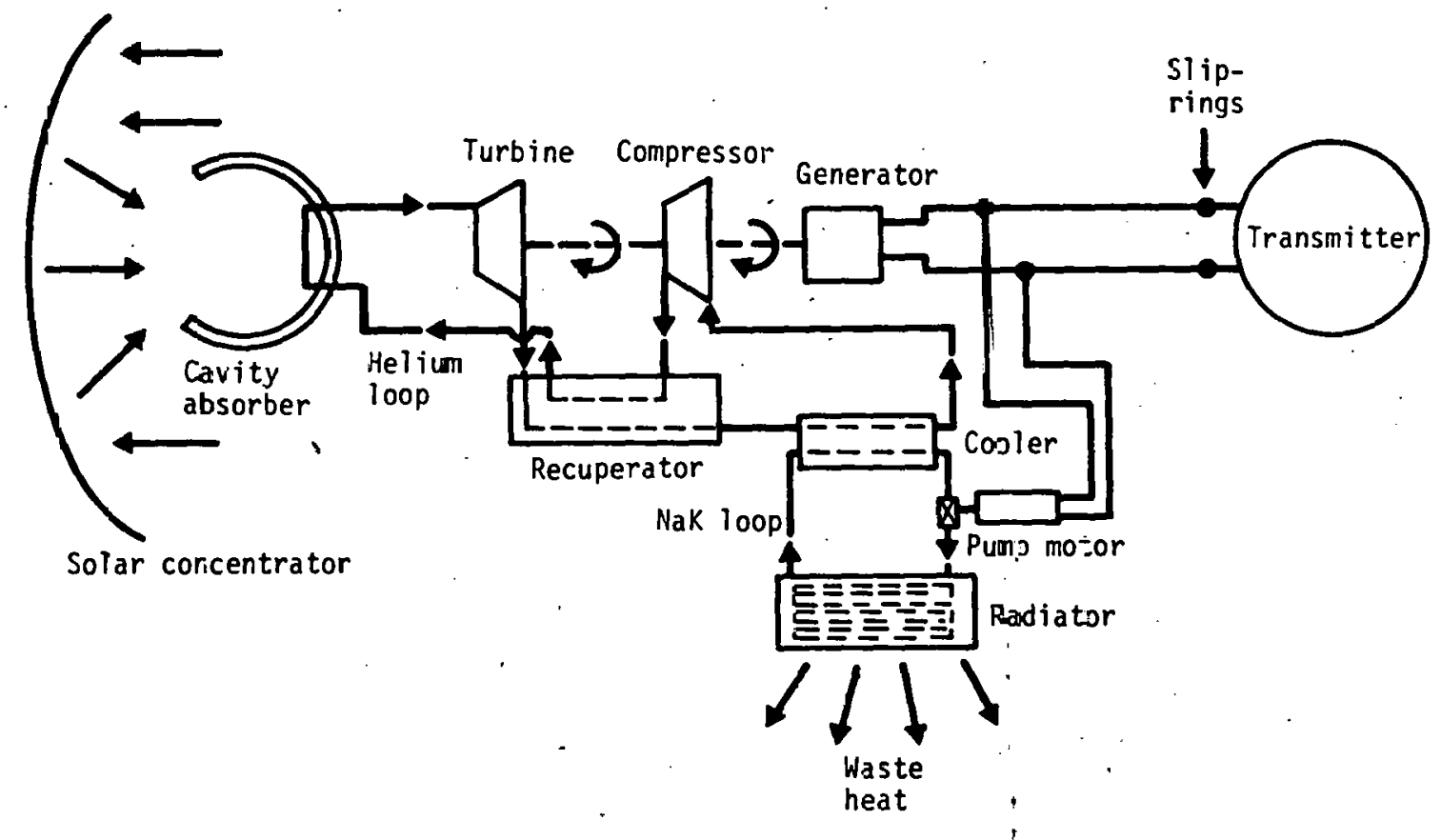

Figure IV-8.- Solar Brayton cycle - helium. 


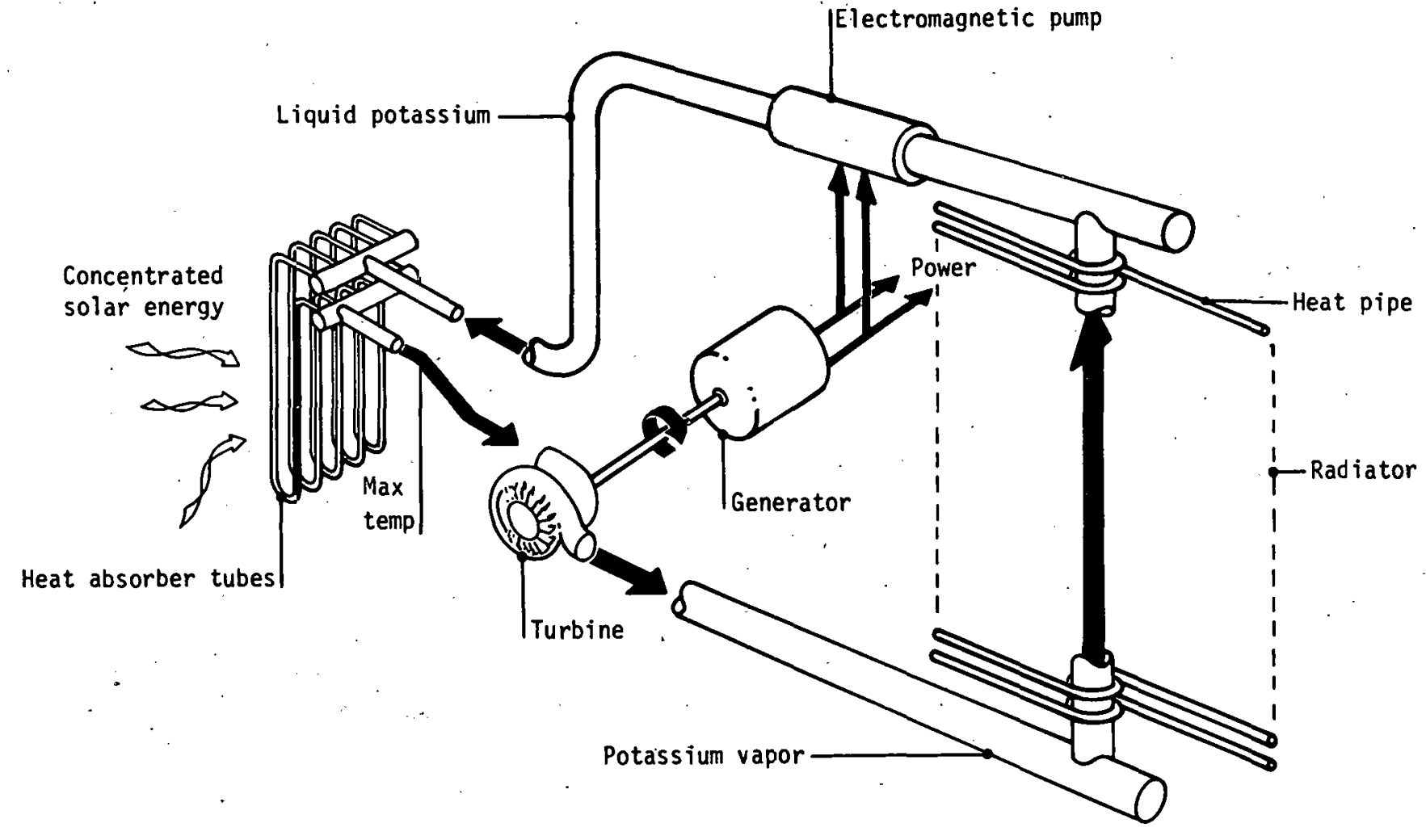

Figure IV-9.- Rankine cycle schematic - potassium. 
Turbirie inlet temperature

Turbine exhaust tenperature

Turbogenerator size (nominal)

Turbogenerators per SPS

Modules per SPS

Radiator projected area

Cycle efficiency

Reflector facets

Satellite orientation

Reflector facet thickness

Total facet area

Power Jistribution

Maintenance
$1242 \mathrm{~K}\left(1776^{\circ} \mathrm{F}\right)$

$932 \mathrm{~K}\left(1218^{\circ} \mathrm{F}\right)$

$31.4 \mathrm{MW}$

576 (6 are "reserve")

16

$1.15 \mathrm{~km}^{2} / \mathrm{SPS}$

0.189

116,000

Perpendicular to eclistic, electric thrust

$2.5 \mu \mathrm{m}$ (aluminized Kapton)

$119 \mathrm{~km}^{2}$

$40 \mathrm{kV}$, passively cooled dedicated aluminum sheet conductors, antenna joints incorporate

diurnal axis with slijrings and annual axis with wind-unwind cables.

Malfunction detection system for shutdown of individual turbogenera:ors as required.

Periodic maintenance.

Figure IV-10.- Pctassium Rankine cycle design features, :0-GW system. 


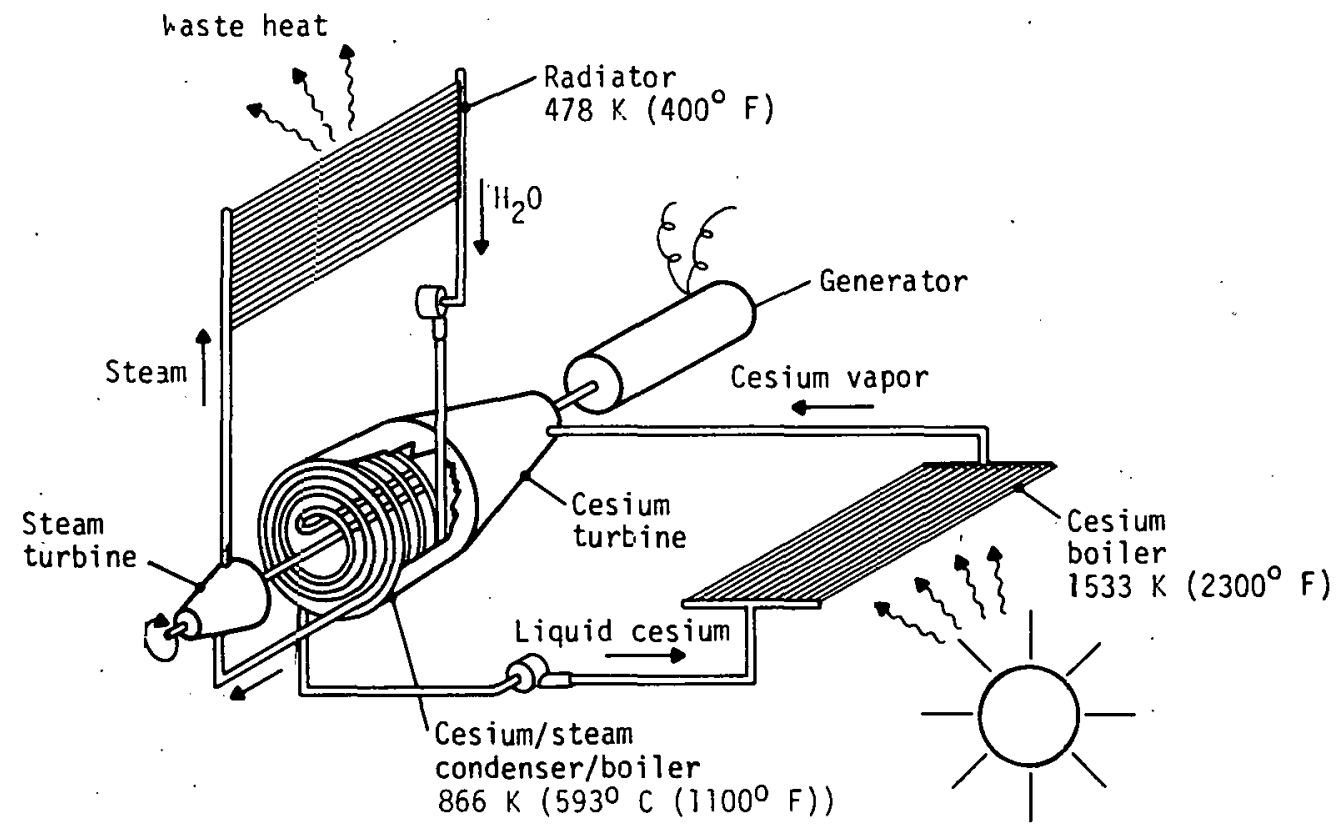

Figure IV-11.- Cesium/steam Rankine cycle, 5 GW. 


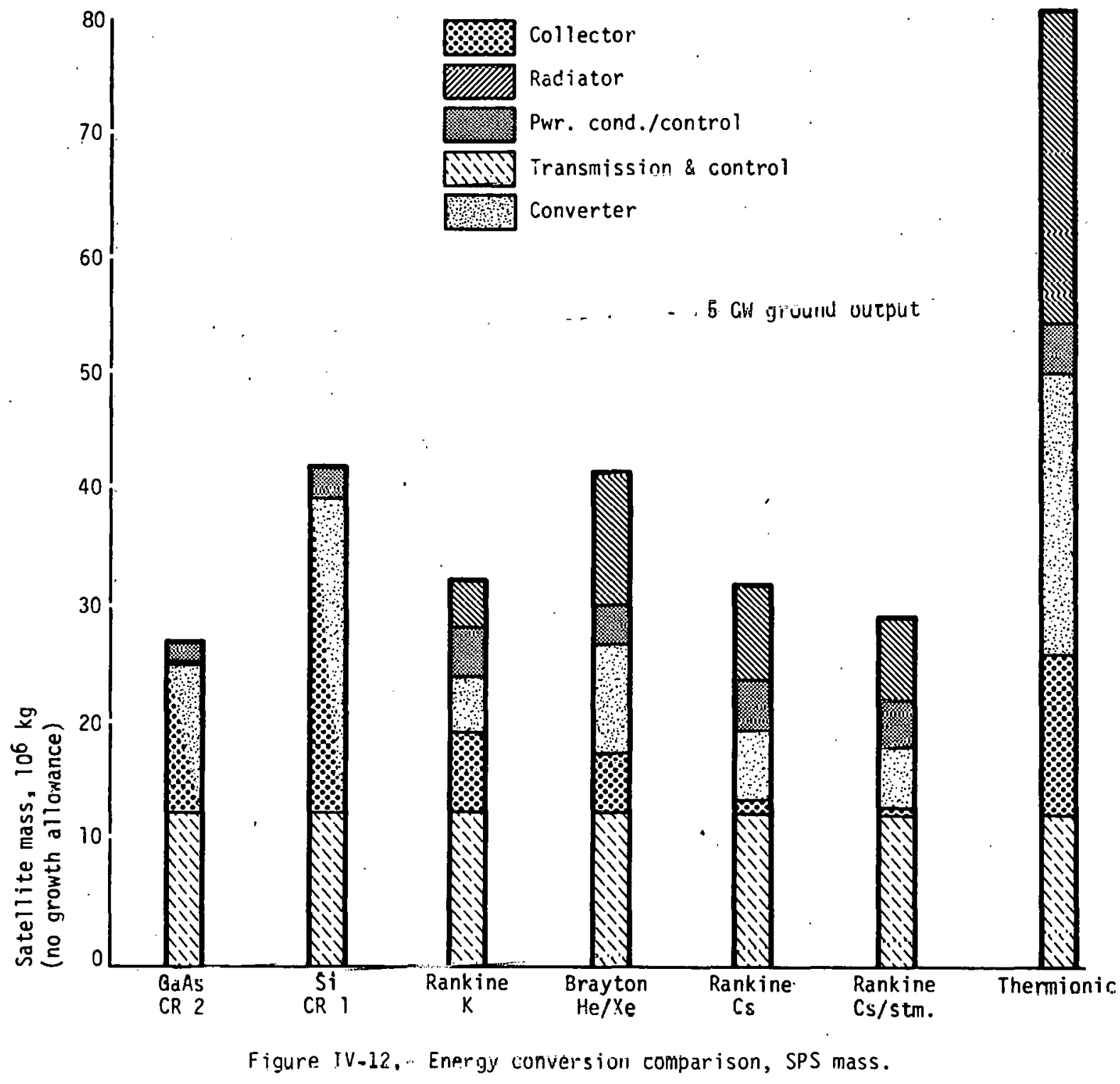


3 main busses:

$38,800 \mathrm{~V}$ Common return

$38,800 \mathrm{~V}$ 1-mm Al sheet conductor

$40,800 \mathrm{~V}$

passively cooled

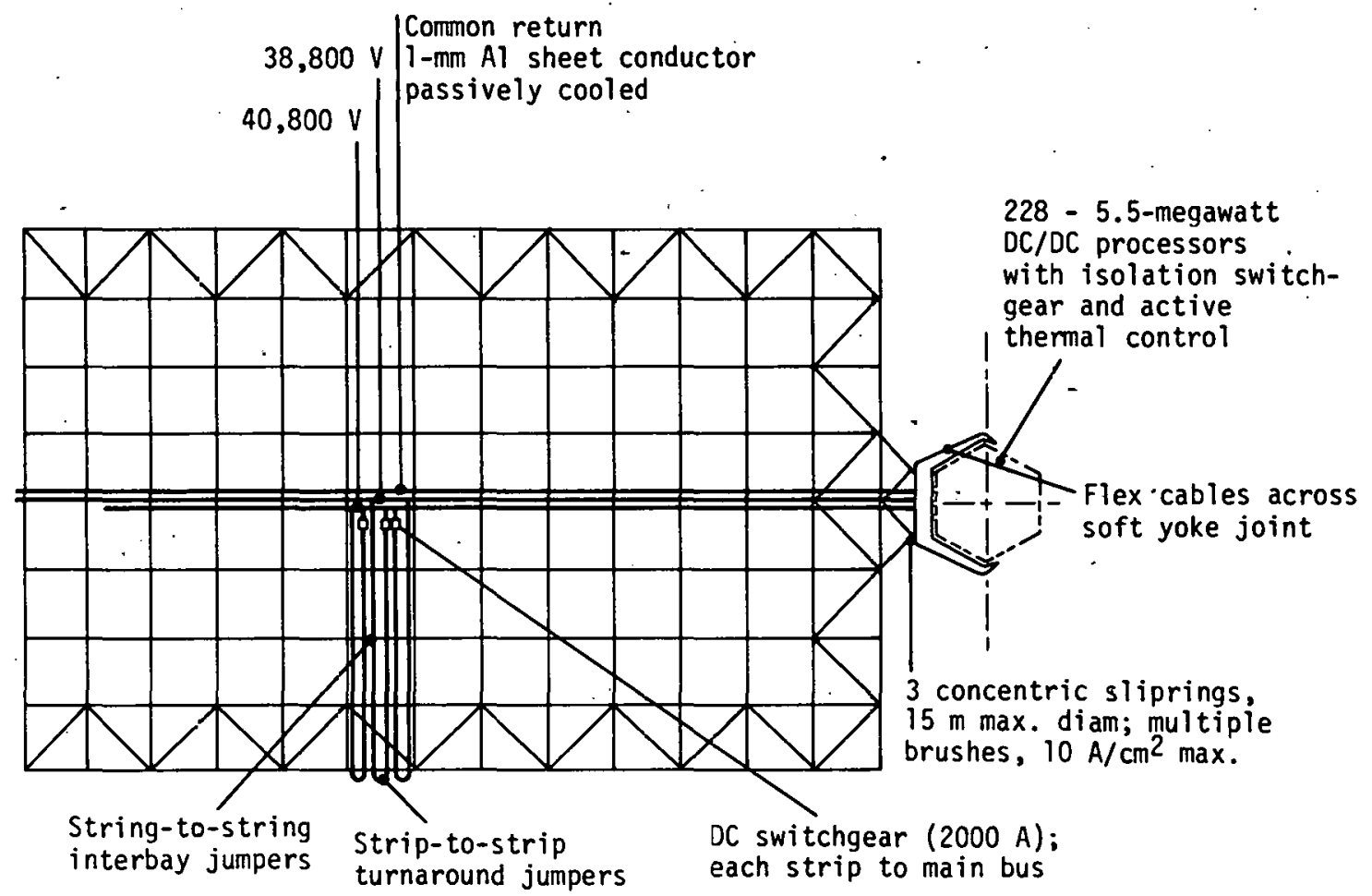

Figure IV-13.- SPS power distribution. 


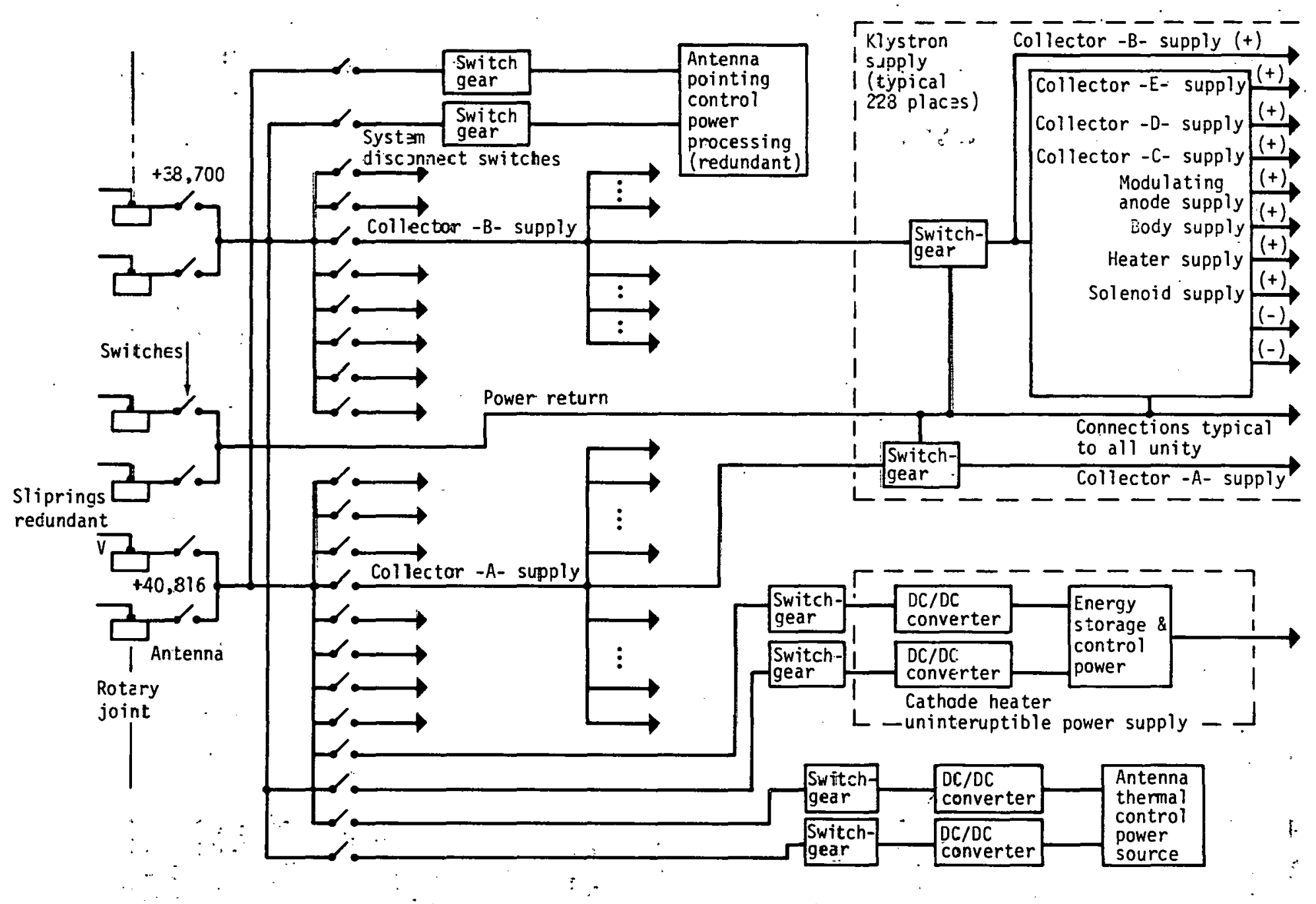

Figure Ili-14.- Power distribution system block diagam. 


\section{POWER TRANSMISSION AND RECEPTION}

\section{A. Summary and Introduction}

Definition and assessment of the SPS power transmission and reception (PTAR) system has been a major part of the DOE/NASA Concept Development and Evaluation Program (ref. 2), systems definition ef fort, and critical technology supporting investigations. One output of the systems definition effort has been the NASA Reference System Report (ref. 10), which contains a detailed description of the microwave PTAR system as well as detailed discussions of system and subsystem trade-offs that led to the reference system.

Since the issuance of the NASA Reference System Report, major system assessment activities have been in support of (1) solid-state PTAR system studies, (2) critical technology supporting investigations, and (3) continued PTAR system and subsystem trade-offs. Preliminary laser concepts have been analyzed for overall SPS integration feasibility but not to the depth of the microwave system analysis. These concepts are-discussed in Section III.C.3.

System assessments have generally resulted in the conclusion that transferring gigawatt power levels between two points using microwaves is technically feasible. Certain changes are recommended herein to the reference concept regarding phase control to the power module level, allowable amplitude jitter on the antenna, and startup/shutdown procedures. Alternative concepts have been studied in each of the subsystem areas as follows.

1. System performance - smaller systems, multiple beams

2. Phase control - retrodirective, ground based

3. Power amplifier - klystron, magnetron, and solid state

4. Radiating elements - slotted waveguide, resonant cavity, aluminum, metal matrix composites

5. Rectenna - dipole/diode, yagi-uda/diode, other higher gain receive elements

Certain critical supporting investigations have developed a better understanding of the hardware implications in the phase control, power amplifier, and radiating element areas, which are surmarized in following subsections. The microwave system conclusions and remaining issues are documented in the last subsection.

\section{B. System Assessment Activities}

A considerable body of work has been developed in the microwave PTAR area as part of the joint DOE/NASA program. The information and experience thus gained will serve as an excellent data base for future activities in this area. Most of the activities have been contracted efforts through the two NASA SPS centers, the Johnson Space Center (JSC) and the Marshall. Space Flight Center (MSFC). There also has been a considerable amount of in-house effort devoted to special projects. All of the efforts were tied together in a major peer review and assessment process at the SPS Workshop on Microwave Power Transmission and Reception (ref. 30).

\section{SPS contracted efforts}

System evaluation activities can be categorized into three major areas, each of which has received an approximately equal share of the total funding allocated to the microwave PTAR area: (a) microwave system studies, including that portion of the overall SPS system definition studies which concentrated on the microwave system and subsystems, conducted primarily by Boeing Aerospace Company and Rockwe 11 International (refs. 12 to 21 and 31 ); (b) independent subsystem studies, conducted by a variety of contractors as shown in table $\mathrm{V}-1 ;$ (c) experimental critical supporting investigations shown in table $V-2$. 


\section{NASA-sponsored efforts}

The NASA-sponsored efforts have consisted of both contracted studies and experiments funded with non-SPS funds (e.g., Center Director's Discretionary Funds) and special studies conducted by NASA personnel.

a. Sonic simulator/rectenna/multiple-SPS evaluations - The contracted sonic simulator/ rectenna/multiple-SPS evaluations use, in part, the microwave PTAR sonic simulator developed by the NOVAR Electronics Corporation. The simulator was evaluated for possible use in investigating the effects of the disturbed ionosphere on the phase control uplink pilot signal. Atmospheric and ionospheric amplitude scintillation characteristics of a continuous wave (CW) microwave signal using an existing geosynchronous communications satellite were experimentally determined: In addition, the rectenna was modeled to evaluate radiofrequency interference (RFI) levels and patterns resulting from scattering, harmonic generation, and fundamental reradiation. Also investigated were system interference and environmental effects due to RF beat-signal generation from multiple SPS's.

b. Metal matrix waveguide - The contracted metal matrix waveguide effort consisted of an evaluation of metal matrix composites (e.g., graphite aluminum) in several areas: (1) capability to hold the tight tolerances required by the SPS waveguides under thermal stress, (2) RF performance, (3) fabrication techniques, and (4) reproducibility.

c. Smaller SFS systems - lechnical and economic trade-offs were made of small optimized SPS systems configured with larger antennas, smaller rectennas, and smaller output power to the grid. This effort involved changing some of the previously assumed constraints (based on analyses) such as the $22-\mathrm{kW} / \mathrm{m}^{2}$ power density limit on the antenna, the $23-\mathrm{mW} / \mathrm{cm}^{2}$ ionosphcric limit, and the transmit frequency of $2.45 \mathrm{GHz}$. Smaller SPS systems are feastble under certain conditions if the resulting increase in cost of electricity is acceptable (within the cost uncertainty).

d. SPS interference - Four areas of potential interference were investigated which relate to operation of the SPS. Spacing of SPS's at GEO can be affected by SPS interference with other SPS's and by SPS interference with communications satellites in the vicinity. Interference of an SPS with another SPS and with a Tracking and Data Relay Satellite System (TDRSS) has been evaluated, and results indicate that sufficient signal-to-interference margins exist to maintain the currently planned spacing. Another area of concern has been potential RFI effects on the uplink pilot signal, from both the power beam and covert interference. Present signal design of the uplink pilot signal minimizes interference from both sources. However, before a quantitative evaluation of covert interference can be made, a thorough jamming and spoofing threat analys is is required.

\section{System work shop}

As part of the system assessment activities, the SPS Workshop on Microwave Power Transmission and Reception was held at the Johnson Space Center, January 15-18, 1980. This workshop evalilater a 11 the efforts funded as part of the DOE/NASA SPS Conccpt Development and Evaluation Program as well as historical data in some areas. Peer review was accommodated by having the workshop material assessed and critiqued by a review panel consisting of prominent individuals in the field.

a. Workshop organization - The objectives of the workshop were (1) to assess and critique the assumptions, methodologies, and conclusions of the investigations and (2) to assess and critique the critical issues identified and the recommended follow-on work. The workshop addressed all aspects of microwave PTAR including studies, analyses, and laboratory .investigations. It was organized into eight sessions as follows: General, System Performance, Phase Contro1, Power Amplifiers, Radiating Elements, Rectenna, Solid-State Configurations, and Planned Program Activities. As part of the documentation of the workshop, summary papers were published and distributed (ref. 30 ).

b. Review panel report summary - The consensus of the workshop review panel was that a 5 GW microwave PTAR system would probably be technically feasible; however. a large amount of work would be necessary in a number of areas to establish certainty and tu determine system efficiency, reliability, RF cumpatibility, security, safety, longevity, and cost. The panel believed that the final system would not resemble the present reference system and urged NASA to recognize this dissimilarity in all future planning. The GBED appeared to be excessively integrated with the reference system. The panel recommended more attention to system engineering, failure analysis, sersitivity studies to optimize 
cost effectiveness, system security and antijamming features, and periodic overall design reviews to update critical design parameters.

\section{System Options}

Investigations into concepts for power transmission and reception have primarily concentrated on microwaves as a transport means, although analyses of preliminary laser concepts have recently begun. Candidate laser systems (e.g., electric discharge, indirect optically pumped, and free electron lasers) are currently under evaluation for overall SPS integration feasibility. Although the use of lasers for PTAR offers several potential advantages (transmission of smaller blocks of power, not subject to concerns of possible long-term low-level microwave effects), these are offset by major difficulties (achieving high-efficiency.power transfer, laser system complexity, personnel and public safety, atmospheric propagation characteristics, and general state of technology development). This assessment report only addresses the concepts of microwave PTAR.

Microwave PTAR can be accomplished in a variety of ways. Five options are illustrated in figure $V-1$. The power amplifiers (RF converters) can be located on an antenna which is separate from the photovoltaic array or they can be an integral part of the photovoltaic array. In turn, the separate antenna can be designed to accommodate all three types of power amplifiers: linear beam tubes, crossedfield tubes, or solid-state devices. The primary advantage of the separate antenna is that it can accommodate maximum packing density of the power amplifiers up to the thermal operation and dissipation limit. Because of the power thermal limits (channel temperature) on solid-state amplifiers, transmitted power is not as great and the antenna is larger when compared to a tube configuration. The same limitation is even more pertinent to the integrated photovoltaic/solid-state power amplifier option since this configuration is area/power limited rather than thermal limited. Overall size per delivered kilowatt of this configuration is also larger. The major anticipated advantages of the solid-state concept (both separate and integrated antenna) are higher reliability (and thus lower maintenance costs) and greater amenability to mass manufacturing.

The integrated solid-state RF reflector option converts photovoltaic DC immediately to RF, and $R F$ is distributed along the array to a reflector antenna. This option was dropped from further consideration at the present time because of the difficult technology development requirements anticipated in the disciplines of RF waveguides and RF reflectors.

Of the five options illustrated, the antenna-mounted klystron configuration has been thoroughly evaluated and developed into the present SPS reference system. Within the last several years, projected efficiency, gain, and power output of solid-state devices have made them attractive for application to the SPS concept. The separate antenna configuration and the integrated photovoltaic/power amplifier (so-called "sandwich") configuration were evaluated for technical and cost effectiveness. To the depth studied, it appears that cost per kilowatt may be somewhat higher than that of the reference system, although as the cost estimates have been refined, the costs have trended toward convergence.

\section{System Definition Drivers}

Several basic assumptions and constraints affect the total microwave PTAR definition. The present klystron reference configuration was optimized at $5 \mathrm{GW}$ delivered to the utility grid, a $1-\mathrm{km}-$ diameter transmit antenna, and a 10-km-diameter rectenna. This optimization was based on two assumptions and three assumed constraints (based on analyses) as follows.

1. Minimum cost of electricity

2. Projections of system efficiencies

3. Transmit antenna RF power density 1 imit of $22 \mathrm{~kW} / \mathrm{m}^{2}$

4. Maximum RF power density in the ionnsphere of $23 \mathrm{~mW} / \mathrm{cm}^{2}$

5. Power transmission frequency of $2.45 \mathrm{GHz}$ 
The assumptions and assumed constraints are the same for the solid-state configuration except that (1) the thermal dissipation limits are changed so that device thermal resistance is a minimum and the operating temperature is in the range of 373 to $398 \mathrm{~K}(1000$ to $1250 \mathrm{C})$. and (2) the projected system efficiencies are based on the use of solid-state amplifiers.

These assumptions and assumed constraints are based on best available analyses and experimental data. If these are changed, then definition of the system also changes. For example, if the ionospheric limit could be changed to $54 \mathrm{~mW} / \mathrm{cm}^{2}$, the rectenna diameter could be reduced to $6.8 \mathrm{~km}$, with an increase in transmit antenna diameter to $1.5 \mathrm{~km}$. These changes would impact the entire system and might result in an increase in cost of electricity. This may be an acceptable alternative to the reference sizing; however, what is needed is a realistic assessment of the actual ionospheric power density limit. Various trade-offs using different assumptions and constraints have been made and are documented in reference 22 .

\section{E. Reference System Updates and Studies}

The microwave PTAR system is defined in the October 1978 SPS Reference System Report (ref. 10). The concept for the transmitter is shown in figure $V-2$. In this concept, the linear beam klystron is used to convert from DC to RF energy. The $70-\mathrm{kW}$ klystron, together with a cooling system, slotted waveguide radiators, phase control receiver and conjugation electronics, and other necessary hardware, comprises the transmit antenna's power module. There are 4 to 36 power modules in an antenna subarray depending on where the subarray is located across the overall tapered antenna array. There are 7220 subarrays in the 1-km-diameter array.

The receiving rectifying antenna (rectenna) on the ground is characterized by immediate rectification from RF to DC. A typical configuration is shown in figure $V-3$. Individual dipole antennas are used as the receiving element, and since rectification takes place immediately, DC power is collected from each element and fed into parallel and series strings to build up the voltage and current levels. The overall microwave PTAR concept is illustrated in figure $V-4$, which shows subsystem interrelationships in both the transmit and the receive arrays.

As a result of continuing NASA and contractor system investigations and trade-offs since 1978, several improvements could now be made to the reference system.

\section{Level of phase control}

Phase conjugation should be performed at the power module (klystron) level (101,552 points) rather than at the subarray level (7220 points) (fig. V-4) because (a) it results in an increase in main beam gain (more power delivered to grid), (b) it reduces antenna array and subarray mechanical tolerance requirements, (c) it reduces the effects of distributed phase errors with the subarrays, and (d) the grating lobes incident upon the Earth are reduced in amplitude and quantity. The disadvantage is of course the additional cost of approximately 94,000 phase control receivers. It is projected that all phase control circuitry at each coniugation nnint, inrluding the recoiver, can be ineolporated illu a microwave integrated-circuit chip and thereby greatly reduce the costs for high quantity production. Thus, in addition to the already stated advantages for phase control at the power module level, it is also projected to be a cost-effective approach.

\section{Allowable amplitude jitter}

The reference system has an allowable amplitude jitter across the surface of the subarray of $\pm 1 \mathrm{~dB}$. Analysis indicates that power transfer efficiency ( $88 \%$ for the refercnce system) is relatively insensitive to amplitude jitter. Since amplitudes for the klystron tubes must be maintained to approximately $1 \%$ for satisfactory operation, the allowable amplitude jitter in the antenna error budget should be changed to $\pm 1 \%$. This change does not affect the microwave transmission efficiency chain.

\section{Startup/shutdown procedure}

Because of the numerous times the SPS will require shutdown/startup (in response to Earth, Moon, and SPS eclipses, as well as for scheduled maintenance), a number of possible sequences for energizing/deenergizing the transmit antenna array have been analyzed. Of primary concern during these operations is the requirement to keep the sidelobes impinging upon the Earth to acceptable levels. It has been determined that there are three startup sequences which assure that the sidelobe levels are 
lower than the steady-state levels which occur during normal operations. These three sequences are random, incoherent phasing, and center-to-edge concentric rings. When one of these sequences is used, no microwave radiation problems are anticipated.

\section{Additional studies}

In addition to the system investigations and trade-offs mentioned previousiy, a consider$a b$ le number of studies have contributed to a better understanding of the SPS concept and of the microwave PTAR data base. These studies are described in the following paragraphs. (More details are in Vol. III of the SPS Technical Summary and Assessment Report, ref. 32).

a. System performance - Studies in the system performance area have concentrated on obtaining a better understanding of (1) parametric effects on system performance for all elements in the efficiency chain, (2) ionospheric analyses and test results from Arecibo, Puerto Rico, and Platteville, Colorado, and (3) RFI/electromagnetic interference (EMI) for both the transmit array and the rectenna. Studies into reshaping the power beam have also been made to improve overall rectenna collection efficiency and to provide additional means of sidelobe control. These studies included techniques such as phase reversal, continuously variable phase distribution across the array, suppressor rings, and quadratic phase tapers. Multiple beams from one array have also been investigated, and results indicate that implementation is feasible.

b. Phase control - In addition to the extensive system definition of the reference phase control system, alternate concepts have also been investigated including interferometer and coherent multiple tone ground-based systems. These concepts have several attractive features over the reference retrodirective concept including closed-loop phase control (which reduces effects of time-dependent phase error buildup) and simplified electronics on the transmit antenna. These approaches are described in references 30,33 , and 34 .

A major concern for both the retrodirective concept and the ground-based concept is the potential effect of the ionosphere on the microwave signal phases. To date, there is no available ionospheric model to quantitatively predict phase errors due to ionospheric disturbances. The first in a series of the experiments recommended by NASA was conducted in April 1980 by the University of Texas/ Institute of Telecommunication Sciences (ITS). Future experiments are also planned. Assuming that the end result of these experiments is that the effects are intolerable, a potential method for mitigation of these effects has been proposed by Rockwell International using the "three-tone" pilot beam. This is discussed in reference 32 .

c. Power amplifiers - Besides the investigations into the klystron and its integration into the system, study efforts have concentrated on solid-state amplifiers and the magnetron. Considerable advancement in GaAs field-effect transistor (FET) technology over the past several years has indicated that projected parameters of efficiency, power output, and gain may be suitable for use in the SPS concept. To this end, several analytical and experimental investigations were initiated by NASA to better understand the potential application of the GaAs FET devices (refs. 30 and 35 and table $V-1)$. A typical result to date on an existing amplifier, when optimized for maximum efficiency, is $71 \%$ efficiency, with approximately $1 \mathrm{~W}$ output and $11 \mathrm{~dB}$ gain.

The magnetron gained renewed interest when it was determined that the inherent noise levels could bc rcduced considerably when the filament. was turned off after initial startup. Laboratory investigations were performed to determine some of the operating characteristics (phase stability and control, gain, efficiency, noise levels, power output, etc.) as applied to SPS (ref. 30). 0nce some of these characteristics are understood, the feasibility of integrating the magnetron into the microwave PTAR system should be more fully explored. Factors such as power conditioning and distribution, input RF power requirements, RF load dumping, cooling requirements, methods of phase stability/ control, RF distribution, etc., will require further investigation.

d. Radiating elements - The main thrusts in the area of radiating elements have been to (1) investigate characteristics of a slotted waveguide array (receive/transmit bandwidths, tolerance requirements); (2) the requirements for, and characteristics of, a separate receive aperture; and (3) high-accuracy measurement techniques (RF gain/directivity to $\leq 1 \%$ ) (ref. 30 ). One of the candidate receive antennas, the "credit card" (small enough to be imbedded in between the slotted waveguides), appears to provide the required uplink/downlink isolation with minimum decrease in transmit aperture 
area. Some of the investigations into thin-wall aluminum fabrication and metal matrix waveguide characteristics have yielded favorable results.

e. Rectenna - The reference rectenna concept provides an extremely efficient means of receiving RF energy and converting to $D C$ for use by the utility grid. One of the disadvantages is the tremendous number of receive antennas/rectifiers required. Several studies have been conducted to reduce the number of elements and to reduce the manufacturing costs of so many elements. Problems of reradiation have also been investigated (refs. 30 and 36 ).

\section{F. Solid-State Configurations}

Because of the continued advancement of solid-state technology, application of this technology to SPS appears promising. As illustrated in figure $V-1$, there are two basic configurations for the solid-state application: a separate antenna similar to the reference concept and an integrated photovoltaic/antenna or sandwich approach. Both these concepts have been evaluated by both SPS Systems Definition contractors, Boeing and Rockwell, although not to the same depth as the reference configuration.

Both of the solid-istate concepts are characterized by larger antennas (because of device cooling requirements), lower power output to utility grid, smaller rertennas (bocause of the largcr, higher gain transmit array), and greater satellite mass per kilowatt of delivered power. They have the advantage of increased reliability and thus lower maintenance costs. Disadvantages include increased pliase control system complexity, lower voltage (higher loss) DC power distribution (for the separate antenna), larger parts count, and possible increased noise generation and EMI susceptibility. Investigations to date indicate the following.

1. Use of solid-state devices results in higher satellite mass and cost per kilowatt compared to the reference system, although costs have trended toward convergence as the estimates have been refined (due primarily to higher voltage levels on the device strings).

2. DC-to-RF conversion efficiencies of $>80 \%$ appear feasible using GaAs FET devices operating at conduction angles of $30^{\circ}$ to $45^{\circ}$ (ref. 35 ).

3. Power combining of four amplifiers into a single 2.45-GHz antenna cavity has demonstrated exceptionally high combining efficiencies (close to 100\%) (ref. 17).

4. Low-voltage DC power distribution for a solid-state antenna, previously considered to be a major problem area, appears solvable by incorporating the best balance between device string voltage and reliability (ref. 17).

\section{G. Critical Supporting Investigations}

Critical supporting investigations are a soecial rategnry, generally oxporimontal, and huve Deen tunded as part of the DOE/NASA SPS Concept Development and Evaluation Program. Following is a brief sumary of these activities. (See also table V-2.)

\section{Design and breadboard evaluation of the SPS reference phase control system}

Major objectives of the effort to design a breadboard for testing elements of the SPS reference phase control system are to determine the achievable accuracy of a large phase distribution system, the sensitivity of the system to parametric variations, and the limitations of commercially available components in such applications. Experimental results to date on the phase distribution portion of the system indicate that (a) satisfactory performance can be obtained using available components under closely controlled conditions and (b) commercially available components exhibit nonideal performance which is critical to accurate phase distribution across the antenna array and which must be compensated for by spectal nctworks. The breadboard distribution system is now being incorporated into the overall phase control system; integrated tests will then be conducted.

\section{SPS fiber optics link assessment}

The purpose of the SPS fiber optics link assessment was to demonstrate the feasibility of a fiber optics link for transmission of a $980-\mathrm{MHz}$ analog phase distribution signal. Fiber optics have 
advantages over RF cabling of lighter weight, less volume, more flexibility, and less EMI susceptibility. Several types of fibers and optical components were evaluated, a two-way distribution link was fabricated, and signal transfer tests were completed. The received signal amplitude and phase characteristics were extremely stable and essentially noise free. Incorporation of this distribution link into the phase control system breadboard at JSC remains to be performed.

3. Six-element S-band active retrodirective array phase error evaluation

A series of tests remains to be performed in the laboratory using two elements of the subject retrodirective array. Tests will be conducted to establish accuracy of the phase distribution and conjugating functions.

\section{SPS antenna element evaluations}

The purpose of the SPS antenna element evaluations was to better understand the RF and DC characteristics of a slotted waveguide subarray section. Objectives were (a) to build a full-scale half-module, 10-stick array, (b) to experimentally evaluate the array with respect to antenna pattern, impedance, and return loss, (c) to measure amplitude and phase to provide a data base for understanding the trade-offs of uplink/downlink signal isolation, and (d) to perform trade-offs to determine whether a separate uplink receive antenna is necessary and/or feasible. All the objectives were completed with very good results. Among the more significant findings were that a separate antenna would provide more isolation and that an extremely small "credit card" antenna could be incorporated into-the transmit array without adversely affecting the transmission efficiency.

\section{SPS solid-state antenna power combiner evaluation}

The purpose of the SPS solid-state antenna power combiner evaluation was to experimentally determine methods for summing outputs of many relatively low power solid-state devices with extremely low combining losses. Objectives were to design, fabricate, and test an integrated four-feed microstrip antenna, stripline phasing network, and four transistor amplifiers. All objectives were met with very good results. Pattern measurements were made with and without the power amplifiers. The integrated system was tested for directivity and gain, and the overall efficiency was calculated. The resultant combining losses were extremely low (approaching 0\%, within measurement capability).

\section{SPS solid-state amplifier development}

Early studies of a potential solid-state transmitter for SPS were conducted under contract to JSC. Efficiencies of $\geq 80 \%$ were projected for conduction angles of $30^{\circ}$ to $45^{\circ}$, and an experimental amplifier using a commercial wide-band FET tuned to $2.45 \mathrm{GHz}$ was delivered which operated at $58 \%$ efficiency and had an output of $3 \mathrm{~W}$. Since then, an amplifier development program has been initiated under contract to MSFC. Objectives are to demonstrate an amplifier operating at $50 \%$ efficiency, with a power output of $5 \mathrm{~W}$ and a gain of $8 \mathrm{~dB}$. Results to date are encouraging. An existing amplifier, when optimized for maximum efficiency, yielded $71 \%$ efficiency, with approximately $1 \mathrm{~W}$ output and $11 \mathrm{~dB}$ gain.

\section{SPS magnetron tube assessment}

The SPS magnetron tube assessment consisted of an analytical and experimental evaluation of Lhe characteriatics of a microwavo-oven-type magnetron which may be applicable to the SPS. The magnetron is configured as an injection-locked directional amplifier for evaluation purposes: Charactèristics investigated include amplitude and phase control concepts, various types of noise and sources, harmonics, long-life cathodes, and efficiency. Results to date are encouraging. Control loops for both amplitude and phase have been developed, signal-to-noise ratios of $158 \mathrm{~dB} / 4 \mathrm{kHz}$ bandwidth (no external power applied) have been obtained, harmonic levels were somewhat better than anticipated, carburized thoriated tungsten appears promising for cathodes, and electronic efficiencies of $86 \%$ have been computed (based on measured efficiencies).

\section{Microwave ionosphèric interaction experiment}

The microwave ionospheric interaction experiment consisted of field investigation of a natural and heated ionosphere. There is a major concern about heated ionospheric effects on the phase front of the pilot signal in the SPS phase control system. The initial objective of this experiment was to measure the intensity of the electron density turbulence in the natural and heated ionosphere. Signals 
from the Navy navigation satellites (NAVSAT's) were used to make the measurements, and F-region heating was accomplished using the ITS heater facility at Platteville, Colorado. Data taken formed the basis of a detailed characterization of the electron density perturbations in the ionosphere. Based on these statistical characteristics, effects of the heated ionosphere on the pilot signal will be evaluated.

\section{Solid-state-sandwich concept design considerations and issues}

Solar power satellite solid-state-sandwich concepts have been investigated relative to the microwave system. Typical parameters for this concept are illustrated in the third column of figure V-1. Results have been encouraging, and the concept is considered to warrant further study. Some of the issues and considerations identified to date are harmonic and noise suppression, monolithic technology, RF mutual coupling and input/output isolation, low-voltage distribution, charged-particle radiation effects, and sidelobe suppression.

H. System Conclusions and Remaining Issues

\section{Conclusions}

As a result of the muimervus analytical and experimental evaluations which took place during the DOE/NASA Concept Development and Fvalıạtion Program, therc arc certain comilusiurs whlch can be reached on the microwave PTAR system. These conclusions were presented and discussed as part of the system workshop held at JSC in lanilary 1980. The following conelusions apply lu llie uverall microwave PTAR system. Other conclusions of a more detailed nature are discussed in reference 30 . using microwaves is feasible.

b. Single vs. multiple antennas - Each SPS microwave power transmission system should use one transmit antenna with contiguous radiating subarrays rather than multiple separate antennas.

c. Frequency - The power transmission frequency of $2.45 \mathrm{GHz}$ has been determined to have advantages for power transmission and reception based on system trade-offs including (1) transmit antenna and rectenna sizing, (2) propagation effects through the atmosphere, (3) hardware technology projections, and (4) industrial, scientific, and medical (ISM) band utilization.

d. Microwave system sizing - Transmit antenna size $(1 \mathrm{~km})$, rectenna size (10 km minor axis), and power delivered to the utility grid ( $5 \mathrm{GW}$ ) have been determined on the basis of the minimum cost of electricity per kilowatt hour. The trade-offs were performed assuming a maximum RF power density limit on the transmit antenna of $22 \mathrm{~kW} / \mathrm{m}^{2}$ (tube configuration), maximum power density through the ionosphere of $23 \mathrm{~mW} / \mathrm{cm}^{2}$, and the current projections of microwave system efficiencies. A microwave system using solid-state power amplifiers will have a different thermal limit and different system efficiencies, resulting in different system sizes.

e. Type of transmitting antenna - The transmitting antenna should be a phased array using slotted waveguide feed techniques to meet the requirement of maximum power transfer efficiency.

f. Type of receiving antenna - An SPS rectenna concept theoretically capable of recovering all RF energy impinging on its surface with direct RF-to-DC conversion provides the required maximum conversion efficiency.

g. Antenna construction and subarray alignment. - Construction of a $1 \mathrm{kmm} \cdot$ diameter antenila array with \pm 1 minute of arc flatness tolerance appears to be within the state of the art if low coefficient of thermal expansion (CTE) materials are used. Antenna subarray.aigigments, both initially and operationally, can be maintained to \pm 3 minutes of arc by the use of azimuth-elevation mounts and laser measurement techniques.

h. Power beam stability - Based on analytical simulations and experimental evaluations, it appears feasible to automatically point and focus the power beam with minimum wander ( $\pm 250 \mathrm{~m}$ ) and automatic fail-safe operation (rapid beam defocusing). 


\section{Remaining issues}

In addition to the previously stated conclusions, certain remaining issues have been idenified which must be addressed in any follow-on program. These issues are for the overall microwave . TAR system.

a. Microwave PTAR system performance

b. Noise and harmonic characteristics

c. Antenna transmisssion efficiency

d. Beam forming accuraçy

e. Beam pointing accuracy

f. Beam security

g. Power beam/pilot beam isolation

h. Effects of ionospheric/atmospheric disturbances on pilot signal

i. Mechanicăl alignment/tolerances

j. End-to-end system efficiency

$k$. Corona (tube configuration only)

1. Multipacting (tube configuration only)

m. Plasma (tube configuration only)

n. RFI effects on selected hardware

o. Unit costs

p. Alternate technologies

(1) Solid state

(2) Magnetron

q. Possible new technologies

(1). Photoklystron

(2) Gyrocon

More detailed issues have been identified for each of the subsystem areas and are discussed in reference 30 . 
TABLE V-1.- MICROWAVE PTAR INDEPENDENT SUBSYSTEM STUDIES

\begin{tabular}{|c|c|}
\hline Investigation area & Contractor \\
\hline \multicolumn{2}{|l|}{ Phase control } \\
\hline System definition and simulation & LinCom \\
\hline Pilot beam communication link & Raytheon \\
\hline \multicolumn{2}{|l|}{ Power amplifiers } \\
\hline Solid-state amplifiers & $\begin{array}{l}\text { Radio Corporation of } \\
\text { America (RCA) and } \\
\text { Rockwell International } \\
\text { (RI) }\end{array}$ \\
\hline Solid-etato dovice simulation & Unlversily of Water 100 \\
\hline Class $E$ amplifier dcsign & Dessig̣r Automation \\
\hline Antenna & \\
\hline Subarray alignment. & Axiomatix \\
\hline Pointing control & University of Tennessee \\
\hline High-accuracy measurements. & $\begin{array}{l}\text { Georgia Institute of } \\
\text { Technology }\end{array}$ \\
\hline Rectenna higher gain/power combining & $\begin{array}{l}\text { Rensselaer Polytechnic } \\
\text { Institute }\end{array}$ \\
\hline Ionospheric effects & . \\
\hline Characteristics & Rice University \\
\hline Power beam & E-CON/Raytheon \\
\hline
\end{tabular}


TABLE V.2.- MICROWAVE PTAR EXPERIMENTAL CRITICAL SUPPORTING INVESTIGATIONS

\begin{tabular}{|c|c|}
\hline Investigation area & Contractor \\
\hline Phase control & . \\
\hline Breadboard test, reference system & $\begin{array}{l}\text { JSC/Lockheed Engineering } \\
\text { and Management Service Co. }\end{array}$ \\
\hline Fiber optics distribution & Boe ing \\
\hline Phase error measurement. & $\mathrm{JSC} / \mathrm{JPL}$ \\
\hline \multicolumn{2}{|l|}{ Power amplifiers } \\
\hline Solid-state design/test & RI/RCA \\
\hline Solid-state power combining & Boeing \\
\hline Magnetron & Raytheon \\
\hline Antenna waveguide experiment & Boeing. \\
\hline \multicolumn{2}{|l|}{ Microwave system } \\
\hline Ionospheric effects/modeling & $\begin{array}{l}\text { University of Texas/Institute } \\
\text { of Telecommunication Sciences }\end{array}$ \\
\hline ? & \\
\hline
\end{tabular}


RF Converter Antenna mounted

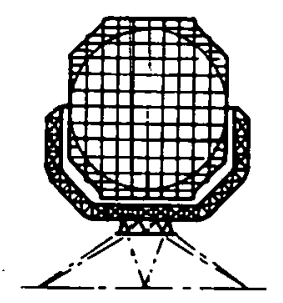

SPS Design

Power output

10 grid

Space antenna

diameter

Rectenna diameter

of $23 \mathrm{~mW} / \mathrm{cm}^{2}$

Antenna
Solar cell mounted (concentration ratio $=3$ )

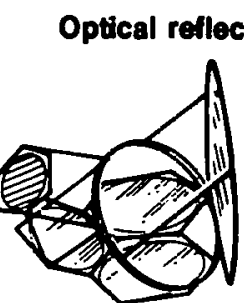

Solid state

Solld state

AF rellector

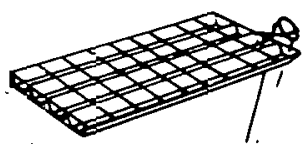

Solld state

2.5 GW

$.4 \mathrm{~km}$

$1 \mathrm{~km}$

\section{$7.1 \mathrm{~km}$}

$10 \mathrm{~km}$

10dB taper $10 \mathrm{~dB}$ taper
$1.2 \mathrm{GW}$

$1.77 \mathrm{~km}$

$5.0 \mathrm{~km}$

Uniform
$0.2 \mathrm{GW}$ per $\mathrm{km}^{2}$ solar cells

High power waveguide

Nol determined

Advanced horn feb paraboloid

Figure V-1.- Microwave system options. 


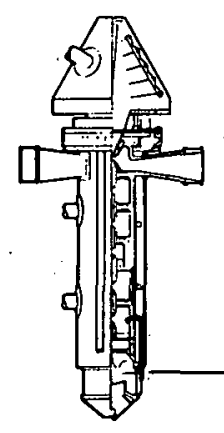

70-kW heat-pipecooled klystron
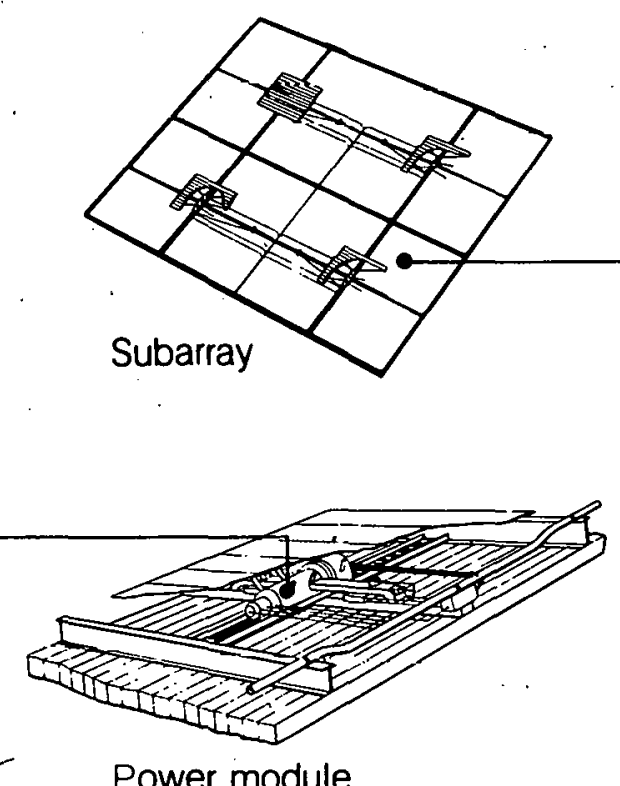

(1)

Main structure
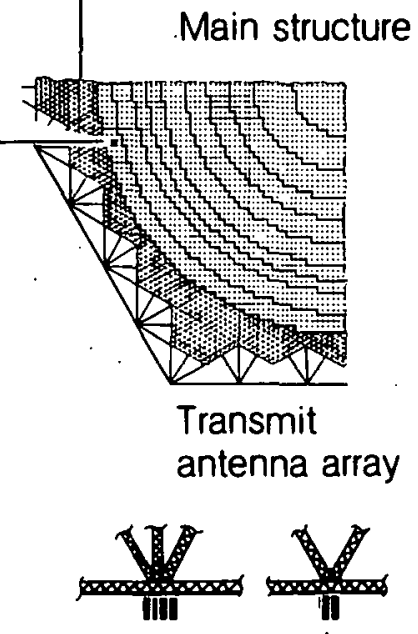

Power processing

\& distribution

Figure V-2.- Microwave power transmission design concept.
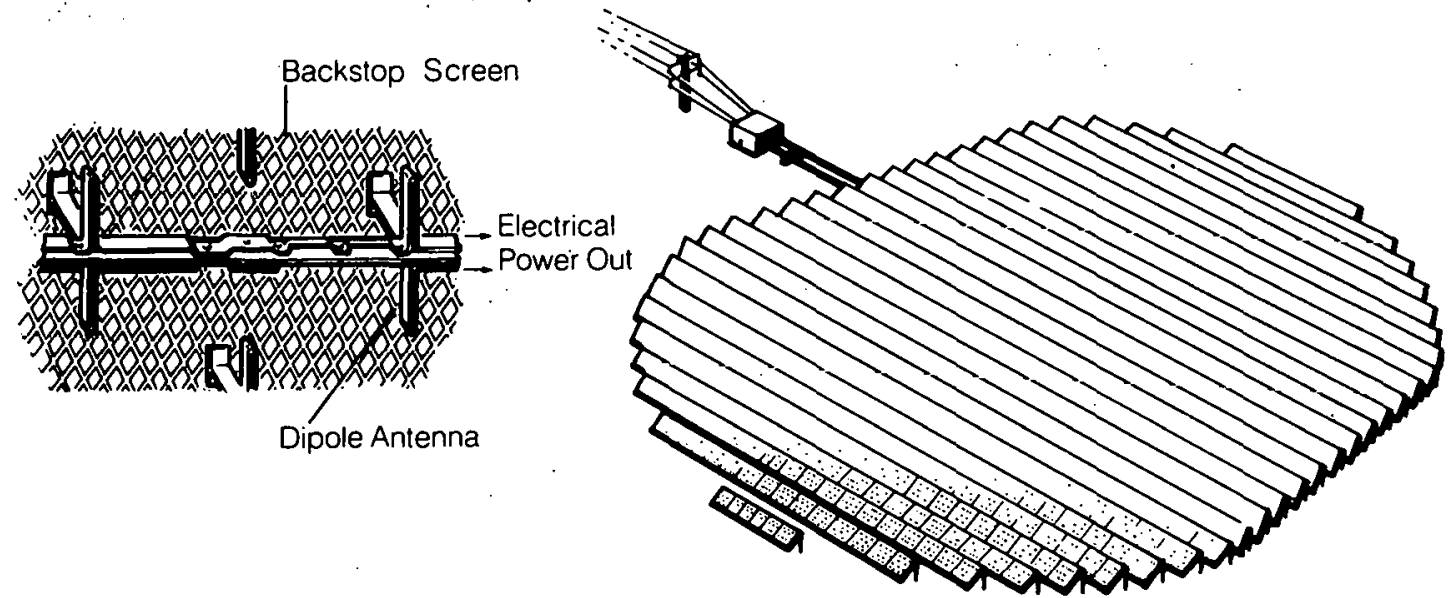

Figure V-3.- Typical rectenna curfiguration. 


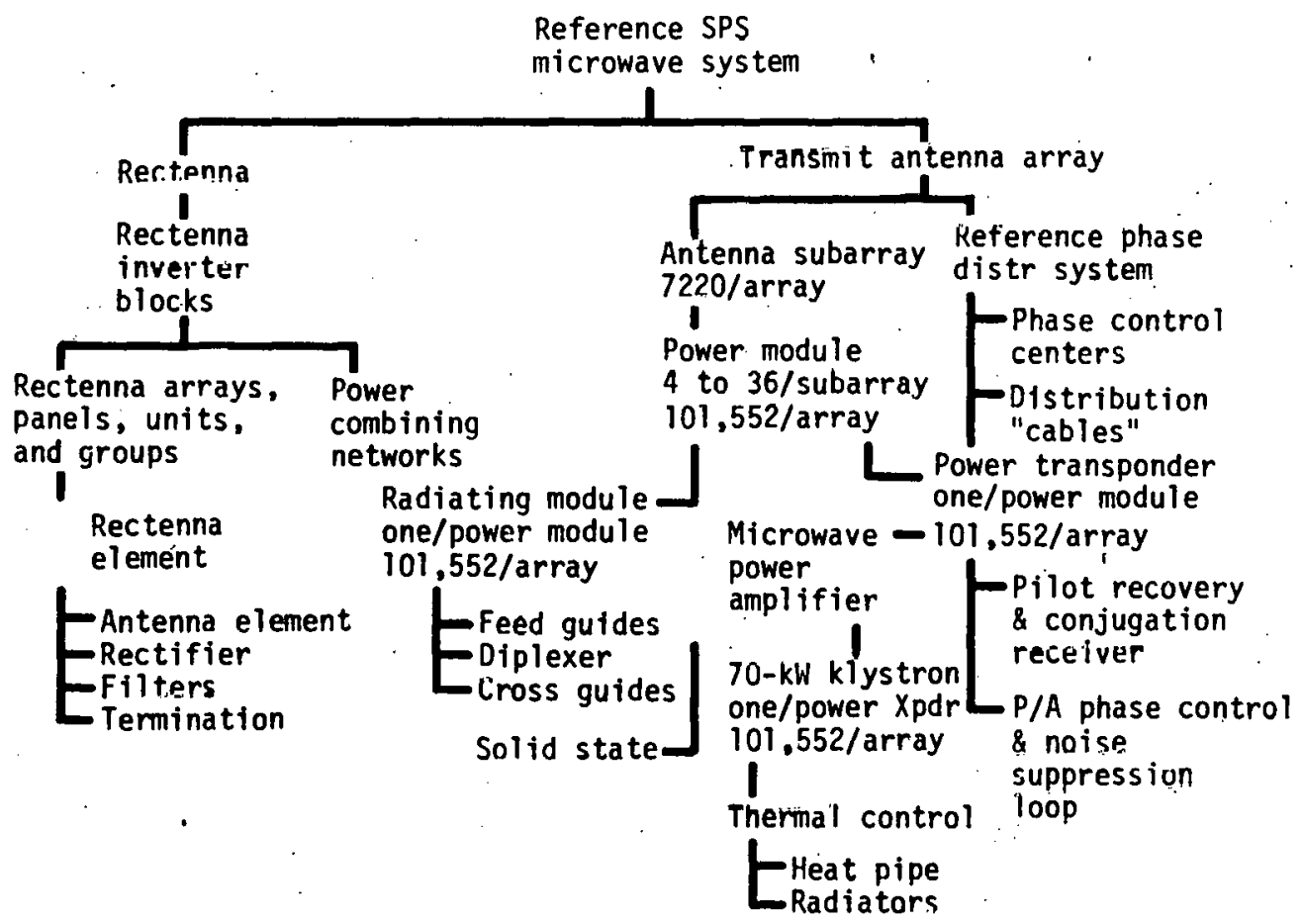

Figure V-4.- Reference SPS microwave syslell. 
VI. STRUCTURES, CONTROLS, AND MATERIALS

\section{A. Summary and Introduction}

The characteristics of the structures and controls subsystems, and associated materials, should reflect the requirements of the particular concepts and configurations embodied within the general concept of a satellite power system (SPS). Although early studies (refs, 6 and 7) investigated alternative satellite configurations, the focus of the CDEP efforts in structures, controls, and materials was the reference system as a reasonable extension of current technology. Based on the DOE/NASA Concept Development and Evaluation Program studies, previous NASA and industry studies, and applicable technology investigations, a general assessment of these subsystems can be made. A major advantage of the SPS concept for energy is the minimal structural mass requirement for a very large satellite. A A though this advantage has been recognized from the onset (ref. 3 ), it is not always obvious in conceptual portrayals of the system in which the structure may appear as the prominent feature. Studies to date indicate that the entire structural mass of an SPS may be generally less than $10 \%$ and possibly on the order of $5 \%$ of the total satellite mass. The reason is the extremely low external load environment of orbiting systems, particularly in geosynchronous orbit. This characteristic is somewhat alien to terrestrial engineering experience, in which structures can dominate mass and energy investment requirements. The prime structural design requirement is to provide adequate stiffness for stationkeeping, attitude control, and pointing control. The design of the structure and control systems is therefore coupled in meeting dynamic stability, shape, and figure performance requirements. Thermal deformations can have a significant influence on the design of these subsystems unless a low coefficient of thermal expansion (CTE) structural material, such as a graphite composite, is employed. Construction, life, and maintenance are significant design requirements for these subsystems. Because terrestrial testing of these subsystems is severely limited, an unprecedented reliance on modeling and analysis results. Space-flight testing will be a requirement in the development and verification of these subsystems. A panel of experts in these areas expressed optimism that with sufficient resources, the technical expertise that has served in the past could meet the challenges presented by the SPS. However, they felt that the work to date has not been sufficiently extensive or detailed to provide the level of confidence required. A substantial amount of work must be done in areas such as modeling, developing techniques for the active control of uncertain systems, and studying the long-term physical properties of composites before this confidence will be warranted. In this report, the most significant loads and environmental influences on the structures and controls subsystems, the general features of SPS structures and controls design (as currently envisioned), the importance of structural dynamics and.control to these systems, the materials issues, and the findings of the SPS Structural Dynamics and Control Workshop are discussed.

\section{B. Structural System}

\section{Loads}

Earth orbit is a balance of the body forces associated with gravitational attraction and centrifugal acceleration. The finite size of the SPS gives rise to a distribution of body forces which, depending on the geometry and orientation, represents one of the largest operational loads. If the moment of inertia of the system is not isotropic, because of configuration and/or construction considerations, there can be a net "gravity gradient" torque on the system. For a planar, rectangular, 5-GW ground put.put configuration in the worst orientation, control forces on the order of $300 \mathrm{~N}$ at the corners of the array would enable an attitude hold. The solar radiation pressure of about $5 \times 10^{-6} \mathrm{~N} / \mathrm{m}^{2}$ acts on illuminated surfaces as a function of the solar reflectance and orientation. The major influence of this force would be daily and 6-month periodic perturbation of the orbit. There is also an antenna recoil from the microwave power transmission of about $25 \mathrm{~N}$. Nonisotropic thermal emission will give rise to a momentum loss and an associated recoil. Solar and lunar gravity and Earth eccentricities give rise to potential orbit perturbations but insignificant direct structural loading. There is no significant atmospheric drag at geosynchronous orbit. However, in low Earth orbit $\left(s_{500}\right.$ $\mathrm{km})$, this pressure $\left(\sim^{1} 10^{-4} \mathrm{~N} / \mathrm{m}^{2}\right)$ can give rise to a force which is significant for orbital decay.

Operational system-induced loads on the SPS must be considered, although they are quite dependent on configuration and system design. Electrical current interaction forces (induced magnetic fields) are generally small, although their greatest influence is felt where the largest currents and the least separation distance between conductors occurs. Interactions between current carriers and the 
Earth's magnetic field are characteristically small and dependent on the power distribution configuration. This interaction can be minimized or enhanced by design. Depending on the configuration and system operation, centrifugal acceleration about the center of mass can also contribute to structural loading. The applied forces and moments for attitude control and pointing are significant inputs to the structural loading. In the studies to date, the largest structural loads obtained are those associated with isometric stress applied for stiffness or to minimize distortion. This loading is very sensitive to configuration and structural design. A generic characterization is a lightly prestressed column reacting membrane tension.

Structural loads associated with maintenance, construction, transportation, handling, and all relevant aspects of the SPS activities must be considered in the structural design. Any governing loads other than operational must be weighed against the impact to the system and, uitimately, compared to the cost of delivering electricity. For example, if large structural loads were incurred by alternative transportation or construction schemes, these could dominate the structural mass requirements.

\section{Environment}

The normal environmental concerns of terrestrial structures (e.g., wind loading, oxidation and moisture effects, soil mechanics, etc.) are not encountered in Earth orbit. However, other environmental factors in Earth's orbit must be considered: heat transfer, vacuum, particulate and ultraviolet radiation, and interactions with a tenuous plasma. Heat transfer is essentially limited to thermal radiation, since conduction and convection effects are generally negligible or nonexistent.

In normal operation, the MPTS is most affected by the thermal environment resulting from the waste heat generated by the DC-RF generators and from the daily r.ycle of orientation relative to the incident solar flux. Since the waste heat must ultimately be radiated to space, the characteristic operating temperature levels of a tapered microwave emission profile can range from almost $500 \mathrm{~K}$ at the center to $\backsim 300 \mathrm{~K}$ at the edge. The center temperature limits the local power emission and, therefore, the extent of emission tapering. Temperature levels can limit system and subsystem designs, material selections, and lifetime characteristics. Important aspects of structural design are the distribution of temperatures and the time variations resulting from changes in orientation relative to the Sun or shadowing effects (local or systemwide by way of occultation). Structural temperature levels in space are greatly affected by surface properties, overall geometric configurations, and orientation relative to the Sun. Temperature differences can cause significant local structural distortions, degraded structural performance, and overall configuration distortion. These effects are influenced by structural material, structural design, and overall configuration. They can be particularly significant to the flatness of the MPTS transmission surface and the dynamic behavior of the entire system.

To illustrate the magnitude of thermal environments, temperature differences across simple structural members can be on the order of $50 \mathrm{~K}$ (Sun side to space side), temperature differences between structural elements can easily be greater than $100 \mathrm{~K}$ (because of orientation relative to the Sun), and temperature changes due to occultation are nominally $200 \mathrm{~K}$ and can be $400 \mathrm{~K}$. To accommodate this thermal environment, the structural material must be insensitive to temperature gradients (low $\left.C T E, s 2 \times 10^{-7} / \mathrm{K}\right)$, the structure must be active, or the structural design and configuration must be insensitive to thermal effects (environment and/or distortion). The last option is difficult to achieve without compromising other structural requirements.

The significance of the other environmental effects - vacuum, particulate and ultraviolet radiation, and plasma interaction - is difficult to assess because of limited experience with exposure to this environment. The vacuum environment mainly affects the loss of volatile ingredients and surface deposition of effluents. The primary concern with particulate and ultraviolet radiation and with plasma interaction is the stability of surface properties such as solar absorptance and infrared enissivity. It is possible that structural properties of minimum-gauge materials may be affected. Some spacecraft have maintained operational performance in this environment for a number of years, whereas other spacecraft have undergone degradations of performance which can be correlated to environmental effects. This is an area requiring further study since no statisticnlly significant Jald dre avall. ab le. 


\section{Structural design}

In light of the rather benign load environment, the prime structural function is one of providing adequate stiffness for attitude control and pointing. System studies have focused on passive structures which meet overall system requirements as a product of an underlying philosophy that adequate, simple approaches will be cost effective. This passive approach appears to be adequate even for the stringent dimensional control tolerances of an MPTS; however, the dynamic performance and control aspects of the integrated MPTS and solar array are still under study.

The basic feature of a representative SPS structure is one of minimum-gauge material operating under low stress, tiered into a truss element of rather large dimensions, and sized on the basis of an adequate margin for elastic buckling. The structural design and configuration should reflect the requirements of construction, system operation, attitude control, stationkeeping, pointing control, and the environment. Structural design approaches are evolving with ideas generated as a result of an improved understanding of the relatively novel requirements of the SPS.

Current SPS system studies include structural subsystems that incorporate space-constructed columns assembled into a particular structural configuration and sized to accommodate the required loads. These columns generally reflect the NASA "beambuilder" technology development activities for composite triangular and geodetic columns. Relatively detailed stress analyses have been performed on select configurations to enable proper sizing of structural members and assessment of system performance. It is clear that structural element properties will depend on the in-space manufacturing processes in terms of dimensional control, pretensioning, repeatability, quality control, inspection, and repair.

The study of joining structural elements to form the basic structural forms has proceeded in a number of ways, all of which have reflected consideration of the assembly process. Structural performance calculations have been based on rigid joints since it makes little sense to assemble highperformance, efficient, stiff columns into a truss with joints that are relatively flexible or have appreciable slack.

The attachment of subsystems to the structure has received only modest attention. The in-depth definition of structural design requirements from overall system to equipment mounting depends on more detailed design study. It should also be mentioned that although the prime structure and/or large structural members have received the greatest attention, the potentially large number of smaller structural members in secondary or tertiary structures can represent the largest fraction of the structural mass. For example, in the reference MPTS structure for which the total structural mass fraction is $6 \%$, the prime structural mass fraction is less than $0.5 \%$, the secondary. structure is about $2 \%$, and the subarray structure is more than $3.5 \%$.

\section{Thermal/Structural}

In space, there is no ambient atmosphere to equilibrate temperatures as on the Earth. Therefore, temperature levels, differences, and transients must be considered in the system and structural design. The structural materials must be capable of withstanding the range of temperatures experienced as well as the cycles. Thermal engine systems characteristically operate at the practical lifel thermal limits of materials, whereas a photovoltaic system encounters only moderately high temperatures $(\backsim 500 \mathrm{~K})$ as a limit to' microwave power transmission. Low temperatures ( $\sim 120 \mathrm{~K})$ might be obtained as the result of solar/occultation for a system designed to efficiently radiate waste heat and/or reject the solar heat flux.

This range of temperatures and associated cycling are important to the selection of a structural material and to structural design, but equally important are the temperature gradients and changes in temperature gradients. The latter lead to thermal distortions and/or stresses and potentially dynamic distortions and/or stresses. Thermal distortions would be significant to system performance (e.g., MPTS flatness) or certainly to elastic-buckling-limited columns. One approach to desensitizing the structural design to the thermal environment is through the use of low-CTE structural materials such as graphite composites. Graphite fibers exhibit a negative longitudinal CTE, which, when suitably combined in a composite with positive CTE materials, can produce extremely small CTE's.

Other approaches toward desensitizing the structure to the thermal environment are through structural element configuration and through appropriate thermal control (passive or even possibly 
active). These approaches require extensive and detailed thermal analyses and testing, associated structural analyses and testing, and combined thermal/structural analyses and testing. The low-CTE material approach, in turn, requires extensive material/structural development and testing.

There is operating system experience with all three of the cited approaches for handing thermal/structural interactions. Current SPS studies have favored the low-CTE material approach as appearing to be most cost effective.

\section{Structural Dynamics}

The large scale, large inertias, and low structural mass fraction of SPS concepts to date, the pointing and configuration precision requirements (e.g., MPTS), cyclic disturbances (such as gravity gradient and configuration kinematics), and the seasonal solar occultations dictate consideration of the system dynamics and associated configuration requirements such as structural stiffness. The classical approach toward achieving dynamic stability for a system under control is through the use of frequency separation. This separation is achieved by having the control system frequency greater than the various disturbance frequencies, the system (structural) frequency greater than the control frequency, and the subsystem or component frequencies (e.g., solar blankets) greater than the system (structural) frequencies. The largest magnitude operational disturbances have frequencies equal to or less than the gravity-gradient cycle $\left(-2 \times 10^{-5} \mathrm{~Hz}\right.$, or 12-hour period). Since the large-magnitude disturbances have such a low frequency, the classical approach has been evaluated, in the preliminary analyses of selected concepts, and found to offer significant potential. Although the SPS concepts studied to date have not completely precluded structure/control interactions, they do minimize these interactions by taking advantage of lightweight, delicate but stiff structures.

The structural dynamics and control aspects of the SPS have received limited attention so far; however, it is an area in which considerable early work will be required. Although the structural characteristics of an SPS (as currently envisioned) are much simpler than those of existing systems (e.g., the Shuttle), the dynamic modeling of the system is an extensive calculation, particularly if the dynamic characteristics of the component subystems are included. Computation of the dynamic response to particular disturbances and control forces will be laborious, and stability assessment for particular control laws, with realistic actuators and sensor models, is an even greater challenge. Current activities are based on considerable simplification to gain insight and understanding. In the future, accuracy and reliability assessments will be required together with statistical considerations of system properties (i.e., material, structural element, sensor, actuator, etc.). Development of adequate simulation capability and experimental confirmation of modeling and system performance will require significant effort.

At this point, it is felt that a continuation and expansion of the simplified approaches, which ideally retain the significant phenomena but not all the specific detail, is the most productive approach. At the time of the selection of a preferred concept, a simulation capability for the major governing parameters should be in existence.

Finally, it is reemphasized that the final structures and controls design verification must rely heavily on simulation and will require a strong interactive working relationship among the structures, controls, and thermal analysis disciplines.

\section{E. Control (Rigid Body)}

Rigid body control, as discussed here, is concerned with two major aspects of satellite control: (1) translation control to maintain the vehicle in a nominal point in orbit (stationkeeping) and (2) attitude control to maintain the proper pointing of the vehicle and its elements. The latter involves three separately identifiable problems. For the operational SPS in geosynchronous orbit, the collector array (or reflector for certain configurations) must be maintained in a solar direction while the gimballed power transmitting element remains pointed toward Earth to radiate to the ground rectenna. The third problem, and perhaps the most challenging to rigid body control, is associated with the construction phase during SPS buildup and the accompanying large changes in mass and mass properties.

Overlaid on these problems are the effects on control caused by the structural flexibility and the attendant structure/control/thermal interactions. These added complexities are discussed in subsequent sections with the discussion of rigid body control serving as a point of departure. 


\section{Disturbances}

The SPS is orders of magnitude larger and more massive than any contemporary spacecraft. $n$ reference $19 \mathrm{c}$, it is shown that attitude control parameters for a large-aspect-ratio SPS typical of . class of photovoltaic configurations in geosynchronous orbit are dominated by gravity-gradient effects and are strongly dependent on the characteristic length. Quantitatively, gravity-gradient torques can be as large as $2 \times 10^{6} \mathrm{~N}-\mathrm{m}$. However, the force required to react this torque, as mentioned earlier, is on ly a few hundred newtons.

Peak solar pressure torques have been calculated to be about half an order:of magnitude less than the peak gravity torques. The combined disturbance torques which would be encountered during a geosynchronous orbit construction cycle of a photovoltaic system are shown in figure VI-1.

Analyses contained in references $16 \mathrm{~d}$ and $19 \mathrm{c}$, which have examined the effects of Earth triaxiality, Sun/Moon perturbations, and solar pressure perturbations, have shown that solar pressure is the primary stationkeeping disturbance and can cause as much as a $\pm 3^{0}$ east-west excursion if not corrected.

Analysis of disturbances and their effects on control have been conducted for other configurations such as the thermal engine systems and are-contained in the cited references. Results are not elaborated here since they are naturally configuration dependent and do not contribute substantially more or different insight to the understanding and appreciation of the disturbance environment.

The preceding discussion is also limited to geosynchronous orbit. Trades of LEO and GEO construction exist in the literature. All aspects of the control problems are compounded in LEO. Aerodynamic effects become important for both attitude control and stationkeeping. Gravity-gradient torques are 200 times larger because of their dependence on the square of the orbital frequency. These conditions impose additional requirements on orientation, require configuration mass balancing to keep the control effector systems manageable, and reduce the separation between control and structural frequencies. The compounding of the control problem together with a host of operational and transportation problems makes GEO construction the current preferred mode; therefore, LEO consideration is not discussed further.

\section{Attitude control}

Because of the dominance of gravity-gradient torques; the control designer's first thought is to eliminate or minimize the problem by inertia balancing or spin stabilization techniques. Some schemes discussed in reference $19 \mathrm{c}$ were evaluated but eventually rejected because of weight penalties and/or mechanical complexity. For the operational photovoltaic SPS, the flight mode finally selected is one which maintains the long axis perpendicular to the orbit plane (POP) with the array maintained pointing at the Sun (quasi-inertial mode). This mode requires that the transmitting antenna be gimballed and separately controlled to maintain the required Earth-pointing attitude. A similar mode has been adapted for the construction cycle with the special provision that the solar arrays point away from the Sun (so as not to generate unwanted power) until the assembly is complete.

Pointing requirements for the collector array are a function of acceptable cosine loss and of concentration ratio (if concentrators are used). A value of \pm 0.50 appears to be acceptable and achievable with existing technology. A requirement for shape or figure control for the collector array has not been identified.

Pointing of the transmitting antenna is much more stringent. Whereas electronic steering is used for vernier pointing, mechanical pointing of the complete antenna is required to about 3 arcminutes. The capability of achieving this accuracy for a $1-\mathrm{km}$ structure has not been analytically verified. Active figure control of the antenna has not been identified as a requirement provided the electronic phasing requirements are met,

Before further discussion of attitude control and control policy, it is necessary to discuss stationkeeping requirements.

\section{Stationkeeping}

The primary disturbances resulting in spacecraft excursions in the assumed geosynchronous equatorial orbit were described in subsection E.1. To maintain the operational spacecraft at a nominal 
position in orbit to an accuracy of approximately $0.1^{0}$, east-west velocity correction requires on the order of $300 \mathrm{~m} / \mathrm{sec}$ per year and north-south velocity requirements are on the order of $50 \mathrm{~m} / \mathrm{sec}$ per year.

Obviously, these corrections must be made-with a thrust device (as differentiated from a torquing device which could handle gravity and solar torques). One is then led to the consideration of developing a control policy which would use a.single system to react both types of disturbances. This in $\mathrm{fact}$ is the preferred approach for array control as described in the following subsection.

\section{Control system}

The attitude control system is in actuality a subsystem of a much more elaborate data management and communications system. The electronics section takes on the characteristics of a distributed architecture, which is the current trend in information systems technology. Redundancy levels and methods of failure detection and isolation have not been studied in any detail, but it is estimated that the overall system complexity for rigid body control will be no greater than the redundant system to be flown on the Space Shuttle. Although more hardware elements and more software systems will be involved, the overall complexity, in terms of a technology issue, appears manageable.

Structure/control interaction effects are thought to bc the main uriver on complexity. Howcver, unless dn actively controlled structural figure is required, the added complexity will have its primary impact on the software system.

As to the choice of actuatoi's, Il was prevviously stated that torquing devices such as control moment gyroscopes (CMG's) could react the gravity gradient and solar pressure torque. disturbances. However, as seen in figure VI-1, peak momentum reyulrements can be as high as $6 \times 10^{10} \mathrm{~N}-m-s e c$ (mission phase E). The Skylab CMG's, which are the largest that have been flown in space, have on the order of $3000 \mathrm{~N}-\mathrm{m}-\mathrm{sec}$ storage capability. It is clear that conventional momentum wheels, even with an order. of magnitude improvement in storage efficiency, are impractical for array control because of the large number required.

Control of the transmitting antenna is another matter. Results of a rudimentary rigid body analysis indicate that the antenna can be controlled by a set of 12 conventional CMG's of unspecified storage capacity located on the periphery of the antenna. Trades between this approach and simple gimbal torquers have not been completed.

Reference $19 \mathrm{c}$ describes a study which was done on the design of an "unconventional" momentum wheel for an SPS concept. The device, which resembles a bicycle wheel of $350 \mathrm{~m}$ radius, would be space constructible with a momentum capability of $4 \times 10^{8} \mathrm{~N}-\mathrm{m}-\mathrm{sec}$ at about $0.6 \mathrm{rad} / \mathrm{sec}$ (6 rpm). Data were developed for both aluminum and composite wheels and traded against various types of reaction control systems. Results of one such trade are shown in figure VI-2 for a photovoltaic configuration with a center-mounted antenna. It is vividly illustrated that the propellant mass, as a percentage of spacecraft mass, is tolerably small with systems of specific impulse $I_{s p}=10,000$ seconds and above. The space-constructible momentum wheel, not. shown in the figure, would begin to trade favorably. with engines of 20,000 seconds after about 30 years.

Based on these types of trades together with considerations of logistics, technology status, costs, etc., an argon ion thruster system was selected as the reference system for array control. The Isp selection is in the range of 13,000 seconds. A typical application is approximately 25 engines mounted on a gimballed thruster panel, which is boom-mounted to each corner of the SPS. Conventional chemical thrusters (with $I_{s p}$ of about $400 \mathrm{sec}$ ) are required to maintain control during equinoctal occultations. A similarly configured system is proposed for the construction phase and is described in reference $16 \mathrm{~d}$.

The ion engines, nominally 100 to $120 \mathrm{~cm}$ in diameter with thrust levels from 5 to 15 $\mathrm{N}$, are arranged to provide a total thrust equal to the solar pressure force. Attitude control is achieved by modulating the thrusters about this hias level to provide the necessary contrul torques. With this cuntrol policy, thie propellant penalty for attitude control is minimal.

The sensor system would consist of the usual Sun sensors, star trackers, rate/attitude gyros, etc., for rigid body attitude determination and control. Requirements for sensing the structural modes will determine the overall size and complexity of the sensor system. 


\section{F. Materials}

Early SPS concepts employed aluminum as an efficient structural material with a wealth of aerospace experience. As the thermal/structural and thermal/structural/dynamic interactions became apparent, however, the desirability of a structural material which was insensitive to the thermal environment also became apparent. Since this insensitivity can be readily obtained by the use of graphite composites (more than two orders of magnitude lower coefficient of thermal expansion than aluminum), this matertal has been considered as the prime candidate for an SPS structural material. The graphite composite materials have a higher Young's modulus-to-density ratio than aluminum; however, the raw material costs are an order of magnitude higher than for aluminum today. The trend of graphite composite material costs is downward because of an expanding market; however, for the raw material cost to approach that of aluminum would require a major market acceptance such as the replacement of steel in the automobile or an SPS program. Energy investment requirements for the production of graphite composites are on the order of one-half to one-quarter that of an equal mass. of aluminum. Currently, production facilities are being built for high-modulus pitch-based graphite fibers. These fibers are lower strength and lower cost, which is not at all inconsistent with SPS requirements.

Raw material costs are only one facet of the structural system costs. The ease with which a material can satisfy overall system requirements or conversely restrict system performance could have a much greater influence on the final cost of electrical energy. For example, the reference system material is a thermoplastic resin which provides ease of forming. It should be emphasized, however, that this selection is preliminary and is based on the current level of understanding of the structural material requirements. There are a number of candidate graphite composite materials including epoxy, polyimide, and metal matrices and glass/graphite-fiber combinations. The material selection requires a development which is integrated with structural design and structural fabrication in a symbiotic process that addresses all the significant structure and material requirements.

The long-lifetime characteristics of structural materials and coatings in the geosynchronous orbit environment is an area requiring considerable study and appropriate development plans. There is a need for extensive experimental data and the construction of phenomenological models. Avenues should be developed for taking advantage of current and upcoming flight experience. For example, the ATS-6 satellite has a graphite epoxy truss structure which, after a number of years, might offer a benchmark data point if recovery is accomplished.

\section{G. Workshop Summary}

An SPS Structural Dynamics and Control Workshop was held at JSC on January 22 and 23, 1980. The pane 1 members represent some of the nation's leading experts in controls, structural dynamics, structures, and materials. The objectives of the workshop were (1) to assess and critique the assumptions, methodologies, and conclusions of existing SPS studies in the areas of structural dynamics and control (with structural design and materials also being considered) and (2) to identify critical issues in these areas and make recommendations for future work. The official panel findings are expressed in the panel's final report and summarized here.

1. Although the work to date lacks depth and breadth, the panel members are generally confident that, with sufficient resources, the challenges presented by the SPS can be met. However, a substantial amount of work must be done in areas such as modeling, developing techniques for the active control uf uncertain systcms; and studying the long-term physical properties of composites before this confidence is fully warranted.

2. Since the SPS system cannot be tested in the terrestrial environment, many types of experimental verification techniques possible for more conventional engineering projects are excluded. Thus, the successful design, development, and construction of the SPS will rely, to an unusualiy high degree, on modeling and dynamic analysis. The panel feels that substantial further work is required in the areas of modeling the system components and environment.

3. Current SPS structural designs use forms which are derived basically from 19th century bridge-building technology (not necessarily bad). As the overall system concept evolves, as communication is developed between structures, materials, and controls specialists, and as an understanding of construction in space is developed, it is anticipated that more advanced concepts capable of exploiting the potential of the nearly benign environment will emerge. 
4. To approach this evolution, however, the panel felt that the controls problem had received disproportionately little attention and that the following should be accomplished: recognition of modeling limitations as a key issue, trade-offs among active surface control, trade-offs between the bounds of structure and control, trade-offs between electronic phasing and active figure control, analyses sufficiently. detailed to encompass specific controls hardware considerations, and means to accomplish verification of the controlled system design. The controls problem for construction is compounded by the additional parameters of transient geometry and performance requirements.

5. A requirement of the SPS which sets it apart from all spacecraft launched to date is the fact that it must be constructed in space. Lack of experience with systems of this type merits careful consideration of this feature. The construction phase may in fact be critical in terms of establishing structural and control system design requirements.

6. The panel feels that much additional work is required to provide a confidence level necessary for the selection of graphite composite as the SPS structural material. A number of design/structure/ material trade-off studies should be performed. The basic question of the long-term stability of materials and coatings in the space environment is crucial.

7. The nature of the SPS is such that the design and proof of feasibility will rest primarily on a foundation of analysis. However, experiments are needed to verify the results of analysis insofar as possible. These experiments should be directed toward verification of modeling techniques, validation of control policies, and determination of material properties. 


\begin{tabular}{|c|c|c|c|c|c|c|c|c|}
\hline \multirow{2}{*}{$\begin{array}{c}\text { Mission } \\
\text { Phase }\end{array}$} & \multirow[b]{2}{*}{ Config } & \multicolumn{3}{|c|}{$\begin{array}{l}\text { Torque } \\
10^{3} \mathrm{~N}-\mathrm{m}\end{array}$} & \multicolumn{3}{|c|}{$\begin{array}{l}\text { Momentum per orbit } \\
\qquad 10^{8} \mathrm{~N}-\mathrm{m}-\mathrm{sec}\end{array}$} & \\
\hline & & $T x$ & Ty & $T z$ & $H x$ & $\mathrm{Hy}$ & $\mathrm{Hz}$ & \\
\hline \multirow[t]{2}{*}{ A } & 1 & 1.11 & 15.8 & 2.70 & .153 & 3.89 & .742 & 21 days \\
\hline & & GG & $G G / S$ & $\mathbf{G G}$ & $\mathbf{G G}$ & $\sqrt{5}$ & $\mathbf{G G}$ & \\
\hline \multirow[t]{2}{*}{ B } & 2 & 76.7 & 155.3 & 12.0 & 36.0 & 120. & 7.9 & 42 days \\
\hline & & $\mathrm{GG} / \mathrm{S}$ & $\mathrm{GG} / \mathrm{S}$ & GG/S & GG/S & $\sqrt{5}$ & $\mathrm{~s}$ & \\
\hline \multirow{6}{*}{ C } & 3 & 119. & 589. & 31.5 & 41.9 & 399. & 19.6 & \multirow{6}{*}{42 days* } \\
\hline & & GG/S & $G G / S$ & $G G / S$ & $S$ & 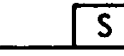 & $\mathrm{s}$ & \\
\hline & 4 & 589. & 552. & 2120. & 179. & 367. & 592. & \\
\hline & & $\longdiv { G G }$ & $\mathrm{GG} / \mathrm{S}$ & $\longdiv { G G }$ & $G G / S$ & 5 & $\mathbf{G G}$ & \\
\hline & \multirow[t]{2}{*}{5} & 602. & 40.9 & 48.0 & 202. & 27.7 & 26.9 & \\
\hline & & GG/S & $\mathrm{GG/S}$ & GG/S & $\mathrm{GG} / \mathrm{S}$ & 5 & GG/S & \\
\hline \multirow[t]{2}{*}{ D } & 6 & 739. & 219. & 224. & 199. & 162. & 144. & 42 days \\
\hline & & $\longdiv { G G }$ & 5 & 5 & $\mathrm{GG} / \mathrm{S}$ & 5 & 5 & \\
\hline \multirow[t]{2}{*}{ E } & 7 & 1070. & 889. & 1800 & 402. & 641. & 518. & 21 days \\
\hline & & $\longdiv { G G }$ & 5 & $\longdiv { G G }$ & $G G / S$ & S & $\mathbf{G G}$ & \\
\hline
\end{tabular}

Legend: GG Grav grad primary source

\begin{tabular}{|c|c|c|}
\hline $\mathrm{s}$ & Solar pressure primary source & * Configuration 4 requirements are used to \\
\hline GG/S & Comparable grav grad \& solar & phase $C$ for propellant \\
\hline
\end{tabular}

calculations

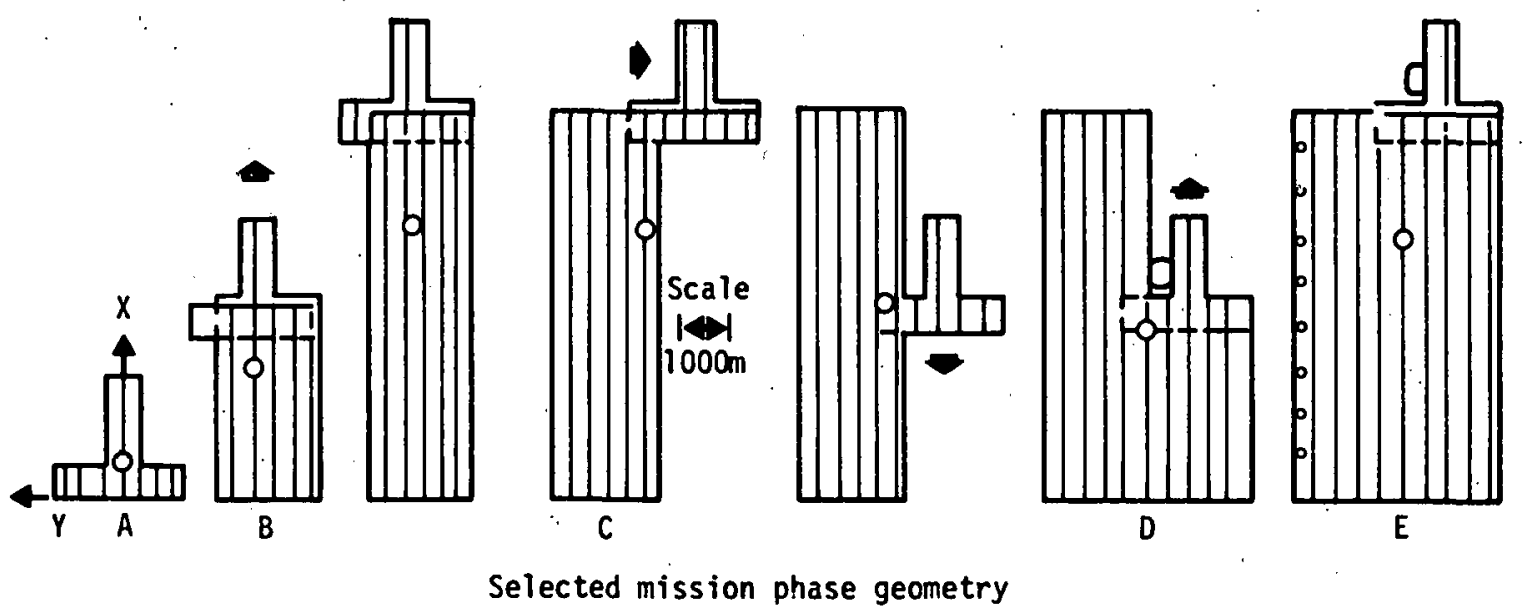

Figure VI-1.- Environmental disturbances during GEO construction. 
- Attitude control \& stationkeeping propellant

- Ccntinuous solar pressure stationkeeping

correction is dominant requirement

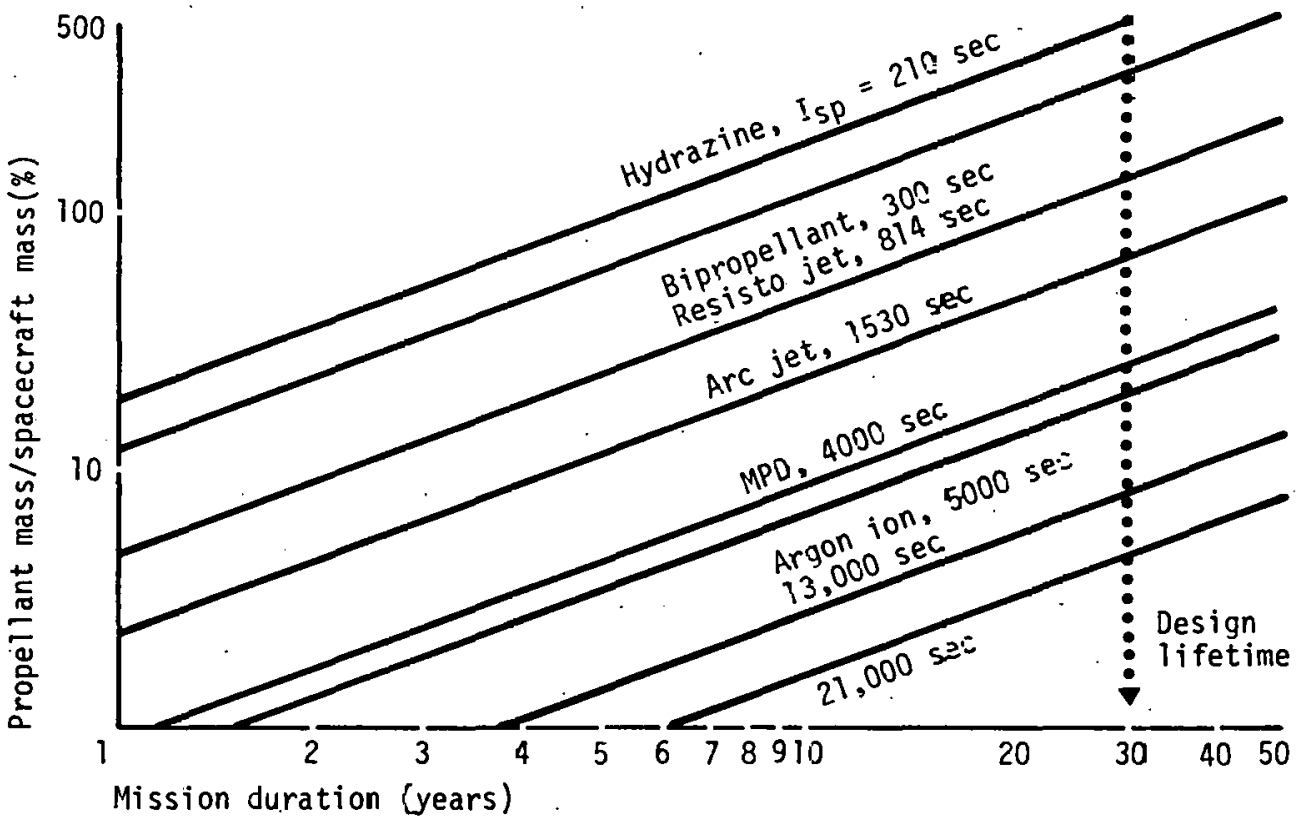

Figure V1-2.- Propellant trades. 


\section{A. Surmary and Introduction}

This section consists of a brief review of the construction, operation, and maintenance required for an SPS, including the space and ground systems. This work utilized a reference system focus for design details to thoroughly understand the construction and operations scenarios. Based on these scenarios, logistics data were developed to properly visualize the construction requirements, and the results and their sensitivities should be applicable to any type 5-GW satellite. The basic construction guidelines are explained, and construction location options are discussed. The space construction tasks, equipment, and base configurations are discussed together with the operations required to place an SPS in geosynchronous Earth orbit. A rectenna construction technique is explained, and operation with the grid is defined. Maintenance is summarized for the entire system. Finally, key technology issues required for SPS construction operations are defined.

Studies of SPS construction, operation, and maintenance have led to an understanding of the manpower and time required to construct an SPS. Such a system would require approximately 600 workers in space and the orbital construction bases and equipment. Results of these studies indicate that a satellite could be built in 6 months. The rectenna construction is typical of other Earth-based projects but can benefit from the application of specialized machinery. Maintenance of the entire SPS would invoive satellite refurbishment, primarily in the antenna, transportation of the refurbishment material and manpower to orbit, and a limited amount of rectenna component replacement on the ground.

These studies have identified the following technology emphasis for SPS construction and operations work which could be conducted on the ground.

1. Zero-g and space vacuum simulations

2. Analytical modeling

3. Automated construction equipment

This technology work will provide a basis for detailed definition of early orbital experiments, later system-level flight projects, and an SPS "demonstrator."

\section{B. Space Construction}

1. Guidelines

Two main guidelines were used in the space construction studies.

a. The construction system would build two 5-GW SPS's per year.

b. SPS construction will use only materials derived from the Earth.

\section{SPS construction location}

Because of the size of the SPS structure, construction must take place in space. The absence of gravitational loads in space allows very. lightweight, low-density structures to be used. Also, constructing the low-density satellites in space permits high-density payload packaging of materials and thus minimizes the number of launches.

Studies have shown that either LEO or GEO construction is feasible. The GEO construction location is used in the reference system.

Construction of the satellite in GEO has several advantages. Gravity-gradient loads are two orders of magnitude lower than in LEO, aerodynamic drag loads are not significant, thermal effects from passing through the Earth's shadow are negligible, collision hazard from other satellites is low, and the construction sequence is simpler. Personnel logistics requirements and transportation costs for the construction base, on the other hand, are greater than in LEO, but the percentage cost impact appears to be small. 
Building the satellite as a complete unit in LEO for transport to GEO is not practical because of control requirements and loads to the structure due to gravity-gradient torques. The most effective mode of construction in LEO is to build the satellite in modules whose LEO-GEO transfer requirements are sized to be compatible with the thruster requirements for the control of the SPS in GEO operation. The modules are then berthed and assembled together in GEO for final assembly.

LEO construction offers a potential transportation cost saving by using a self-powered mode, in which output from the partly deployed SPS solar cells is used to power a LEO-to-GEO electric propulsion system which uses high-efficiency ion engines. Although chemical propulsion could be used, the use of an independent electric OTV concept for GEO construction could eliminate any cost differential between LEO and GEO sites. Radiation degradation of the solar cells during transit of the Van Allen belts remains a technical issue.

\section{Tasks, equipment, and facilities}

Several construction approaches were evaluated. Because of the large scale of the operation, a high degree of automation can and must limit the number of personnel and reduce the total construction time. The personnel principally perform monitoring, repair, support, and other functions which cannot be automated efficiently. The activities involved in one approach to SPS construction are shown in figure VII-1. The annalysis and results apply to the Reforence System.

Heavy lift launch vehicles deliver 400 M.T. of cargo to a LEO base at a rate of about 8 launches per week, or 400 per year. Similarly, personnel launch vehicles take 75 to $80 \mathrm{crewmen}$ from Earth to the LEO base 32 times per year. rrew stay time for cach trip i3 about 90 Jays. Aluuut 135 crewmen would be stationed at the LEO base all the time to handle cargo. The LEO base also constructs several electric orbital transfer vehicles that carry SPS materials to GEO in unmanned trips 1 asting about 6 months. The LEO base alșo provides a staging depot for personnel and supplies for transfer to chemically powered personnel orbital transfer vehicles for a 6-hour Hohmann transfer to GE0.

At GEO, the 6400-M.T. construction base receives cargo from the electric orbital transfer vehicles and, with a crew of about 400 people, constructs each 5-GW SPS in 6 months. Of the 400 people, about 270 are involved directly in construction, which includes deploying the solar energy conversion system, assembling the antenna, installing various subsystems, maintaining construction equipment (beambuilders, cherrypickers, transporters, manipulators, etc.), and performing base logistics and testing. The remainder of the personnel provide base operations and support functions (lodging, food, health, communications, etc.). The GEO base also serves as a staging area for maintenance crews and systems that travel periodically to operational SPS's, as well as a refurbishment center for disabled SPS components. The number of people required for the maintenance function varies with the number of SPS's in service. About 380 people are needed to maintain 20 operational SPS's.

It is assumed that crewmen rotate about every 90 days. A 90 -dayy space stay time is considered a reasonable compromise based on the psychological effects of remote confinement, the effect of zero $g$ on the body, and radiation exposure limits. Radiation expnsure considerations are bascd on limted extravehicular activities and provision of "storm cellar" shielding for major solar events. For instance, with a high flux and nominal shielding, a quarterly maximum dose of 35 rem to blood-forming organs would be reached in about 90 days.

The method of construction should involve simple, repeatable, highly automated steps. For the gallium arsenide configuration, a single fixture (fig. VII-2) is used to build the three-trough cross-section shape of the satellite. Equipment mounted on this fixture builds the SPS solar array in a single piece. For the silicon configuration, the GEO base bujlds the SPS in twn rnnstrurtion paseos as shown in flgure VII-3. The microwave antenna is built at the same time on the side of the base, then mated at the end of the second pass. Following SPS checkout, the construction base would separate from the satellite and transfer to the next SPS construction location.

\section{Recterind Construction}

The rectenna is the ground-based unit of the SPS which receives microwave energy and converts it to grid-compatible electrical power (fig. VII-4). Recent analysis favors a concept using individual antenna elements with dedicated rectifiers and filters for RF to DC conversion. These elements are mounted on flat panels arranged to be perpendicular to the incoming RF beam. A steel mesh is used behind these elements as an electrical ground plane. Elements are connected in parallel and series 
groups, as required, to produce voltage levels compatible with $D C$ to $A C$ conversion. The rectenna ground area varies with location and is elliptical because of its position relative to the equatorial orbit plane of the SPS antenna.

Rectenna site locations and alternative structural designs were investigated. The rectenna structure selected as a reference is constructed of steel with aluminum electrical conductors. Aluminum, wood, and concrete have also been examined for structural use. Several studies have been conducted on availability of suitable sites. Brief summaries of these areas follow.

\section{Site location studies}

a. Utility interface, site availability - A siting analysis was conducted to develop information on siting criteria and to make a preliminary assessment of siting problems. Three areas were surveyed: (1) Pacific Northwest, (2) north-central region, and (3) southern California. Information was informally exchanged with power companies in these areas. The analysis was conducted manually using aeronautical charts, contour plots, and roadmaps. From this study, it was concluded that the number of potential sites available exceed the estimated requirements (ref. 15b).

b. Offshore rectennas - A preliminary feasibility and cost study was performed on the concept of an offshore rectenna to serve the upper east coast. A candidate site was selected and several types of support structures analyzed. Results indicate that a rectenna could be built offshore but that the practicality of this system is undemonstrated (ref. 37).

c. Site requirements - A number of studies have focused on site layout for typical locations. Maintenance facilities, access roads, converter stations, distribution towers, control buildings, and other similar factors were examined in the construction analysis ( $r e f s .15 b$ and $20 f$ ).

\section{Construction concepts}

Current reference system concepts for rectenna structure and construction techniques are based on standard methods of implementation (fig. VII-5). Because of the large projected costs for these methods, automatic rectenna panel fabrication methods are desirable. Several studies have examined potential construction scenarios, various types of specialized heavy equipment, and manpower for rectenna fabrication. Specialized machines for rectenna fabrication are expected to provide significant cost-reduction benefits.

\section{Operations and Maintenance}

\section{Satellite}

The bulk of the SPS components are highly reliable, redundant, or relatively inert. Most satellite maintenance will involve periodic replacement or refurbishment of the klystron microwave antenna elements. Even though the reliability is fairly high, cumulative failures of these active elements over the SPS lifetime would result in an unacceptable degradation in performance. Alternative concepts for maintenance are a permanent maintenance base and crew at each satellite or mobile maintenance crews who return to one of the GEO construction bases with components to be refurbished. The latter concept is illustrated in figure VII-6.

At the GEO base, maintenance workers board a mobile crew habitat. Along with maintenance equipment and replacement components, they travel to an operational SPS, which has been shut down before their arrival, and dock to the satelilite's antenna. Using built-in equipment (e.g., cranes and cherrypickers), over a 3-1/2-day period, they remove defective components and replace them with new or rebuilt parts. Defective components are returned to the GEO base. The crew, mobile maintenance equipment, and replacement parts then move on to the next satellite, visiting as many as 20 satellites in a $90-d a y$ period, which is consistent with crew rotation time.

At the GEO base, other crewmen diagnose defective components, repair or replace them as appropriate, reassemble, and test. When possible, the refurbished components can then be reused on other SPS's.

For 20 satellites, a mobile maintenance crew requires about 80 people with about another 300 needed for the refurbishment work. The crew size varies with the number of satellites in service. 
The primary components on the reference satellite which require maintenance are the $k$ lystron tubes and the $D C-D C$ converters. These parts are removed from the satellite and transported to the GEO construction base, where they are refurbished. Repair and/or replacement of the solar cell blankets is not considered cost effective because of the circuit redundancy inherent in the design. If the degradation of the output of the silicon cells due to radiation becomes a factor in SPS output, the cells must be annealed or the array oversized. A concept for annealing the damage by heating the cells with a laser system was defined for the silicon system. On the gallium cell satellite, the cells are annealed by operating at a temperature high enough to cause self-annealing.

\section{Rectenna}

The rectenna provides the interface between the satellite and the electrical utility grid. Power generated in space must be transferred through the rectenna to the user in a controlled manner. Operations include startup, shutdown, and steady-state control under normal and emergency conditions. Extensive use of computer hardware will be required because of the extreme complexity involved in interfacing large amounts of power at very high speeds. All communications and telemetry will be interfaced through the rectenna control center. Rectenna operation under various conditions and maintenance has been studied. Direct-current power from rectenna rect if iers is collected by parallel and series interconnection into 40-MW power blocks. A group of 40-MW solid-state DC to $A C$ inverters converts the power from these power blocks to alternating current. The synchronous operation of inverter output power with the ut.ility grid is controlled in a manner to provide rectenliato-grid power transfer. This management system will include devices for line phase, voltage control, and active controls for load shedding and line acquisition.

The SPS transmitting antenna and rertenna have been analyzed for all phases of operation. The operation and cuntrol of the two, in conjunction with grid particulars, determine startup, normal and emergency shutdown, and steady-state procedures.

During startup, the mechanical alignment of the antenna would be established and array temperatures allowed to stabilize. System status verification is followed by power-up of power processors, klystron heaters, magnets, and phase control system. The pilot beam is then acquired and RF drive confirmed. Power is ramped on in steps from the antenna center ring to outer edge in a timed manner as desired for grid load acquisition. This same technique may be used for system throttling. • Klystron power is varied by controlling beam current with a modulating anode. In a shutdown, power is ramped down by klystron control, ring by ring from antenna outer edge to center; the pilot beam is disrupted, the circuit breakers are opened, and power is transferred from on-orbit to storage if required. During an emergency shutdown caused by grid operations such as load trip, the rectenna elements would shift power to resistive load banks, the pilot beam would be disrupted, and onboard sircilit hreakers would be tripped.

Operation will involve a very high reliability of transmission and power utilization in the grid. Because of the high probability of not ever having a complete nower loss from an SPS, the needed grid reserve might decrease with increasing SPS grid penetration (ref. $15 f)$.

Maintenance for SPS and rectenna systems can be limited to performance during scheduled downtimes only if grid penetration is sufficiently low to maintain operation with adequate generation reserve.

Because of the high probability of lightning striking a rectenna and the potential for damage to various low-voltage elements, special provisions mist he made for adequatc lightning protei:tion (ret. $2 y)$.

\section{E. Workshop Summary}

The space construction and materiais workshop was conducted on January 24 and 25 , 1980, at the Johnson Space Center with an independent panel made up of experts fram the arademic community, industry, dul yuverment. The objective of the workshop was to determine whether areas which could be considered critical to the construction and materials aspects of. the SPS program were adequately covered.

The workshop committee reported (ref. 38) that, in general, the studies done to date were commendable in their efforts to truly visualize a complex assembly process. The assembly concept.s 
investigated seemed to be credible and the GBED (Ground-Based Exploratory Development Program) appeared to be an excellent first attempt at near-term goals definition. The committee also noted that work in this development area would be well supported if GBED plans are implemented.

According to the workshop committee, areas which could require greater emphasis are:

1. Better definition of structural factors and, particularly, structural dynamic loads during construction and assembly

2. The interaction of these loads with the attitude stabilization control system and with those required for stationkeeping

3. A broader view of structural design concepts beyond those envisaged for the immediate development program

4. More experimental verification of some of the assembly concepts, possibly including some early space-based experiments and a better definition of the advantages and disadvantages of automatic compared to manual assembly

5. A better definition of material requirements, in particular the use of polymer compared to metallic structures

6. Further systems trade-off studies, in particular the optimization of the orbit-to-orbit transportation and the choice of GEO or LEO assembly

Members of the workshop felt that it was essential to keep in mind that the SPS program currently is in a very evolutionary phase. Although the need for a baseline concept to plan the future program was recognized, it was believed essential to actively pursue advanced technology concepts and to maintain a degree of flexibility in the program.

\section{F. Conclusions, and Remaining Issues}

The construction facility provides a framework for the conduct of the many operations necessary for the completion of the satellite system. Since the primary structure of the SPS is not subjected to large-load conditions in geosynchronous orbit, the structure has very low mass and volumetric density. The material for the structural elements can be densely packaged for launch, then expanded by machines (beambuilder) to be assembled into a lightweight efficient structure. The SPS subsystems such as solar array blankets, reflectors, power conductors, and antenna subarrays will need a variety of special equipment and techniques for installation on the primary structure. Although these subsystems are fabricated on Earth, dense packaging will be necessary for launch into orbit, where final deployment and installation is accomplished. Delivery of the material encompasses a number of construction support functions involving transport, handling, positioning, alignment, and attachment of subsystems and modules. Equipment and operations to provide these support functions require a technology base which must be developed.

Another operational function which will be required is the capability to berth or dock very large elements or components. For example, controllable members might be extended to acquire the component, then retracted under controlled conditions to permit a firm attachment of the components without excessive loads or damage.

The operational SPS should be viewed as a long-range goal at the end of an extended evolutionary process. This evolution will include developing capability and experience for large-scale manned operations in space. Space evaluation of new technologies needed for very large satellites will require activities involving the space construction of sealed versions or whole modules of an SPS. 
The type of work which could be conducted on Earth to support SPS construction technology can be grouped into three major areas:

1. Zero-g and space vacuum simulation

2. Analytical modeling

3. Automated construction equipment

Ground simulation development would include experiments conducted to develop space construction techniques including use of construction aids such as cranes and cherrypickers. These simulation facilities could be used as trainers when final equipment is developed. In addition to these simulations, joining experiments should be conducted including strength tests. Analytical modeling should include extensive loads analyses for SPS structural configurations to enable better understanding of loading conditions on an SPS. These analyses must include gravity-gradient, thermal-cycling, docking and berthing, and control loads. During construction, a wide range of control requirements will be encountered. These wide variations and the flexible nature of the structure will entail a range of system dynamic parameters requiring extensive dynamic modeling and possible dynamic model tests in space.

Aulumated constructioñ equipment includes it.ems surh as heambuilders, manipulators, and other programable equipment. This technology area is a high-leverage means of reducing manpower costs in space and on the ground. With the Reference System, the rectenna is extremely labor intensive, and automated fabrication, assembly, and field erection can be used to reduce costs. Implementation of an SPS program would require automated construction techniques on the ground and in space and thus would stimulate the development of automation technology.

These ground tests would provide a basis for refinement of the SPS analysis and the definition of flight tests or experiment,s needed for program decisions. 


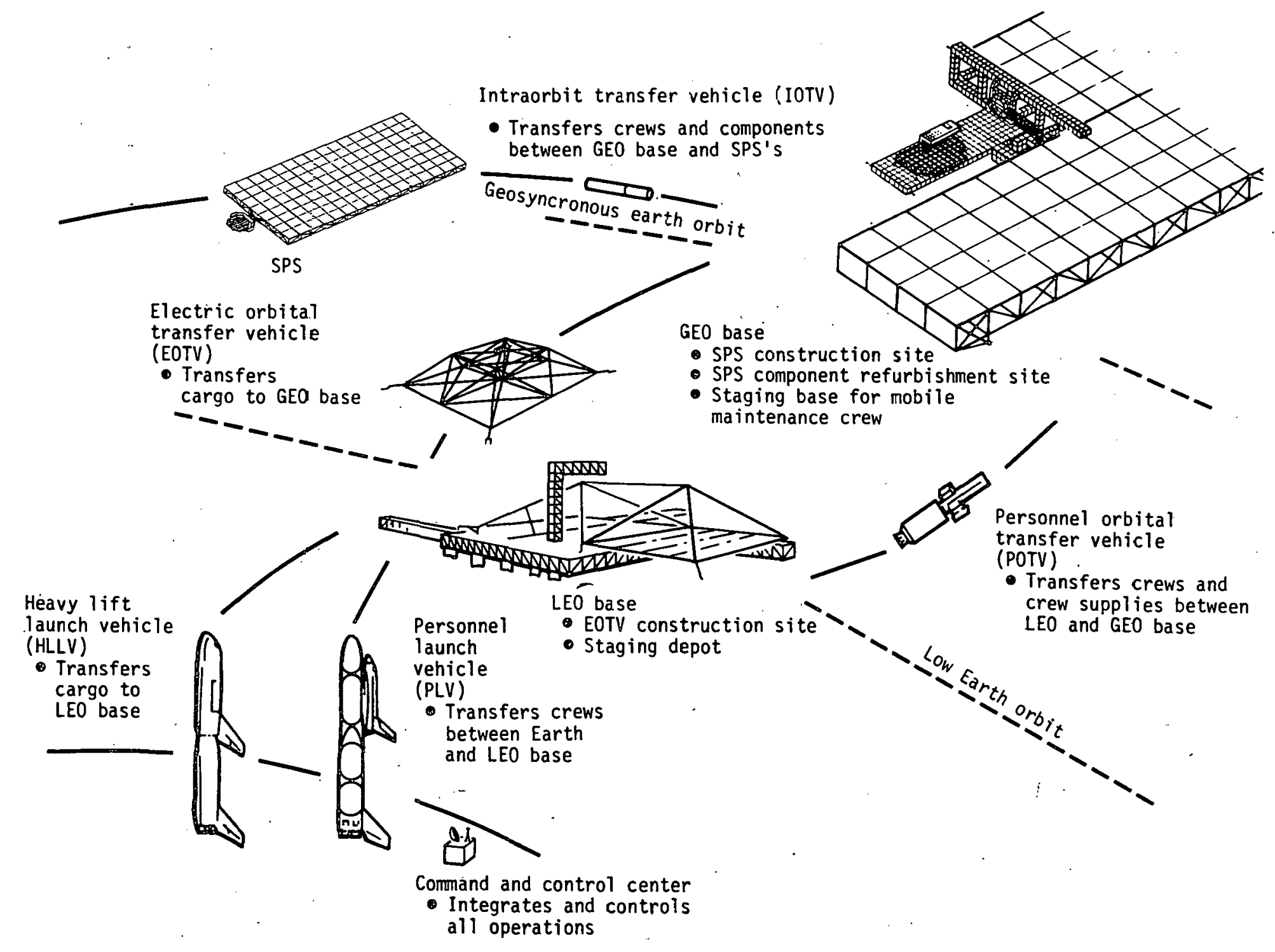

Figure VII-1.- SPS operational elements. 

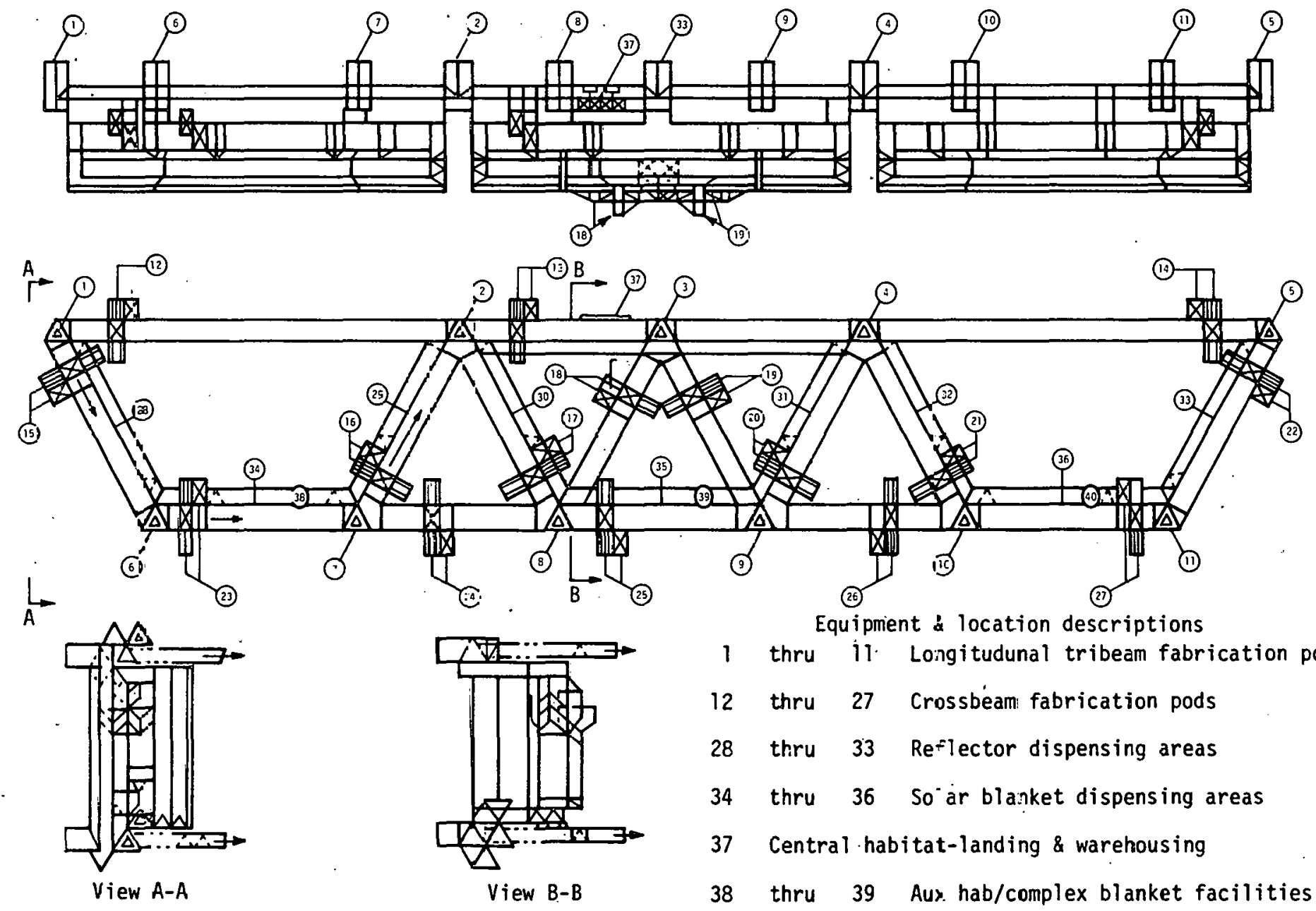

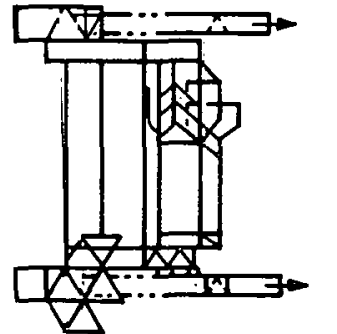

View B-B
Equipment \& location descriptions

1 thru il Longitudunal tribeam fabrication pods

12 thru 27 Crossbeam fabrication pods

28 thru 33 Reflector dispensing areas

34 thru 36 So ar blanket dispensing areas

37 Central habitat-landing \& warehousing

38 thru 39 Aus. hab/complex blanket facilities

Figure VII-2.- Satellite construction base. 

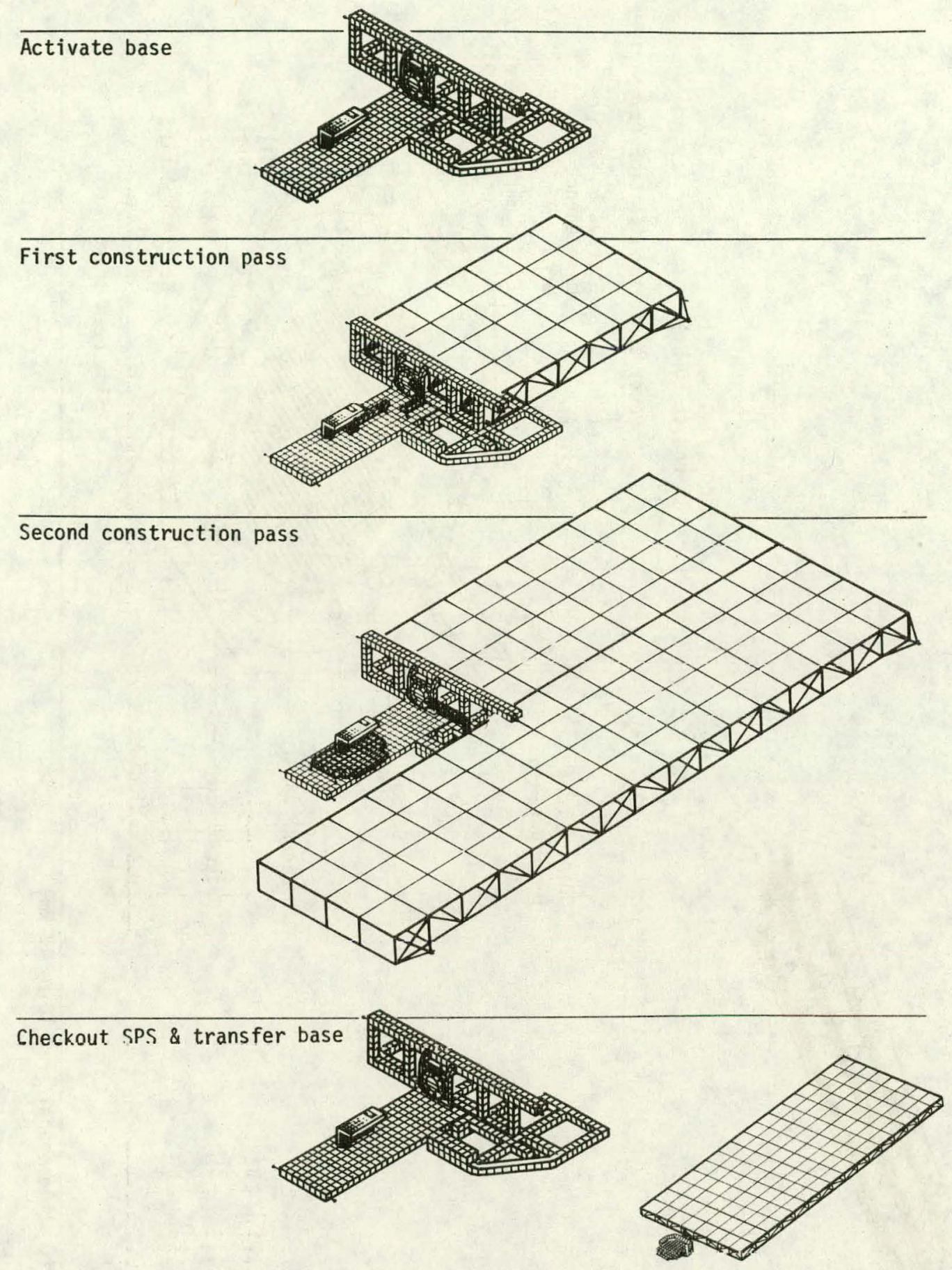

Figure VII-3.- SPS construction - four-bay endbuilder. 


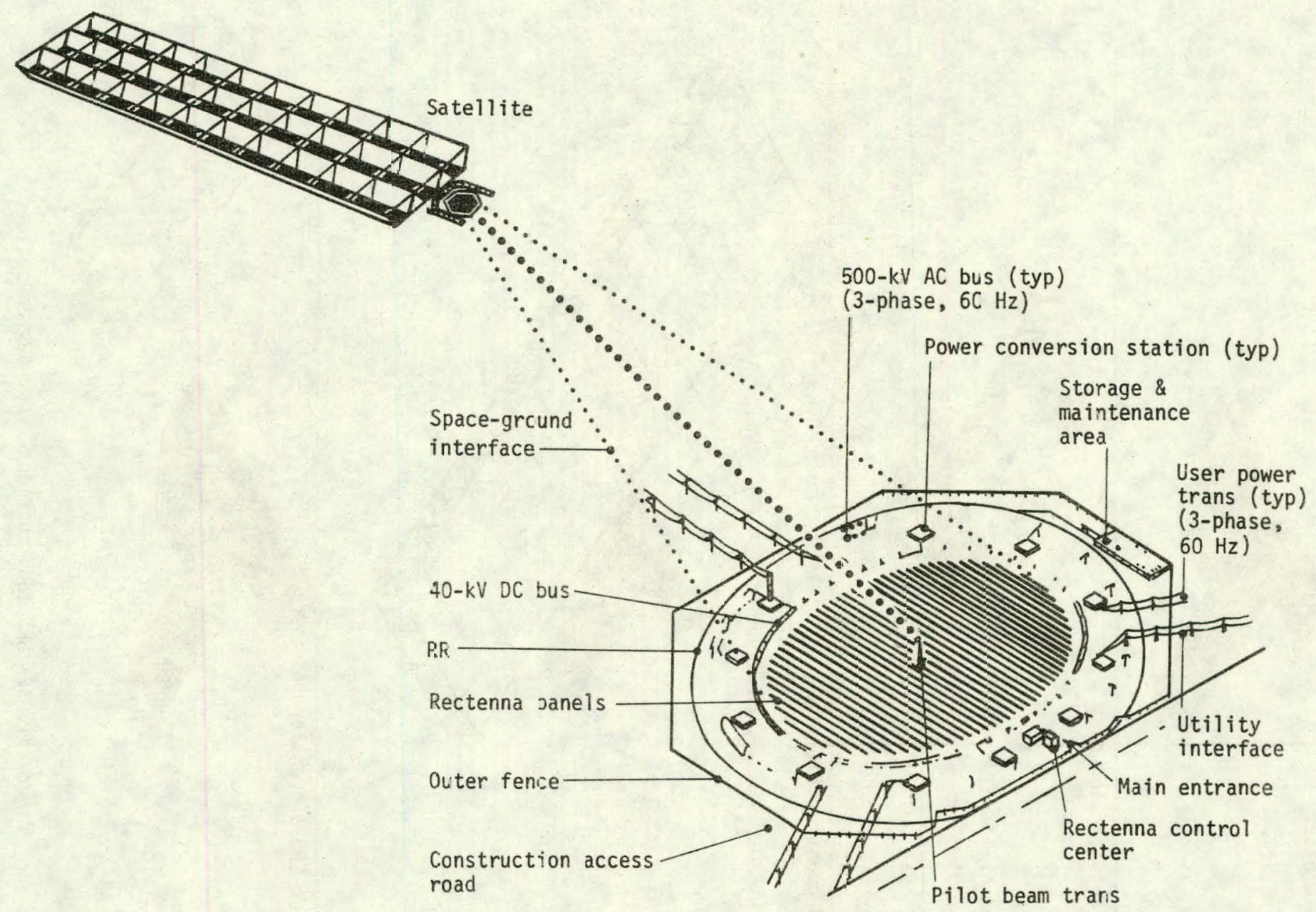

Not to scale (parel area 10 by $13 \mathrm{~km}$ )

Figure VII-4.- SPS system showing rectenna details. 


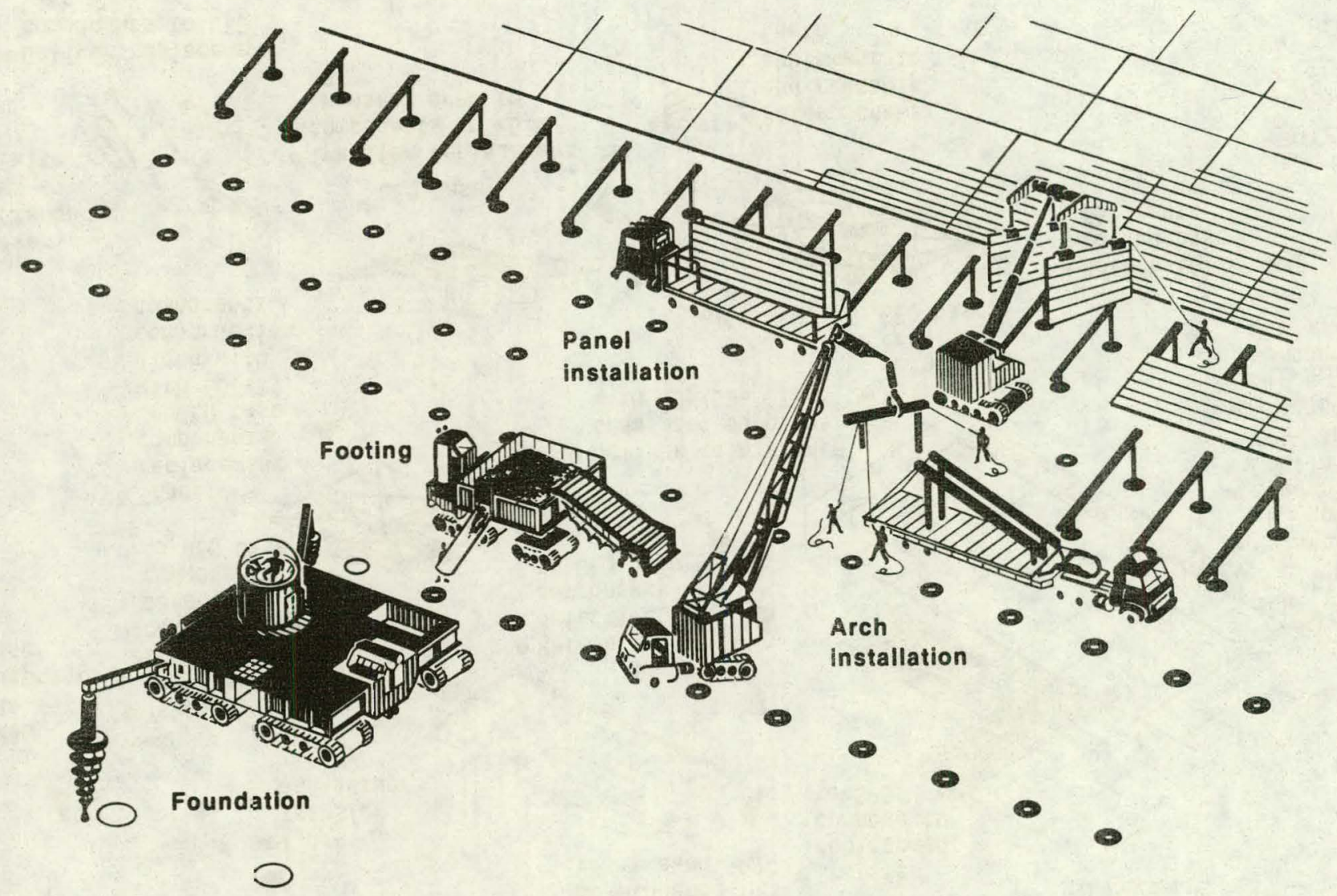

Figure VII-5.- Rectenna construction concept. 


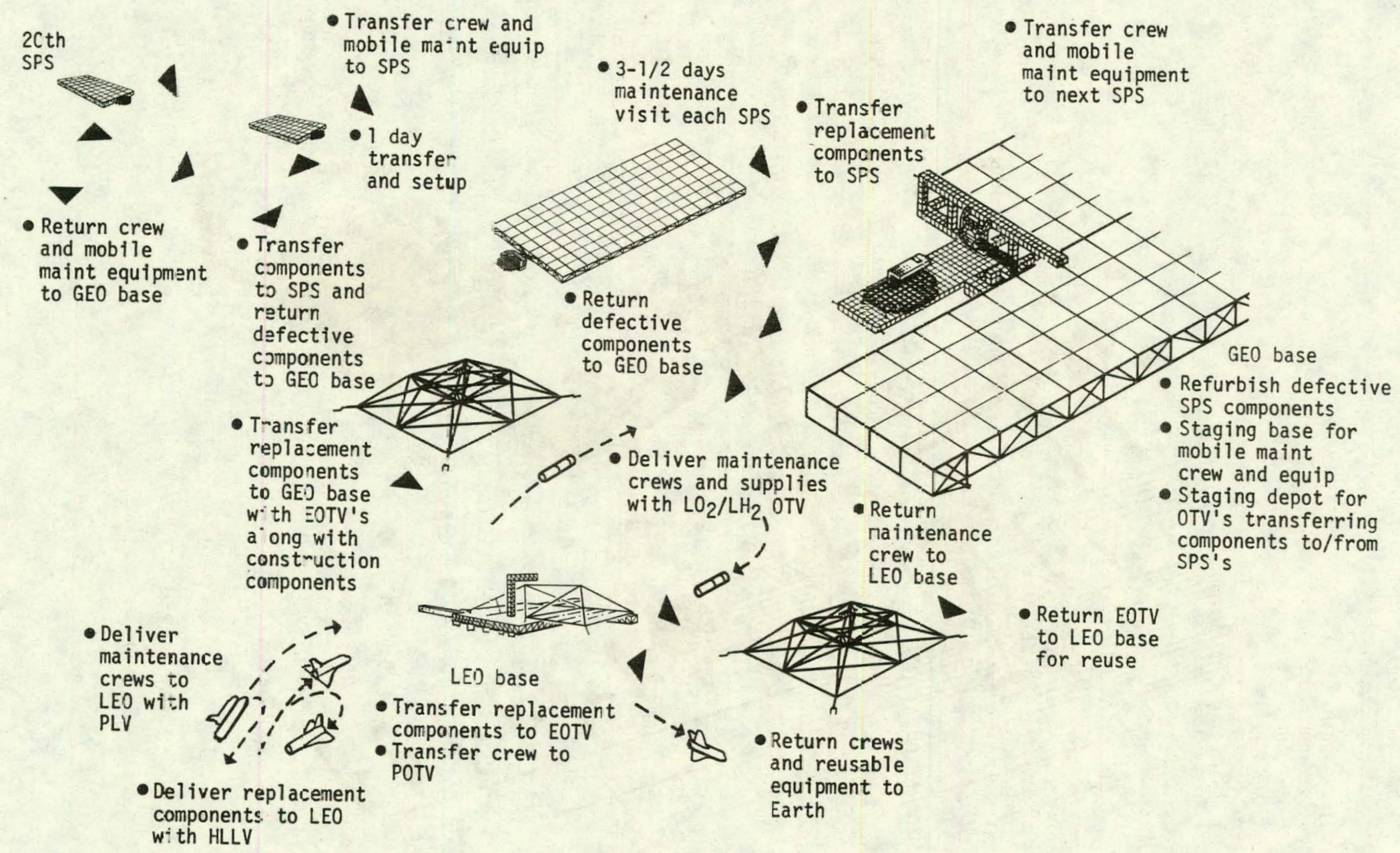

Figure VII-6.- Integrated maintenance mission concept. 


\section{SPACE TRANSPORTATION}

\section{A. Introduction and Surmary}

The SPS transportation system is required to transport building material, subassemblies, equipment, supplies, and personnel to geosynchronous Earth orbit (GEO). Performance and economic considerations dictate that the Earth to low-Earth-orbit (LEO) transportation be accomplished by launch vehicles designed for the appropriate flight rates and the loads associated with launch, atmospheric flight, reentry, and landing, whereas the LEO to GEO transportation vehicles (orbital transfer vehicles (OTV's)) must be designed for nonatmospheric loads and high-specific-impulse (possibly low thrust) propulsion. A single transportation vehicle design suitable for both flight regimes would be a difficult feat with present technology and would be, at best, a compromise design that would not be cost effective compared with separate vehicles.

The Earth to LEO transportation requirements can be met by heavy lift launch vehicles (HLLV's) of 100- to 450-M.T. payload class for general cargo and by personnel launch vehicles (PLV's) of a 100-M.T. class for personnel and priority cargo. The primary factor in the selection of an HLLV configuration was attaining an acceptably low cost per mass to LEO with conservative technology assumptions. For the reference system, a two-stage winged vehicle carrying a payload of 420 M.T. was used for the Earth to LEO cargo transportation. The PLV configuration chosen as reference is a Shuttle derivation employing a winged, returnable $\mathrm{LO}_{2} / \mathrm{CH}_{4}$ booster replacing the solid rocket boosters (SRB's) and carrying the passerigers in a personnel module mounted in the cargo bay.

The alternative concepts that had the largest impact on the options for orbital transfer vehicles were: (1) construction of the station in GEO, (2) construction of the station in LEO and transportation to GEO in modules for final assembly, and (3) construction of the station completely in LEO and transportation to GEO as a single unit. The reference system involved construction in GEO and used independently powered electric OTV's (EOTV's) for cargo transportation.

The transfer of personnel (and priority cargo) between LEO and GEO requires a high-thrust propulsion system to minimize the trip time and exposure to Van Allen radiation. A two-stage LOX/LH 2 space-based configuration was selected as the reference personnel orbit transfer vehicle (POTV). Subsequent analyses have indicated advantages for single-stage systems which refuel at both LEO and GEO.

In summary, it should be noted that $90 \%$ of the transportation cost per SPS is for cargo transportation and $10 \%$ for personnel transportation. Approximately $77 \%$ of the cargo transportation cost is for HLLV transportation to LEO and $23 \%$ for transportation from LEO to GEO. Of the $10 \%$ transportation cost devoted to personnel, $95 \%$ is required for transportation to LEO and only $5 \%$ from LEO to GEO.

\section{B. Heavy Lift Launch Vehicle}

The HLLV is required to transport all SPS freight, except crews and priority cargo, from the reference launch site (KSC) to LEO. Cargo hauling is the dominant transportation cost factor, requiring about $70 \%$ of the total recurring transportation expenditures. In consequence, a key figure of merit in the selection of the HLLV is the cost per pound of payload to orbit.

A number of HLLV configurations were synthesized and evaluated on the bas is of technology requirements, sensitivities, interfaces, and program impact. In general, no revolutionary advanced technology was assumed and propulsion and structural characteristics were predicated on evolved 1990-period technology with the exception of a more advanced single stage to orbit system. The concepts investigated include:

1. Two-stage ballistic series-burn

2. Two-stage winged series-burn vertical-take-off

3. Two-stage winged parallel-burn vertical-take-off

4. Single-stage winged horizontal-take-off (advanced technology). 
The two-stage ballistic vehicle (fig. VIII-1) employs water landing for both stages. The first stage is recovered downrange; the second stage; near the launch site. The first stage has 16 $\mathrm{LO}_{2} / \mathrm{RP}-1$ engines for launch and 6 Space Shuttle main engines (SSME's) for landing. The second stage has eight SSME's. This configuration, with a payload of 391 M.T., represents the most conservative technology with the primary technical problems centering on the water recovery of reusable stages (ref. 12e).

The two-stage winged series-burn vehicle (fig. VIII-2) enables a horizontal-landing recovery for both stages near the launch site. The first stage has $16 \mathrm{LO}_{2} / \mathrm{LCH}_{4}$ engines for launch and 12 airbreathing turbojets for return to the launch site. The second stage (Orbiter) has 14 standard SSME's for ascent propulsion and 4 advanced space engines (ASE's) for orbital maneuvering. It is recovered in a manner similar to the STS Orbiter. This configuration, which has a gross payload capability of 424 M.T., was selected as the reference because of the operational advantages of launchsite recovery and relatively conservative technology requirements (refs. 10 and $16 \mathrm{~b}$ ).

A subsequent analys is and concept definition was conducted to evaluate a smaller (100-M.T. class) two-stage winged series-burn HLLV. This configuration employed six $\mathrm{LO}_{2} / \mathrm{LCH}_{4}$ engines and four airbreathing engines for flyback. The Orbiter employed six. SSME's. This smaller HLLV offered a smaller nonrecurring cost with a slightly higher rccurring cosl dild a reduction in noise and sonic overpressure, but with an increase in effluents deposited in the upper atmosphere. In figure VIII-3, this concept is compared with the Saturn and the large HIIV described proviously (rêf. 17).

Tlié lwu-slage wingéd parallel-burn vehicle (fig. VIII-4) concept differs from those previously described in its parallel-stage configuration, which has the advantage of a lower stack height and the use of second-stage (Orbiter) engines during inftial ascent. The first stage has seven Lox/RP engines for ascent and eight turbojets for recovery. The second stage has four $\mathrm{LO}_{2} / \mathrm{LH}_{2}$ engines and is recovered in the same manner as the STS Orbiter. The payload capability is 227. M.T., and the gross lift-off weight. (GLOW) is 7150 M.T. (A smaller, 114-M.T. payload version was also evaluated.) These configurations are competitive with the reference series-burn concepts and must be considered as a possible selection following more detailed trade studies (ref. 2lc).

The single-stage winged horizontal-take-off configuration (fig. VIII-5) represents the most advanced technology of those studied. The concept employs 10 high-bypass, supersonic-turbofan/airturboexchanger/ramjet engines for atmospheric flight and three SSME-type engines for ascent. The payload is 91 M.T., and the GLOW is approximately 2000 M.T. This configuration enables the change from a KSC launch inclination to an equatorial LEO through an atmospheric flight regime, and the single stage offers additional operational advantages. The advanced engine requirements, however, make this the least conservative option for projected 1990's technology (ref. 20e).

\section{Orbital'Transfer Vehicle Concepts} The total cost of delivery of an SPS to GEO is strongly influenced by the cost of delivery
of the OTV and its propellant to LEO. To minimize the mass of material transported to LEO, high-I sp (low propellant consumption) thrusters are required. Advanced vehicles employing these thrusters will require significant advancement over the current state of the art. Studies to date have given some preliminary comparisons of OTV's which could be available at the time of construction of the SPS (refs. 12c, 12e, $16 \mathrm{~b}, 20 \mathrm{e}$, and $21 \mathrm{c}$ ).

Three types of OTV propulsion systems were considered. Chemical propulsion was considered for the GEO construction option, in which the payload consists primarily of unassembled hardware that permits higher accelerations than an assembled or partly assembled SPS. The relatively low Isp of $\mathrm{LO}_{2} / \mathrm{LH}_{2}$ propulsion options and the corresponding increase in the mass of propellant to be transported to LEO by the HLLV penalized this system heavily with respect to self-powered electric propulsion options (ref. 12e).

A preliminary analysis was devnted to a nuclear gas-core propulsion system. Although this system ofters an $I_{S p}$ of between 1000 and 5000 seconds, its advanced technology and high development costs make it also less desirable than the electric propulsion options. 
For electric propulsion, two major configurations, two different power collection systems, and three types of thrusters were considered. The configuration concepts were:

1. LEO construction with self power to GEO

2. GEO construction with delivery by an independently powered orbital transfer vehicle

The configuration concepts are related to the construction location. Construction in LEO enables use of the SPS solar arrays, or sections of them, to provide power for an electric propulsion system (ref. 12e). Construction in GEO precludes the use of SPS arrays and requires a self-powered 0TV. It was determined that transportation costs were nearly the same for both self-powered and independently powered systems (ref. 15b). The advantage of the self-powered system in using a "payload" power supply was counteracted by its large distributed mass and high moments of inertia, which magnified the attitude control problem. The independently powered EOTV transports the payload in a concentrated mass which reduces the control problem.

The power collection systems considered were silicon and gallium arsenide solar cells to correspond with the choice of SPS cell. The gallium arsenide configuration employed concentrators to reduce the area of solar cells required. The increased temperature, because of concentration, provides annealing of nearly all radiation damage to the solar.cells. In the silicon configuration, loss in power output due to temperature rise indicated that concentrators should not be used. Annealing for power recovery at GEO using lasers is considered one option for extending the useful lifetime of the silicon-array-powered OTV. To save weight, power is supplied to the thrusters in both systems by direct drive; i.e., power conditioning equipment for the various voltages required by the thrusters is not used.

For the main propulsion thrusters, three types of engines were considered applicable: resistojets, magnetoplasmadynamic (MPD), and ion bombardment. The selection of a thruster depends on engine lifetime and the optimization of $I_{s p}$ compared to total EOTV mass. This latter consideration in turn depends on attitude control thrust level requirements in the low-altitude portion of the flight. The resistojet has low $I_{\text {Sp }}$ ( 1200 seconds) and, therefore, offers insufficient propellant mass savings compared to chemical propulsion. The Isp of MPD thrusters is currently est imated to be between 2000 and 2500 seconds. It is estimated that development could increase $I_{s p}$ to around 4000 seconds.

The favored candidate is the ion bombardment engine, which can have an $\mathrm{I}_{\mathrm{Sp}}$ of from 5000 to 13,000 seconds. These thrusters have been used in space using mercury and cesium propellants, and ground tests have shown that argon and xenon are also suitable. Since metals could have serious environmental impacts, and xenon is sufficiently scarce to preclude its use, argon was used in the reference system. Characteristics for a 120-cm argon thruster are shown in figure VIII-6.

The silicon cell reference EOTV is shown in figure VIII-7, and the gallium arsenide cell reference EOTV is shown in figure VIII-8. Table VIII-1 lists parameters for these systems along with chemical and nuclear systems data.

\section{Personnel Launch Vehicle}

The PLV provides transportation for personnel and priority cargo between Earth and low Earth orb1t. The reference system employed the Shutt.le Orbiter as the basic element with a self-contained personnel module (PM) carried in the cargo bay.

Several approaches to uprating the Shuttle were investigated, each involving the replacement of the SRB's with a recoverable liquid stage (or stages). The reference system (fig. VIII-9) uses a winged, horizontal-landing booster employing four $\mathrm{LO}_{2} / \mathrm{CH}_{4}$ engines. This booster provides an evolutionary path to the reference HLLV (refs. 10 and 16b).

The alternative concept replaces each SRB with a $\mathrm{LO}_{2} / \mathrm{LH}_{2}$ booster, each using four SSME's (fig. VIII-10) (ref. 21c). 


\section{E. Personnel Orbit Transfer Vehicle}

The function of the POTV is to transport personnel and priority cargo between LEO and GEO. The need to limit crew exposure to Van Allen radiation and other obvious considerations preclude transferring crews on EOTV's with low-thrust engines and long trip times. Therefore, $\mathrm{LOX}_{\mathrm{L}} \mathrm{LH}_{2}$-fueled vehicles, which can make the trip in less than 6 hours, were studied for the crew rotation function.

The reference POTV configuration is a space-based common-stage OTV with both stages having the same propellant capacity (fig. VIII-11). The first stage provides approximately two-thirds of the delta-velocity $(\Delta V)$ requirement for boost out of low Earth orbit. It is then separated for return to the LEO staging depot. The second stage completes the boost from low Earth orbit as well as the remainder of the other $\Delta V$ requirements to place the payload at GEO and also provides the required $\Delta V$ to return the stage to the LEO staging depot. Subsystems for each stage are identical in design approach. The primary difference is the use of four engines in the first stage because of thrust-to-weight requirements. Also, the second stage requires additional auxiliary propulsion because of its maneuvering requirements including docking of the payload to the construction base at GEO. The vehicle delivers a payload of $150,000 \mathrm{~kg}$ and returns $55,000 \mathrm{~kg}$. The stage start-burn mass without payload is approximately $890,000 \mathrm{~kg}$ with the vehicle having an overall length of $56 \mathrm{~m}$ (ref. 10).

Several other propulsion configurations were analyzed, including single-stage and stageand-a-half cuncepts. Single-stage configurations which refuel at LEO and GEO recelved extensive analys is subsequent to the reference system. This conn.ept requirac a much amaller prupulstun system because of llie reduced propellant requirements per flight and allows the GEO to LEO propellant to be transported to GEO by the more efficient EOTV (refs. 16h and 21c). Figure VIII-12 sliuws une potential single=staye cunfiguration. Several POTV personnel modules have been considered which vary from the reference system with a capability of up to 160 personnel to a 60 -man STS-compatible module considered for the single-stage POTV.

\section{F. Ground and Flight Operations}

The reference launch and recovery site for the SPS transportation systems is the John $F$. Kennedy Space Center (KSC). Preliminary studies have suggested that HLLV and PLV launch rates sufficient for the installation of two 5-GW SPS's per year can be accommodated, although space limitations as well as environmental concerns are critical factors.

A preliminary survey of western U.S. launch sites was conducted. These sites would permit KSC to service projected STS traffic without the added pressure of SPS transportation and would alleviate such environmental concerns as the sonic shocks accompanying stage recovery.

A preliminary design study was performed for an offshore launch and recovery facility using current offshore platform technology. In addition to relieving the environmental restrictions of populated areas, this offshore facility would give the performance and operational benefits of a nearequatorial launch (ref. 16d).

\section{G. Technology Summary}

The primary technology advances required for the SPS space transportation system are for HLLV and EOTV development. The PLV requirements for advanced technology are shared with the HLLV. The POTV requires no developmental advances, although space basing and orbital propellant loading entail new operational and technical requirements.

Technology advances offering special advantages to the HLLV (and PLV) are:

1. Propulsion system and fuels - The development of a reliable, easily maintained main propulsion system using hydrocarbon propellant is a primary requirement.

2. Insulation - An efficient, fully reusable liquid-hydrogen tank insulation requires investigation.

3. Therma 1 protection system - Improved, lightweight, reusab le thermal protection systems for reusable vehicles must be developed. 
Key technology issues pertaining to the EOTV are:

1. Technology for scaling ion thrusters from $30 \mathrm{~cm}$ to $100 \mathrm{~cm}$ and larger
a. Grid stability
b. Multiple-cathode design

2. Replacement of mercury by argon as propellant

3. Ionospheric effects of argon

4. Systems design trade data to select:
a. Thruster life
b. Power
c. Thrust
d. Isp

General technology needs identified for the EOTV include:

1. Capability for comprehensive analyses of complex, extremely large structures under gravity-gradient loads, nonconstant applied forces, and thermal transients

2. Selection of structural materials for thermal, vacuum, and radiation environment of LEOGEO flight; measurement of required properties for design

3. Annealing of radiation damage in solar cells

4. Highly reliable, redundant attitude control system which guarantees stability during occultation of the Sun

5. Autonomous navigation, guidance, and control system

6. Means to insure against reentry from low Earth orbit

H. Workshop Summary

An SPS Space Transportation Workshop was held January 29-31, 1980, at Huntsville, Alabama. A summary of the observations and conclusions reflecting a consensus of this workshop follows.

A considerable number of concepts have been studied for enhancing the capabilities of the current Shuttle transportation system so that its role can be extended in the early SPS demonstrations and other flight operations. Beyond the growth and derivative versions of the present Shuttle concept lie the possibilities for relatively low cost transportatiun fruin [arth to LEO.

First steps in enhancing the Shuttle will probably include the Titan-based liquid boost module (LBM) and liquid-propellant boosters (LPB's) to replace the present solid rocket boosters. The next choice between new ballistic or winged boosters must still be made as well as the choice between series (staged) and parallel operation.

Entirely new, large vehicles will be required before the economic and environmental problems of the prototype, or even demonstration, SPS can be resolved. The need for single stage to low Earth orbit (SSTO) vehicles using either vertical or horizontal take-off and/or landing remains to be determined by future analyses or the course of events. In any event, considerable analysis, research, and technology will be required before the choice can be properly made. Social impacts such as noise and atmospheric pollution, locally and in the ionosphere, will need to be fully resolved. 
The Earth to LEO operational requirements and costs dominate the SPS space transportation scene. Launch-vehicle technology must be driven to a rather sophisticated extent to meet the needs as currently perceived, and this perception is immature at the present time. The workshop decided that although rather advanced technology and well-developed operational management would be required to properly target the average cost (based on 1979 dollars) of gross cargo payloads into LE0 at $\$ 30 / \mathrm{kg}$ for construction of the reference SPS, a further goal for repetitive construction of SPS's at $\$ 15 / \mathrm{kg}$ would require the use of very advanced, long-lived vehicles with a sophisticated operational organization using offshore, equatorial launch sites, etc.

The various orbit-to-orbit missions in support of the SPS demonstration, construction, and operation need to be better defined before the vehicle concepts can be identified. Chemical OTV's need further analysis and technology work and a reasonably early start on development to provide a capability that is needed in the present STS. Orbit-to-orbit, including intraorbit, requirements of the 1980's should be coordinated with SPS requirements for chemical rocket 0TV's in the 1990's and beyond. In-orbit propellant processing needs to be fully assessed.

Much work is needed on the definition of and research and technology work for electric rocket propulsion systems. Mission analyses including optimized high-and low-thrust acceleration trajectories are necded that serve llie SPS requirements. High-power ion thrusters and MPD thrusters need urgent development attention to ascertain their characteristics. Much better coordination is needed between the electric rocket propulsion system technology planning and support and the overall NASA need for this kind of propulsion for applications imluding the SPS.

More advanced propulsion systems such as dual-mode sol1d-core nuclear fission systems, gascore nuclear rocket stages, and mass-driver reaction engines (MDRE's) need sustained attention. Orbit-to-orbit propulsion using high-power lasers should also be given attention.

The present Ground-Based Exploratory Development (GBED) Program in space transportation for SPS is entirely inadequate. Its primary aim should be to strengthen the present concepts, but, at the same time and just as importantly, care should be taken not to exclude any promising concepts or technologies. If the GBED is intended to be the next phase for SPS, it should be reconceived from the ground up with an order-of-magnitude increase in funding.

A greatly increased program of SPS space transportation analysis, research, and technology is clearly needed. Efforts must be devoted to areas of system analys is and technology readiness (including ground and space testing) that will reduce space transportation cost uncertainties in the next 5 to 10 years.

Aithough the consensus of the workshop supported the future prospects of the SPS, it was generally believed that much work is needed before space transportation choices could be made.

\section{Conclusions and Remaining Issues}

The conclusions of the studies and reviews concerning the SPS transportation system may be summarized as follows.

1. The selection of particular concepts and design requirements for SPS transportation system elements requires additional technology and systems analysis studies. However, no technical impasse areas (i.e., areas lacking technical or operational alternatives) have been identified.

2. The major contributor to total SPS transportation cost is cargo delivery from Earth to LEO. The HLLV accounts for approximately $60 \%$ of the transportation cost per sat.pllite.

3. Heavy lift launch vehicle design considerations establish hydrocnrhnn fuel ds the design clucice for first-stage propellant because of its greater energy density, and hydrogen as the second-stage propellant because of its higher specific impulse and corresponding lower propellant weight.

4. Both winged and ballistic SSTO HLLV's require a more advanced technology than the ir two-stage counterparts. 
5. Ballistic HLLV systems are smaller and require less development funding than winged vehicles. Winged vehicles reduce operating costs through better recovery and reusability characteristics. Launch-rate requirements will influence the choice of ballistic or winged configurations. Winged HLLV's also offer the opportunity for personnel transfer and thus eliminate the need for the separate PLV.

6. A KSC launch site can support an SPS program goal of approximately $10 \mathrm{GW}$ per year based on launch-pad separation distance and turnaround considerations.

7. Launch sites near the Equator greatly expand the launch windows and offer performance advantages by reducing plane-change requirements for the OTV's. This advantage is not significant for high-specific-impulse electrical OTV's but is for chemical OTV concepts. other conclusions regarding equatorial launch sites are:

a. Terrestrial transportation costs are modest but not negligible.

b. Loss of revenues due to time in transit may be the cost driver for sea freight.

c. Short-range air freight may be cheaper overall than long-range sea freight.

d. Freight mode faster than sea but cheaper than air should be used if available (hovercraft, hydrofoil, dirigible).

.e. Terrestrial transportation costs and delays may be offset by reduction in EOTV costs and delays.

8. Current offshore platform technology makes it economically feasible to construct launch and landing recovery facilities for winged two-stage launch vehicles in equatorial waters as deep as $180 \mathrm{~m}(600 \mathrm{ft})$ (ref. 16d).

9. HLLV ascent and entry sonic overpressures and noise effects do not preclude the use of KSC as the HLLV launch site. The peak sonic overpressures of $1197 \mathrm{~N} / \mathrm{m}^{2}$ (25 psf) during ascent are primarily due to the plume effect and will occur over water about $55 \mathrm{~km}$ (30 n. mi.) downrange from the launch site. Winged vehicle concepts are expected to produce a peak overpressure of 144 to $191 \mathrm{~N} / \mathrm{m}^{2}$ ( 3 to $4 \mathrm{psf}$ ) during reentry. However, with trajectory selection, the maximum overpressure experienced over inhabited areas can be limited to $95.8 \mathrm{~N} / \mathrm{m}^{2}(2.0 \mathrm{psf})$, similar to STS characteristics.

10. The direct injection of HLLV exhaust products may be kept below the ionosphere by using a depressed trajectory with an insertion altitude of $75 \mathrm{~km}$ and a payload penalty of approximately $10 \%$. The exhaust products of the first stage, which burns a hydrocarbon (assumed methane) with oxygen, are $\mathrm{H}_{2} \mathrm{O}, \mathrm{H}_{2}, \mathrm{CO}_{2}$, and $\mathrm{CO}$. The second-stage exhaust products are $\mathrm{H}_{2} \mathrm{O}$ and $\mathrm{H}_{2}$.

11. The SPS HLLV's studied most extensively have generally had payload capabilities of 400 to 500 M.T. Smaller vehicles reduce DDT\&E at the expense of recurring costs and introduce constraints into SPS design. The technical challenge of larger vehicles is greater, especially for winged configurat luils.

12. The primary technology requirement for Earth to LEO transportation is the development of a reliable, safe, easily maintained main propulsion system using hydrocarbon booster engines. Typical preliminary tasks include the analys is and test of engine design improvements and obtaining propellant design data through combustion and heat-transfer tests. Other HLLV technology requirements are the development of fully reusable $\mathrm{LH}_{2}$ tank insulation and improved thermal protection system.

13. The delivery of cargo from LEO to GEO may be accomplished by conventional chemical $\left(\mathrm{LOX} / \mathrm{LH}_{2}\right)$ systems or by solar-powered electric propulsion systems.

14. Key concerns with EOTV systems are the sensitivity of solar arrays and structures to Van Allen radiation and the resulting impact on performance and operational life. 
15. The long trip times of EOTV's ( 150 to 210 days from LEO to GEO) preclude their use for personnel transport; : special personnel OTV's must be used to limit radiation exposure.

16. In-space fueling, refurbishment, and maintenance is required for the space-based OTV's. 
TABLE VIII-1.- PARAMETER COMPARISON FOR PRINCIPAL LEO/GEO TRANSPORT SYSTEMS

\begin{tabular}{|c|c|c|c|c|}
\hline \multirow[t]{3}{*}{ Parameter } & \multicolumn{4}{|c|}{ System } \\
\hline & \multirow[t]{2}{*}{ LOX/LH 2 OTV } & \multirow[t]{2}{*}{ Nuclear 0TVa } & \multicolumn{2}{|c|}{ Electric OTV } \\
\hline & & & Gallium. & Silicon \\
\hline Payload, M.T. $\quad \cdots \cdot \cdots \cdot$ & 400 & 400 & 5171 & 4000 \\
\hline 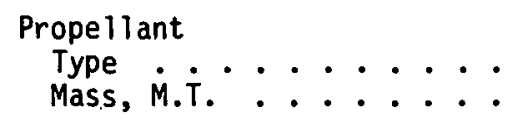 & $\begin{array}{r}\mathrm{LH}_{2} \\
800\end{array}$ & $\begin{array}{r}\mathrm{H}_{2} \\
124\end{array}$ & $\begin{array}{r}\mathrm{Ar} \\
666\end{array}$ & $\begin{array}{r}\mathrm{Ar} \\
515\end{array}$ \\
\hline Start-burn mass, M.T. . . & 890 & 606 & 6928 & 5977 \\
\hline $\mathrm{I}_{\mathrm{sp}}, \mathrm{sec} \ldots \ldots$ & 500 & 1000 to 5000 & 8000 & 8000 \\
\hline 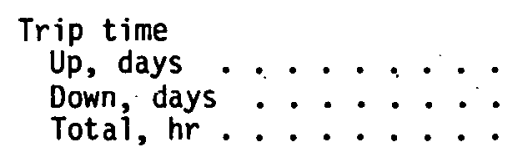 & $\ddot{\overline{11}}$ & $\overline{--}$ & $\begin{array}{r}120 \\
30 \\
--\end{array}$ & $\begin{array}{r}180 \\
40 \\
--\end{array}$ \\
\hline
\end{tabular}

aNuclear gas-core reactor. 


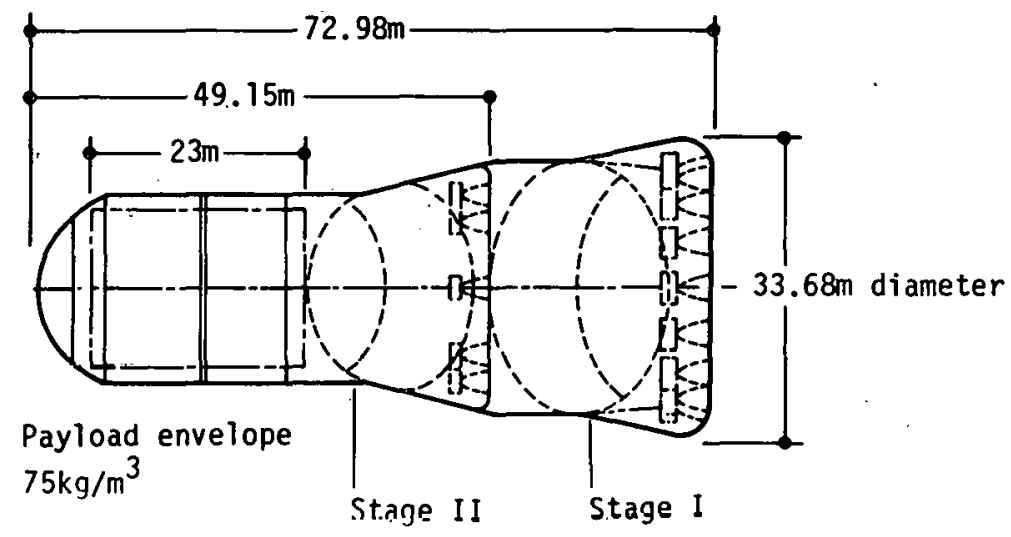

Figure VIIJ-1.- Two-etage balliatic sei ies-burn HLLV.
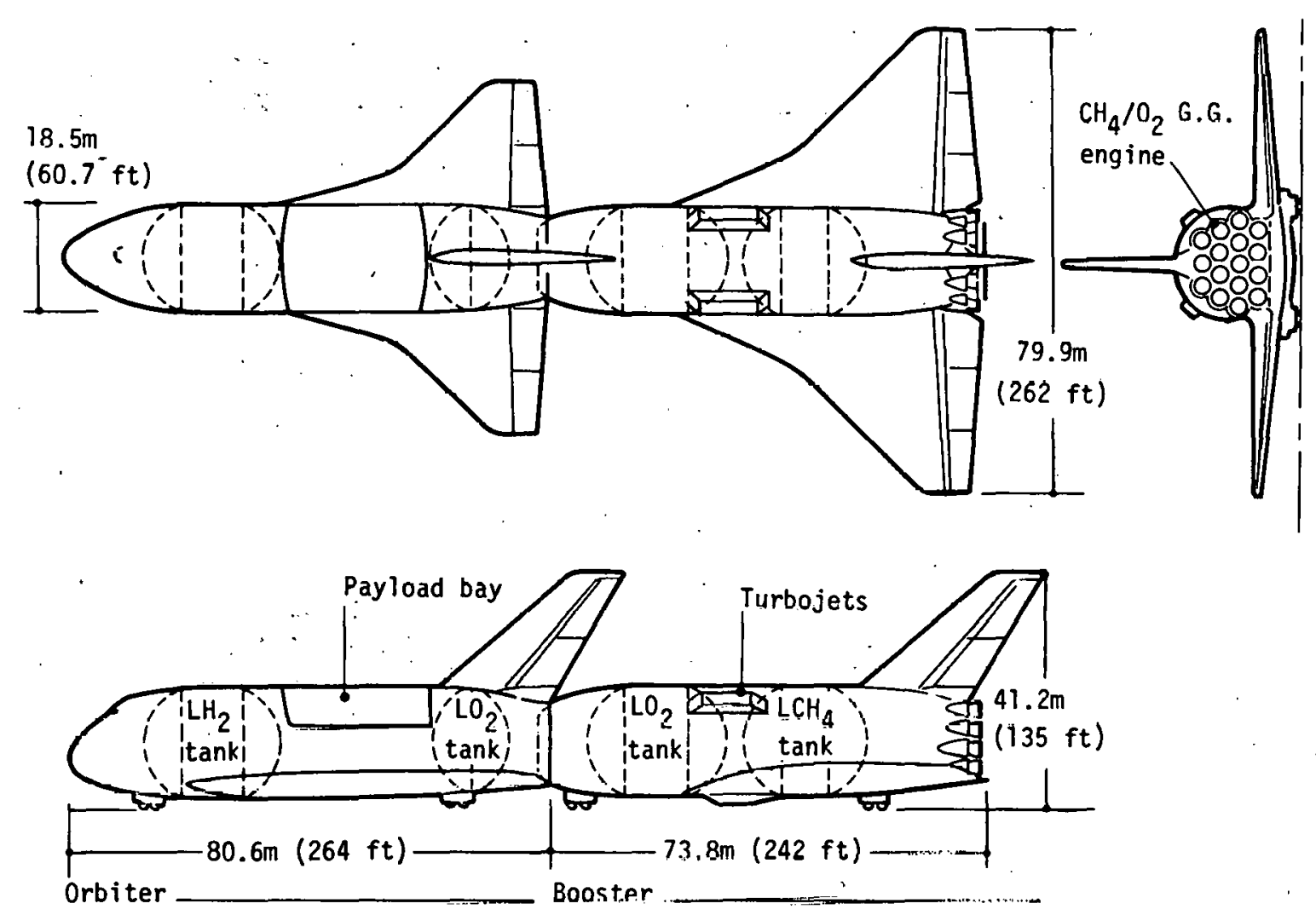

Figure VIII-2.- Two-stage winged series-burn HLLV. 


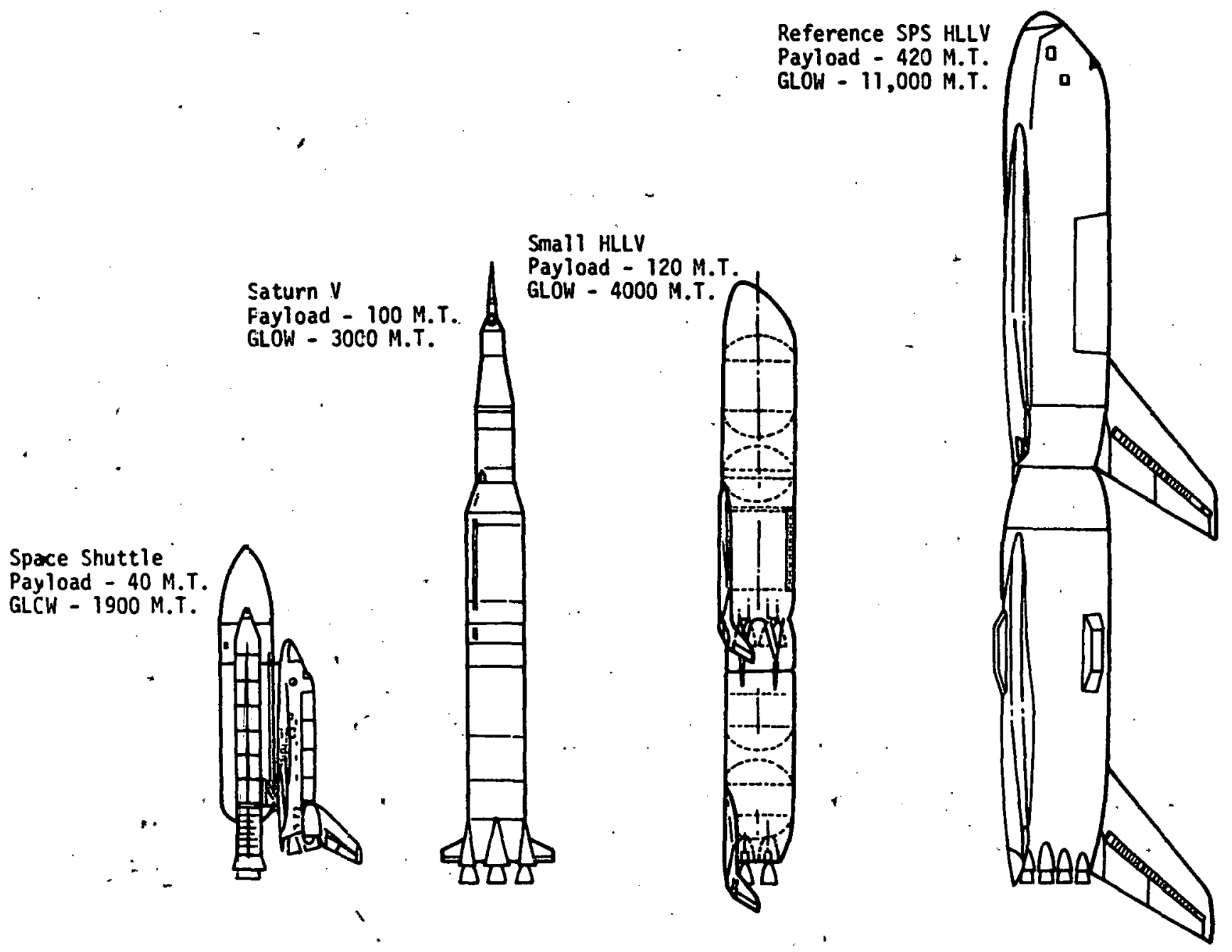

Figure VIII-3.- Small-HLLV comparison with other launch vehicles. 


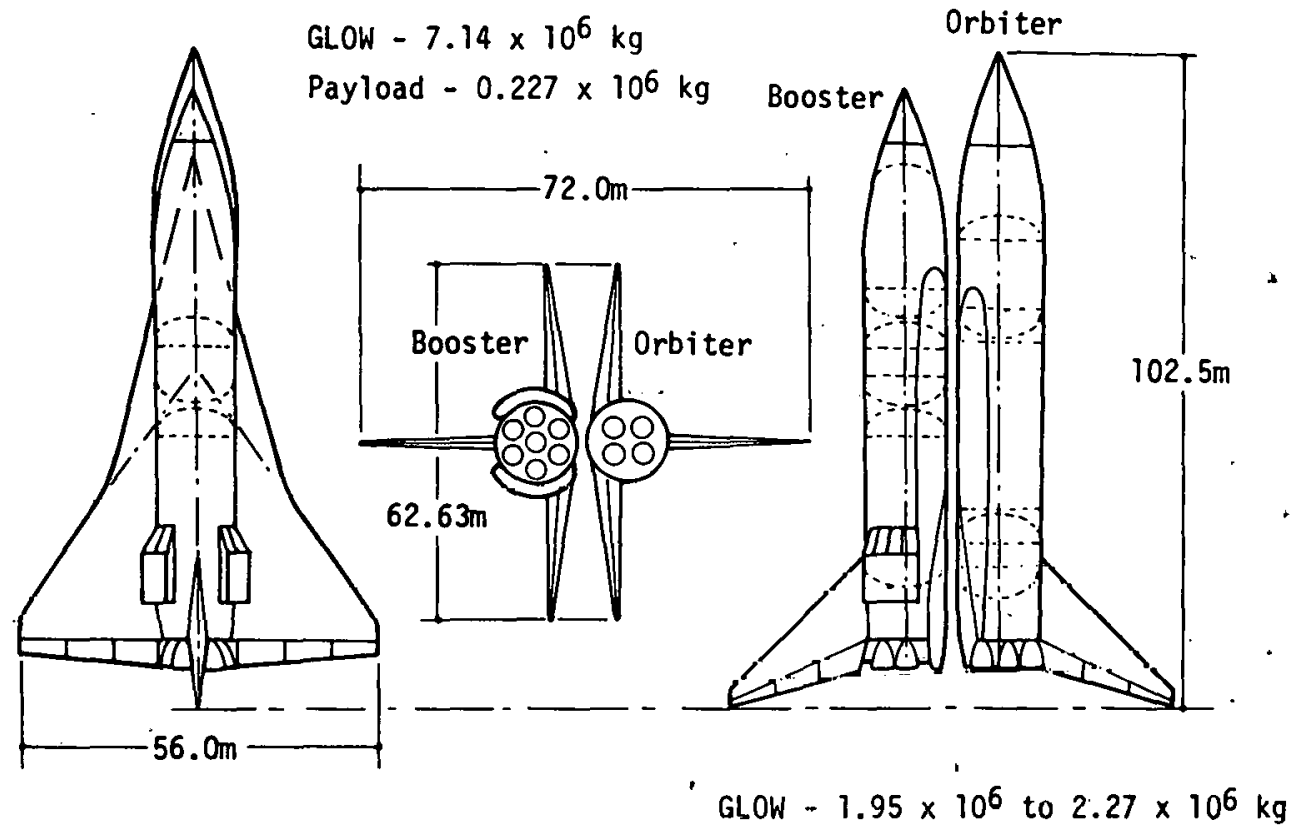

$\left(4.3 \times 10^{6}\right.$ to $\left.5.0 \times 10^{6} \mathrm{lb}\right)$

Airport runway take-off

Parachute-recovered launch gear

Figure VIII-4.- Two-stage winged parallel-burn HLLV.

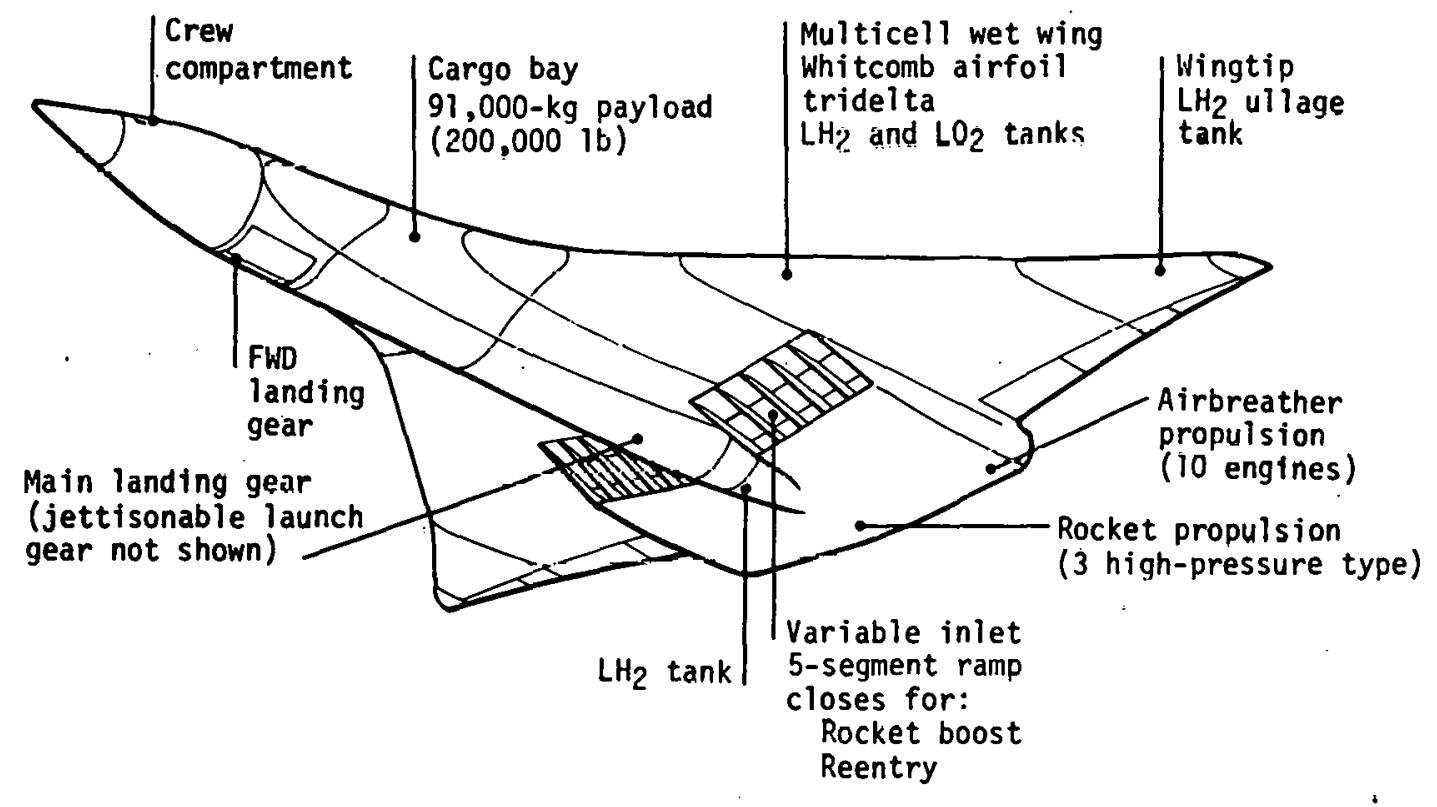

Figure VIII-5.- Single-stage winged horizontal-take-off HLLV. 
Fixed characteristics

\section{Beam current:}

Accel. voltage:

Discharge voltage:

Coupling voltage:

Db1. ion rates:

Neutral efflux:

Divergence:

Discharge loss:

other loss:

Utilization:

Life:

Weight:

Selected characteristics

Screen (beam) voltage:

Input power:

Thrust:

Efficiency:
$80.0 \mathrm{~A}$

$500.0 \mathrm{~V}$

$30.0 \mathrm{~V}$ (f1oating)

$11.0 \mathrm{~V}$

$0.16(\mathrm{~J} 2 / \mathrm{J1})$

4.8384 A equiv.

0.98

$187.3 \mathrm{eV} /$ ion

$1758.0 \mathrm{~W}$

$0.892 \mathrm{~W}$

$8000 \mathrm{hr}$

50. kg

$1700 \mathrm{~V}$

$130 \mathrm{~kW}$

$2.9 \mathrm{~N}$

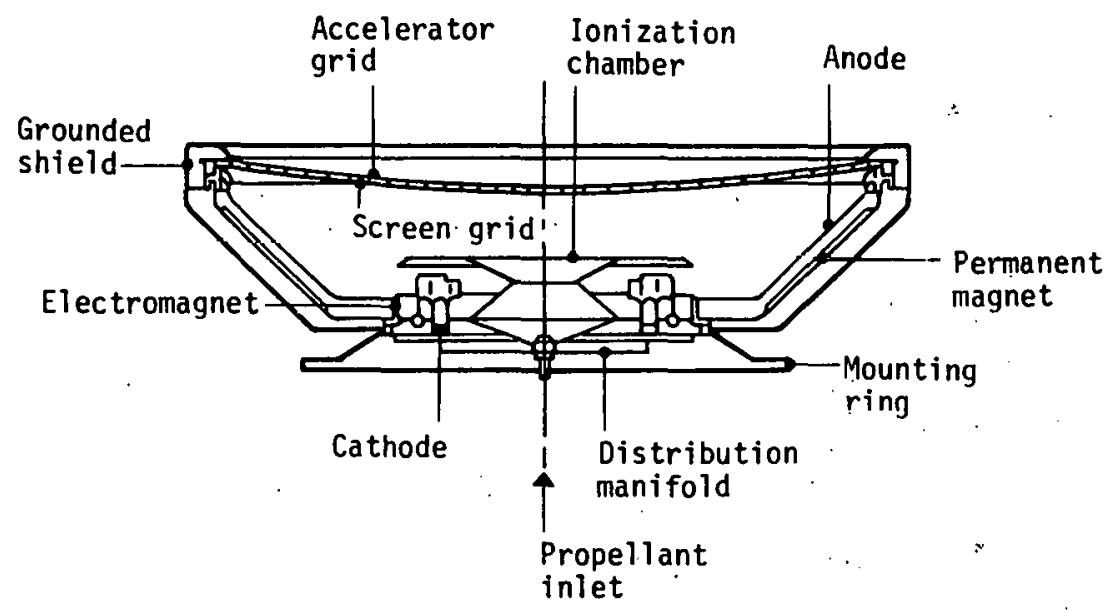

Figure VIII-6.- $120-\mathrm{cm}$ argon ion thruster characteristics. 


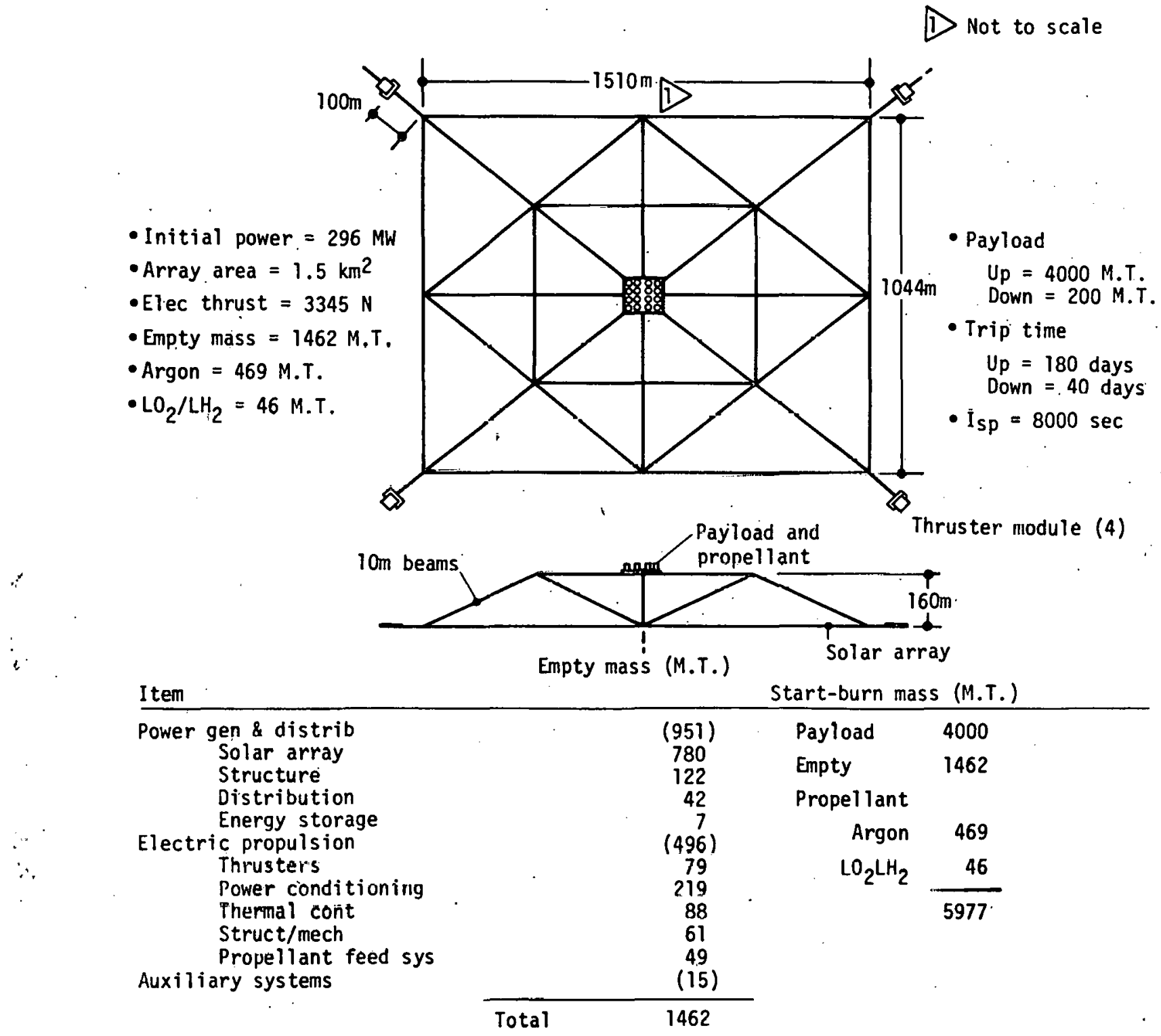

Figure VIII-7.- Silicon solar cell electric OTV. 


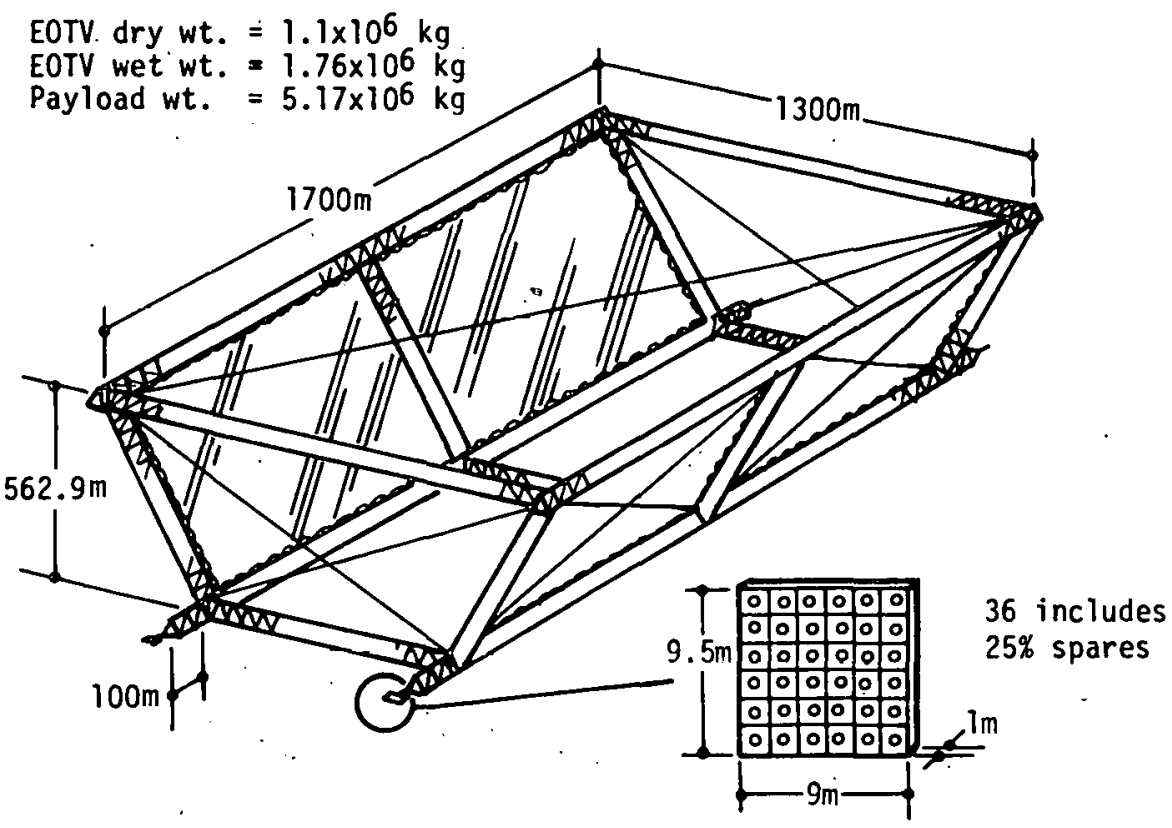

\begin{tabular}{lrr}
\hline EOTV weight/performance summary (kg) & \\
Solar array & & \\
Cells/structure & 299,756 & \\
$\quad$ Power conditioning & 288,440 & \\
Thruster array (4) & 10,979 & 96,685 \\
$\quad$ Thrusters/structure & 4,607 & \\
$\quad$ Conductors & 2,256 & \\
$\quad$ Beams/gimbals & 78,843 & \\
Propel lant tanks & 184,882 & 186,872 \\
Attitude control system & 274 & \\
$\quad$ Power supply & 1,716 & \\
System components & & 871,753 \\
Propellant tanks & & 217,938 \\
EOTV inert weight & & $1,089,691$ \\
25\% growth & 666,660 \\
Total inert weight & 655,219 & \\
Propellant weight & 11,441 & \\
Transfer propellant & & $1,756,351$ \\
ACS propellant & & $5,171,318$ \\
EOTV loaded weight & & $6,927,669$ \\
Payload weight & 4.72 \\
LCO departure weight & & \\
Propellant cost delivered (\$/kg P/L) & &
\end{tabular}

EOTV Thruster characteristics

- Maximum operating temperature - $1900 \mathrm{~K}$

- Total voltage - $8300 \mathrm{~V}$

- Grid voltage - $2000 \mathrm{~V}$ maximum.

- Beam current - 1887 A

- Specific impulse - $8213 \mathrm{sec}$

- Thruster diameter $-76 \mathrm{~cm}$

- Thrust/thruster - $69.7 \mathrm{~N}$

- Number of thrusters - 144 (includes 25\% spares)

- Maximum of 64 thrusters operable simultaneously

Figure VIII-8.- Gallium arsenide solar cell EOTV. 


\begin{tabular}{|c|c|c|c|c|c|c|c|}
\hline \multirow{2}{*}{$\begin{array}{l}\text { GLOW } \\
\text { BLOW }\end{array}$} & \multicolumn{7}{|l|}{$2,714,750 \mathrm{~kg}$} \\
\hline & $1,959,140 \mathrm{~kg}$ & Stage & $E$ & No. & Type & $I_{s p}(S L / v a c)$ & Thrust (vac) \\
\hline \multirow{2}{*}{$\begin{array}{c}W_{P_{1}} \\
\text { OLOW (ET) } \\
W_{P_{2}}\end{array}$} & \multirow[b]{2}{*}{$\begin{array}{l}666,880 \mathrm{~kg} \\
551,720 \mathrm{~kg}\end{array}$} & 1 & 60 & 4 & $\mathrm{High}-\mathrm{P}_{\mathrm{C}} \mathrm{LO}_{2} / \mathrm{LCH}_{4}$ & $318.5 / 352$ & $\begin{array}{l}2.15 \times 10^{6} \mathrm{lbf} \\
9.564 \times 10^{6} \mathrm{~N}\end{array}$ \\
\hline & & 2 & 77.5 & 3 & SSME & $363.2 / 455.2$ & $\begin{array}{l}0.470 \times 10^{6} \mathrm{lbf} \\
2.091 \times 10^{6} \mathrm{~N}\end{array}$ \\
\hline
\end{tabular}

Payload $\quad 88,730 \mathrm{~kg}$

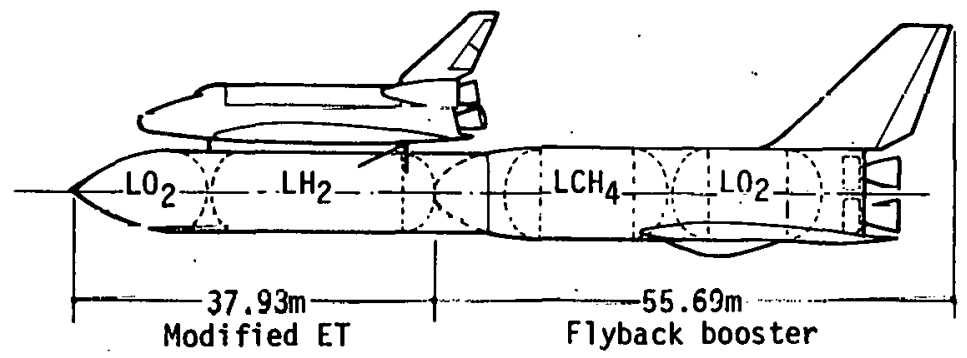

, Figure VIII-G.- Reference STS-derived PLV.

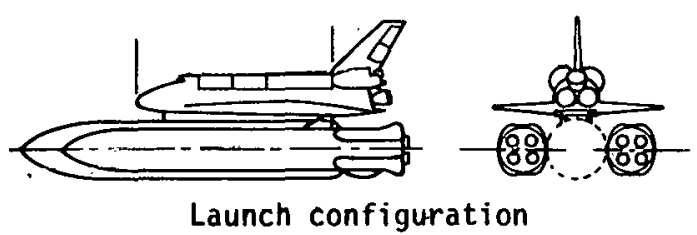

Payload $=45.4$ M.T. GLOW $=1664.7$ M.T.

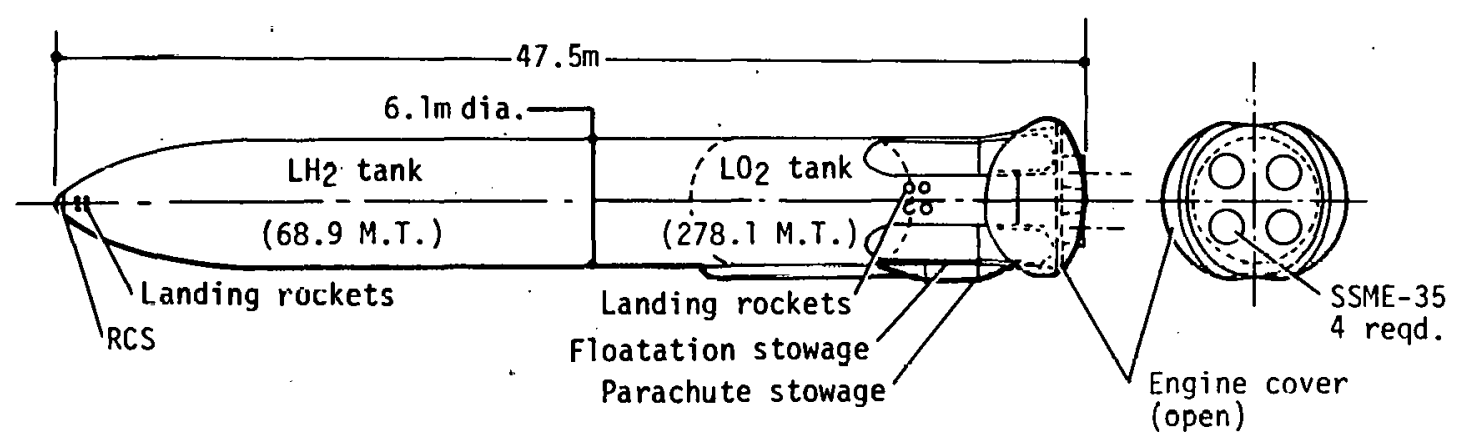

Figure VIII-10.- Alternative STS-derived PLV. 
Flight control module.

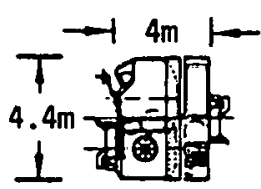

$\begin{aligned} \text { Crew } & =2 \\ \text { Mass } & =4000 \mathrm{~kg}\end{aligned}$
GEO passenger module

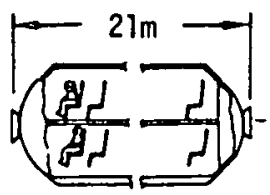

Crew $=160$

Mass $=36,000 \mathrm{~kg}$
Supply module

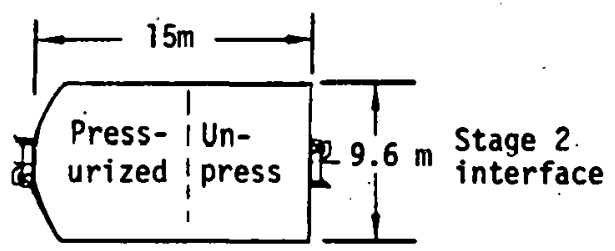

Cargo $=480$ man - mo . $96,000 \mathrm{~kg}$

Module $=15,000 \mathrm{~kg}$

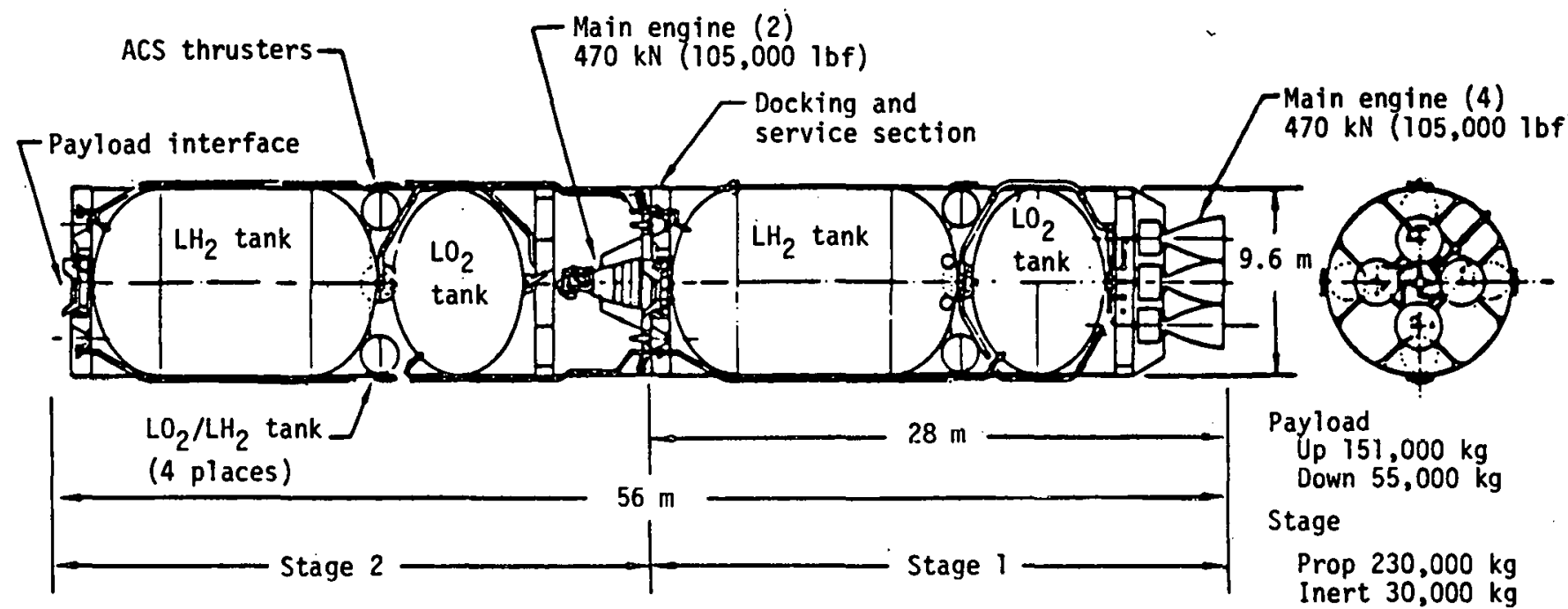

Figure VIII-11.- Personnel OTV: reference system.

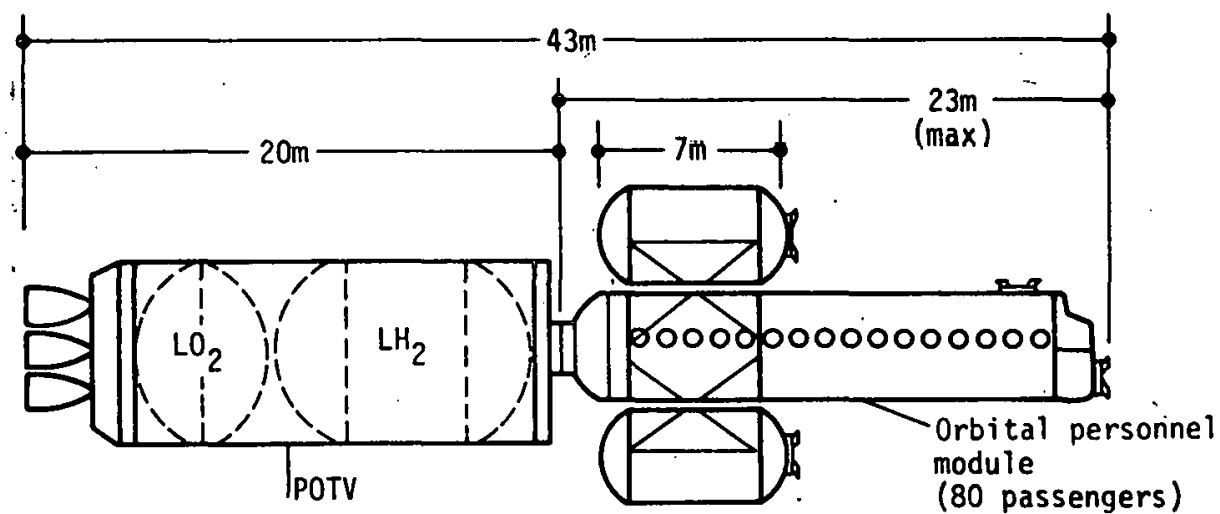

Figure VIII-12.- Personnel OTV: single-stage POTV concept. 
Blark

98 


\section{REFERENCES}

1. Rush, C. M.: Ionospheric Disturbance Overview. Paper presented at Satellite Power System (SPS) Program Review (Lincoln, Nebr.), Apr. 22-25, 1980.

2. SPS Concept Development and Evaluation Program Plan (July 1977-August 1980). DOE/ET-0034, Feb. 1978.

3. Glaser, P. E.: Power from the Sun: Its Future. Science, vol. 162, Nov. 22, 1968, pp. 857-861.

4. Glaser, Peter E.; Maynard, Owen E.; Mackoviak, John, Jr.; and Ralph, Eugene L.: Feasibility Study of a Satellite Solar Power Station. NASA CR-2357, Feb. 1974.

5. Reception-Conversion Subsystem (RxCV) for Microwave Power Transmission System. Raytheon ER 75-4386 (JPL Contract 9533968), Sept. 1975.

6. Initial Technical, Environmental and Economic Evaluation of Space Solar Power Concepts. Johnson Space Center JSC-11568, Aug. 1976.

7. Satellite Power System Engineering and Economic Analysis. NASA TM X-73344, Nov. 1976.

8. Solar Power Satellite Concept Evaluation. Johnson Space Center JSC-12973, July 1977.

9. Final Report of the ERDA Task Group on Sateilite Power Stations. ERDA 76/148, Nov. 1976.

10. Satellite Power System: Concept Development and Evaluation Program, Reference System Report. DOE/ER-0023, 0ct. 1978. (Also available as NASA TM-79762, 1979.)

11. Harron, R. J.; and Wadle, R. C.: Solar Power Satellite Cost Est imates. NASA TM-58231, in preparation.

12. Solar Power Satellite System Definition Study - Part I. Boeing Aerospace Co. (Contract NAS 9-15196), June 1977.

a. Volume I, Executive Sumary (D180-20689-1).

b. Volume II, System Requirements and Energy Conversion Option (D180-20689-2).

c. Volume III, Construction, Transportation and Cost Analysis (0180-20689-3).

d. Volume IV, SPS Transportation System Requirements (D180-20689-4):

e. Volume V, SPS Transportation: Representative System Description (0180-20689-5).

13. Solar Power Satellite System Definition Study - Part II. Boeing Aerospace Co. (Contract NAS 9-15196), Dec. 1977.

a. Volume I, Executive Sumnary (0180-22876-1).

b. Volume II, Technical Summary (0180-22876-2).

c. Volume III, SPS Satellite Systems (D180-22876-3).

d. Volume IV, Microwave Power Transmission Systems (D180-22876-4).

e. Volume V, Space Operations (0180-22876-5). 
f. Volume VI, Evaluation Data Book (0180-22876-6).

g. Volume VII, Study Part II Final Briefing Book (0180-22876-7).

h. Volume VIII, SPS Launch Vehicle Ascent and Entry Sonic Over Pressure and Noise Effects (D180-22876-8).

14. Solar Power Satellite System Definition Study, Part III - Preferred Concept System Definition. Boeing Aerospace Co. D180-24071 (Contract NAS 9-15196), Mar. 1978.

15. Solar Power Satellite System Definition Study - Phase I. Boeing Aerospace Co. (Contract NAS 9-15636), Apr. 1, 1979.

a. Volume I, Executive Summary (0180-25037-1).

b. Volume II, Phase I Systems Analyses and Tradeoffs (0180-25037-2).

C. Volume III, Reference System Description (D180-25037-3).

d. Volume IV, Silicon Solar Cell Annealing Test (0180-25037-4).

e. Volume V, Phase I Final Briefing Executive Summary (0180-25037-5).

f. Volume VI, Phase I Final Briefing: SPS and Rectenna Systems Analyscs (D180-25037-6).

g. Volume VII, Phase I Final Briefing: Space Construction and Transportation (0180-25037-7).

16. Solar Power Satellite System Definition Study - Phase II. Boeing Aerospace Co. (Contract NAS 9-15636), Dec. 1979.

a. Volume 1, Executive Summary (0180-25461-1).

b. Volume II, Reference System Description (0180-25461-2).

c. Volume III, Operations and Systems Synthes is (0180-25461-3).

d. Volume IV, Technical Analysis Report (0180-25461-4).

e. Volume V, Phase II Final Briefing (D180-25461-5).

17. Solar Power Satellite System Definition Study - Phase III. Boeing Aerospace Co. D180-25969 (Contract NAS 9-15636), June 1980.

18. Satellite Power System (SPS) Feasibility Study. Rockwe11 International (Contract NAS 8-32161), Dec. 1976.

a. Executive Summary (SD 76-SA-0239-1).

b. Final Report (SD 76-SA-0239-2).

19. Satellite Power System (SPS) Concept Definition Study, Exhibits A and B. Rnr.kwPll International

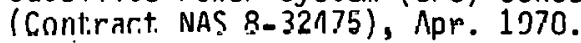

a. Volume I, Executive Surmary (SD 78-AP-0023-1),

b. Vnlume II, SPS System Rrquirements (SD 78-AP-0023-i').

c. Volume. III, SPS Concept Evolution (SD 78-AP-0023-3).

d. Volume IV, SPS Point Design Definition (SD 78-AP-0023-1).

e. Volume V. Transportation and Opcrations Analys is (SD 78-AP-OU23-5). 
f. Volume VI, SPS Techrology Requirements and Verification (SD 78-AP-0023-6).

g. Volume VII, SPS Program PIan and Economic Analysis (2 vols.).(SD 78-AP-0023-7).

20. Satellite Power System (SPS) Concept Definition Study, Exhibit C. Rockwell International (Contract NAS 8-32475), Mar. 1979.
a. Volume I, Executive Summary (SSD 79-0010-1).
b. Volume II (Part I), System Engineering (SSD 79-0010-2-1).
c. Volume II (Part 2), Cost and Programmatics (2 vois.) (SSD 79-0010-2-2).
d. Volume III, Experimentation/Verification Element Definition (SSD 79-0010-3).
e. Volume IV, Transportation Analyses (SSO 79-0010-4).
f. Volume V, Special Emphasis Studies (SSD 79-0010-5).
g. Volume VI, In-Depth Element Investigation (SSD 79-0010-6).
h. Volume VII, System/Subsystem Requirements Data Book (SSD 79-0010-7).

21. Satellite Power System (SPS) Concept Definition Study, Exhibits $D$ and E. Rockwell International (Contract NAS 8-32475), July 1980.
a. Volume I, Executive Summary (SSD 80-0062-1).
b. Volume II, System/Subsystem Analyses (SSD 80-0062-2).
c. Volume III, Transportation Analyses (SSO 80-0062-3).
d. Volume IV, Operations Analyses (SSD 80-0062-4).
e. Volume V, Systems Englneering/Integration Analyses (SSD 80-0062-5).
f. Volume VI, Cost and Programmatics (2 vols:) (SSD 80-0062-6).
g. Volume VII, System/Subsystems Requirements Data Book (SSD 80-0062-7).

22. Arndt, G. D.; and Monford, L.: Solar Power Satellite System Sizing Tradeoffs. NASA TP S-505, in preparation.

23. Walbridge, E. W.: Laser Satellite Power Systemis. Argonne National Laboratory, Jan. 1980.

24. Laser Power Conversion System Analysis. Vol. II. Lockheed Missiles and Space Co., Sept. 1978.

25. Systems Definition of Space-Based Power Conversion Systems. Boeing Aerospace Co. D180-20309 (Contract NAS 8-31628), Feh. 1977.

26. Evaluation of Solar Cells for Potential Space Satellite Power Applications. Arthur D. Little, Inc. (Contract NAS 9-15294), June 1977.

27. Magid, L. M.: The Current Status of the U.S. Photovoitaic Conversion Program. Twelfth IEEE Photovoltaic Specialist Conference (76 CH1142-9ED, IEEE), 1976, pp. 607-612.

28. Satellite Power System Energy Conversion and Power Management Workshop; Marshall Space Flight Center, Feb. 5-7, 1980 .

29. Electrostatic Protection of the SPS and Rectenna. Rice University (Contract NAS .8-33023), Mar. 1980. 
30. Dietz, R. H., coordinator: Solar Power Satellite Microwave Power Transmission and Reception, A Workshop held at Lyndon B. Johnson Space Center, January 15-18, 1980. NASA CP-2141, in preparation.

31. Maynard, Owen E.: Solid State SPS Microwave Generation and Transmission Study. Raytheon Co. (Contract NAS 8-33157), Apr. 1980.

32. Dietz, R. H., coordinator: Satellite Power System Concept Development and Evaluation Program Technical Summary and Assessment Report - Vol. III, Power Transmission and Reception. NASA RP S-507, in preparation.

33. Chie, C. M.: A Ground Based Phase Control System for the Solar Power Satellite, Vol. IV, Final Report. LinCom Corp. TR-0180-0779 (Contract NAS 9-15782). NASA CR-160458, 1980.

34. Ott, J. H.; and Rice, J. S.: Digital SPS Phase Control Using Traveling Wave Interferometry. NOVAR Electronics, Oct. 1978.

35. Belohoubek, E. F.; Ettenberg, M.; Huang, H. C.; Nowogrodski, M.; and Sechi, F. N.: Final Report, Analys is of S-Band Solid-State Transmitters for the Solar Power Satellite. RCA Laboratories PRRL-79-CR-21 (Cont.ract NAS 9-15755). NASA CR-160320, 1979.

36. Gutmanli, Rullald J.; and Borrego, Jose M.: Solar Power Satellite Rcctenna Design Study: Ulirectional Receiving Elements and Parallel-Series Combining Analysis. Rensselaer Polytechnic Inst. (Contract NAS 9-15453). NASA CR-151866, 1978.

37. Study of offshore Rectennas. Rice University (Contract NAS 8-33023), Mar. 1980.

38. SPS Construction and Materials Workshop, January 24-25, 1980 . Johnson Space Center, to be published. 
United States

Department of Energy

Washington, D.C. 20585
THIRD -- CLASS MAII

POSTAGE \& FEES PAIC

U.S. DEPT. OF ENERGYY

PERMIT NO. G 20

THIRD CLASS MAIL.

Official Business

Penalty for Private Use, $\$ 300$ 